\title{
Understanding the Efficiency and Effectiveness of the Dispute Resolution System in South Africa: An Analysis of CCMA Data
}

\author{
Haroon Bhorat \\ Kalie Pauw \\ Liberty Mncube \\ Haroon.Bhorat@uct.ac.za
}

Development Policy Research Unit

DPRU Working Paper 09/137

May 2009

ISBN Number: 978-1-920055-73-8 


\section{Abstract}

This paper, while broadly located within reforming the labour market policy debate, is specifically focused on one aspect of the labour regulatory regime, namely the dispute resolution system. Hence, we attempt to understand the efficiency and effectiveness of the country's institutionalised dispute resolution body, the Commission for Conciliation, Mediation and Arbitration (CCMA). A better and more informed understanding of the nature of dispute resolution and its determinants, it would seem, remains central to any detailed debate regarding labour market institutions in particular and labour market regulation in general. Ultimately then, the study intends to empirically verify the patterns of dispute referral, settlement and determination regionally, sectorally and historically. It should be noted at the outset that this paper, possibly for the first time for South Africa, provides a detailed economic and econometric analysis and interpretation of dispute resolution in the post-apartheid period.

\section{Acknowledgement}

This Working Paper is one in a series eminating from the Critical Research Projects funded by the Department of Labour. This project was commissioned to the Development Policy Research Unit (headed by Prof. Haroon Bhorat at the University of Cape Town) and the Sociology of Work Unit (led by Prof. Eddie Webster at the University of the Witwatersrand) under the auspices of the Human Sciences Research Council (let by Andre Kraak).

We would like to thank the Commission for Conciliation, Mediation and Arbitration (CCMA) for access to their data. We are grateful to Nersan Govender abd Anthea Edwards for technical support in accessing the data. We learnt a great deal from Nerine Kahn, Jeremy Daphne, Afzul Soobedaar, Nersan Govender, Sabata Nakanyane and Kagiso Moleme who took part in a roundtable discussion of an earlier draft. Thanks to Martin Wittenberg, Halton Cheadle and Paul Benjamin for their helpful comments. We have also benefited from a SALDRU seminar presentation at the University of Cape Town.

Development Policy Research Unit

Tel: +27216505705

Fax: +27 216505711
Information about our Working Papers and other published titles are available on our website at:http://www.dpru.uct.ac.za/ 


\section{Table of Contents}

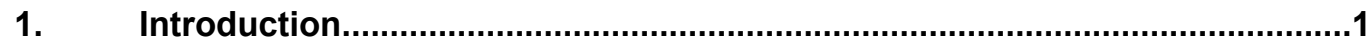

2. The Dispute Resolution System in Post Apartheid South Africa..................2

2.1. The Structure of Dispute Resolution in South Africa........................................

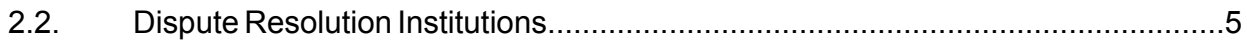

3. Data Overview..................................................................................

3.1. Overall Trends and Patterns of Dispute Referrals.......................................14

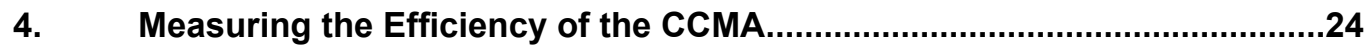

4.1. Efficiency and Dispute Resolution Processes..............................................24

4.2. Internal and Statutory Measures of CCMA Efficiency..................................28

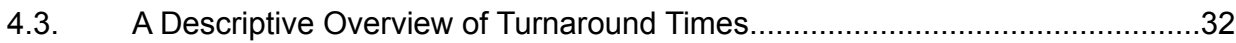

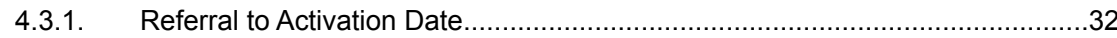

4.3.2. Conciliation and Arbitration Turnaround Times to End Date...........................37

4.4. Determinants of Variation in Turnaround Times.............................................45

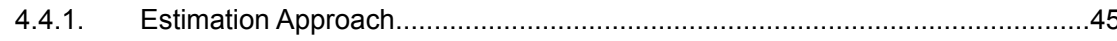

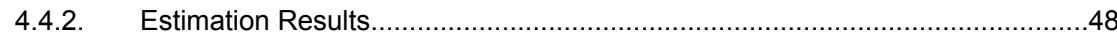

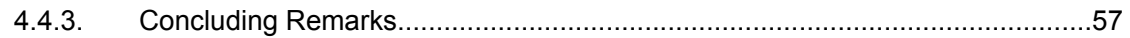

5. Conclusions and Policy Recommendations............................................59

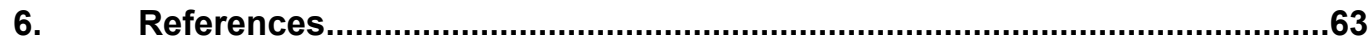

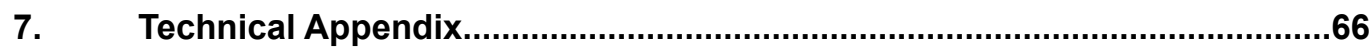




\section{Introduction}

While the economic growth performance in the first decade of democracy continues to be justifiably lauded, severe and seemingly intractable welfare challenges remain. Nowhere is this welfare need more acute than within the area of labour markets. An economy characterised by one of the highest unemployment rates in the world - officially at 22.7 per cent and 35.6 per cent when discouraged workers are included - is a stark reminder of the post-apartheid economy's challenge going forward. In turn, however, the difficulties noted above within the labour market, have placed the idea of labour market reform - in particular labour regulatory reform - high on the agenda of pertinent policy issues in South Africa. A combination of the intrinsic nature of these issues and the fact that the society is characterised by a strong, vocal trade union movement - has meant that reforming the labour market has become a highly contested policy issue in South Africa.

This paper, while broadly located within this policy debate, is specifically focused on one aspect of the labour regulatory regime, namely the dispute resolution system. Hence, we attempt to understand the efficiency and effectiveness of the country's institutionalised dispute resolution body, the Commission for Conciliation, Mediation and Arbitration (CCMA). A better and more informed understanding of the nature of dispute resolution remains central to any detailed debate regarding labour market institutions in particular and labour market regulation in general. Ultimately then, the study intends to empirically verify the patterns of dispute referral, settlement and determination regionally, sectorally and historically. It should be noted at the outset that this paper reflects, very overtly, on economic analysis and interpretation of dispute resolution in South Africa.

The paper begins with a non-legalistic overview of the dispute resolution system in place for labour market disputes (Section 2). Section 3 introduces the data and briefly discusses the overall trends of CCMA dispute resolution. Section 4 provides a detailed empirical analysis of the patterns of dispute resolution with the aim of understanding the main drivers of efficiency of the dispute resolution system in South Africa, followed by a multivariate analysis of dispute resolution. Section 5 draws general conclusions. A Technical Appendix with additional data descriptions, tables and figures is also attached. 


\section{The Dispute Resolution System in Post Apartheid South Africa}

The first legislation in South Africa to comprehensively establish mechanisms for dispute resolution was the Industrial Conciliation Act of 1924. This Act excluded African employees, and was established primarily to resolve disputes of interest. Interest disputes are disputes about the creation of new rights, for example, wage increases and new conditions of employment. Such disputes emerge out of a failure in collective bargaining. These disputes of interest were referred to industrial councils or conciliation boards for conciliation. Disputes of rights had to be referred to ordinary courts. Rights disputes are disputes concerning the violation of or interpretation of an existing right, for example, a dispute over underpayment under a contract or an industrial council agreement or an interdict flowing from an unprotected strike or lockout. The Industrial Conciliation Act of 1924 was amended in 1937 and again in 1956. The 1956 Industrial Conciliation Act created an industrial tribunal to arbitrate disputes although it was limited to job reservation disputes and not all labour disputes.

In the early 1970s under increasing suppression at the workplace, almost as a subset of broader political oppression, urbanised African workers in Durban expressed their opposition in the form of wildcat strikes. One consequence of the strikes among others was the appointment of the Wiehahn Commission in 1977. The commission's brief was to revisit the country's labour legislation. Many of the Commission's recommendations were accepted and as a consequence the Industrial Conciliation Act of 1956 was amended and renamed the Labour Relations Act (LRA). The exclusion of Africans from the LRA of 1956 was removed. The LRA as amended in 1979, introduced the concept of 'unfair labour practice' and charged the Industrial court with adjudicating unfair labour practices. ${ }^{1}$

The adoption of the 1956 LRA resulted in a narrowly focused labour relations system, limited to a competition between management and labour. The system was not only procedurally complex but also administratively burdensome. ${ }^{2}$ Within the spirit of South Africa's negotiated political settlement, the LRA of 1995 replaced the 1956 LRA. Among the intended purposes of the new LRA was the promotion of an effective and efficient labour dispute resolution system in order to overcome the lengthy delays, to save on costs and to reduce the incidence

\footnotetext{
1 See Van Niekerk (2005) and Cheadle (2006) for the dubious heritage of the concept of unfair labour practice which was introduced as a necessary protective mechanism for White workers.

2 The merits of a dispute where often lost in procedural and legal technicalities. See also the discussion on Labour Law available at $h$ ttp://www.legalcitator.co.za accessed on 25/11/2006.
} 
of industrial action which characterised the apartheid dispensation. This marked a new era for South Africa as the labour relations system moved ostensibly from confrontation to cooperation. ${ }^{3}$

\subsection{The Structure of Dispute Resolution in South Africa}

The 1995 LRA regulates individual and collective employment relations. It created the institutions and processes for dispute resolution. These institutions include the Commission for Conciliation, Mediation and Arbitration (the CCMA) and the Labour Courts (the Labour Court and the Labour Appeal Court). The CCMA has the power to licence Private Agencies and Bargaining Councils to perform any or all of its functions. This allows parties in dispute the choice of which institutions to assist them although the Bargaining Council where it exists for parties is always the first institution of engagement and if there is no Bargaining Council then the CCMA has jurisdiction. Figure 1 shows the structure of the dispute resolution system.4 If there is a deadlock in a dispute at the firm level, the parties to a dispute must refer their dispute to conciliation. The procedure of processing disputes takes into account the different kinds of labour disputes. The process makes a specific distinction between disputes of interests and disputes of rights. This classification of labour disputes is important because it determines which resolution technique to use in resolving the dispute. The use of industrial action in relation to interest disputes is considered appropriate as a method of last resort (see Figure 1).

$3 \quad$ However, as noted by Cheadle (2006) and others, the adversarilsm inherited from the pre-1994 industrial relations era continues to be a strong feature of the labour regulatory environment in South Africa.

4 The structure of dispute settlement systems is normally designed to promote collective bargaining, for example by requiring the parties to exhaust all the possibilities of reaching a negotiated solution or to exhaust the dispute settlement procedures provided for by their collective agreement before having access to State provided procedures ( ILO 2001). 


\section{Figure 1: The Structure of Dispute Resolution System in South Africa ${ }^{5}$}

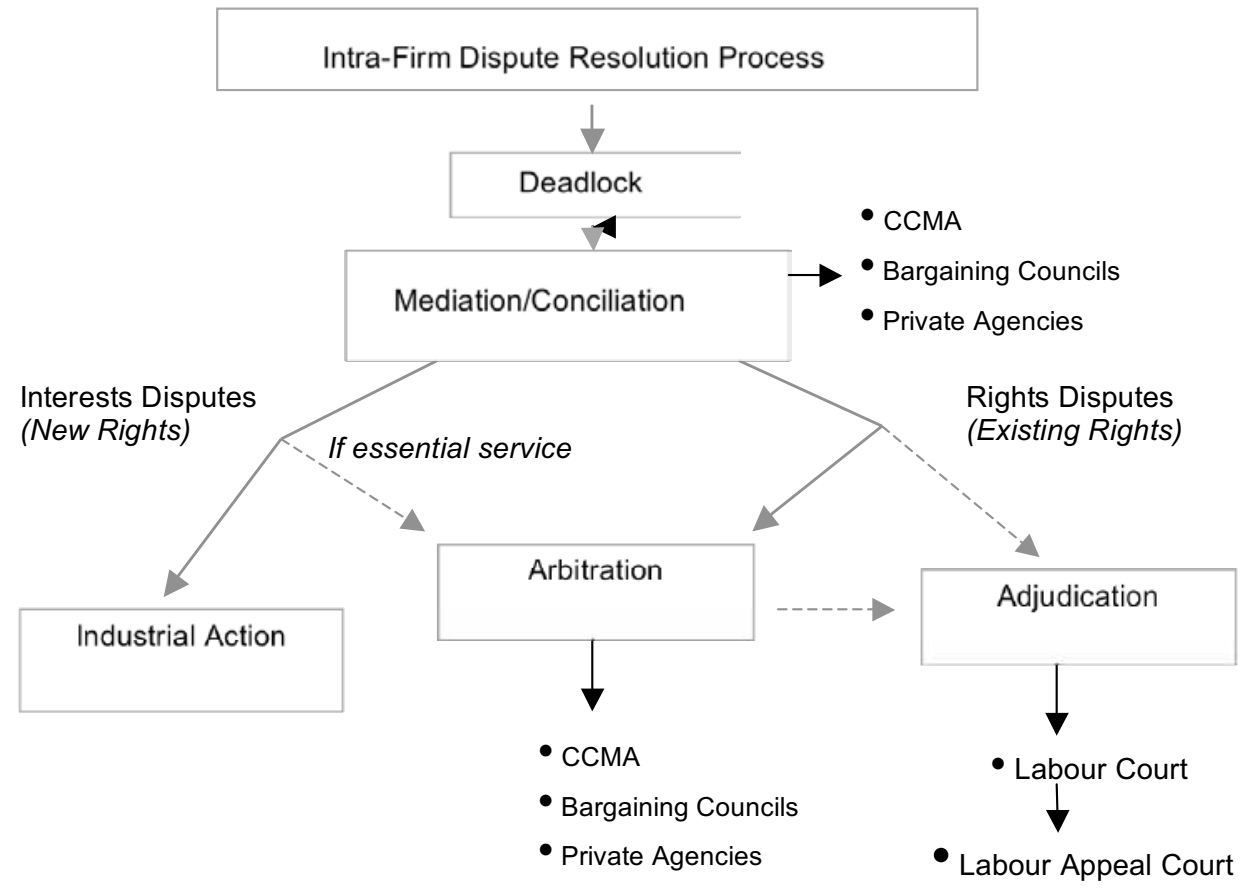

As shown in Figure 1, the LRA provides for the determination of disputes of right through adjudication by the Labour Courts or arbitration either by the CCMA, private dispute resolution institutions or Bargaining Councils. In all cases, disputes have to be conciliated before they can proceed to arbitration or adjudication. ${ }^{6}$ Conciliation involves the use of a neutral or acceptable third party to assist parties to arrive at a mutually acceptable, enforceable and binding solution (Bosch et al, 2004). Disputes of interest, as is clear in Figure 1, if not resolved at the conciliation phase are then prone (unless an essential service activity) to strike action or lock outs although they seldom occur. If disputes of rights are not resolved at conciliation, they are referred to either arbitration or adjudication. The reason for why some disputes go to arbitration and others go to adjudication in the Labour Courts is the public policy aspect of certain kinds of disputes (for example, retrenchments). Hence, issues which could affect public policy fall under the jurisdiction of the Labour Court.

$5 \quad$ This is a simplified structure of the dispute resolution system in South Africa.

6 After conciliation disputes of rights are normally referred to arbitration on the request of the referring party, only in certain cases, such as unfair discrimination and automatically unfair disputes will a dispute be referred to the Labour Court. 
Arbitration refers to a process of settling disputes through the use of an impartial third party. However, unlike conciliation, in which the neutral third party facilitates the settling of a dispute by helping parties to find common ground, an arbitrator settles the disputes by making a final and binding decision. The LRA allows under certain strict conditions that the decision can be reviewed at the Labour Court. ${ }^{7}$ Adjudication on the other hand refers to the legal process of settling a dispute. In what follows we briefly discuss the dispute resolution institutions, currently prevalent in South Africa.

\subsection{Dispute Resolution Institutions}

\section{a) CCMA}

The LRA establishes the CCMA as a statutory but independent body, although it is funded by the state. The primary function of the CCMA is to conciliate and arbitrate disputes. These are disputes referred to the CCMA in terms of the LRA and other labour statutes such as the Basic Conditions of Employment Act of 1997 (BCEA), Employment Equity Act of 1998 (EEA), the Skills Development Act of 1998 and the Unemployment Insurance Act of 2001 (UIF). ${ }^{8}$ The CCMA is also required to compile and publish information and statistics about its work. ${ }^{9}$

As shown in Figure 1, not all disputes go to the CCMA. For example, cases where an independent contractor is involved; ${ }^{10}$ cases that do not deal with an issue in the LRA or Employment Equity Act; where a bargaining council exists for that sector; where a private agreement exists for resolving disputes, and so on, would do not go to the CCMA. ${ }^{11}$ Initially the LRA limited access to the CCMA to individuals employed under a common law contract of employment. The 2002 amendments of the LRA extended labour law protection to more

$7 \quad$ This has been effectively undermined recently. The Labour Court's power to review the CCMA awards is now the same as any other administrative review.

8 See Du Toit et al.(2003).

9 If requested, the CCMA may advise a party to a dispute about the procedures to follow, or assist a party to a dispute to obtain legal advice or representation and may provide advice and training on establishing collective bargaining institutions.

10 If the 'employee' is an independent contractor then the reason why it goes to the other courts is because it is not a labour matter like all other non-labour matters. If however there is a dispute over whether or not the employee is an independent contractor or not, then it will be heard by the CCMA - to determine just that. disputes: dismissal and unfair labour practice disputes relating to probation; dismissal disputes relating to conduct and capacity (excluding dismissal arising from participation in an unprotected strike); constructive dismissal; dismissal where the employee does not know the reason for the dismissal and unfair labour practices. 
vulnerable workers. The first step in all disputes is referral to conciliation. If a dispute has been properly referred, the CCMA will appoint a commissioner to attempt to resolve it. ${ }^{12}$ The commissioner is required to resolve the dispute within 30 days of its referral date. The commissioner determines the process to attempt to resolve the dispute. No legal representation is allowed in conciliation proceedings. ${ }^{13}$ At the end of the conciliation proceedings, the commissioner issues a certificate stating whether or not the dispute has been resolved.

Arbitration proceedings are more formal than conciliation. If there is a request for arbitration, the CCMA will appoint a commissioner. The commissioner hearing the dispute makes a decision which in most cases is final, binding and may be made an order of the Labour Court. The drafters of the LRA of 1995 made the conscious decision that there should be no right of appeal against arbitration awards issued by CCMA commissioners (see Young, 2004). They did agree, however, that a party to arbitration proceedings who was dissatisfied with the outcome of these proceedings could approach the Labour Courts to review the award.

The 2002 amendments of the LRA place the matter of representation in arbitration in the hands of the CCMA. It is sometimes argued that the CCMA has not created proper rules relating to the right of representation as was intended by the enabling legislation and this has created a loophole allowing an unrestricted right to representation before the CCMA (see Collier, 2003). However, the CCMA rejects this interpretation stating that representation at the CCMA remains as it was prior to the 2002 amendments. The 2002 amendments of the LRA institutionalised the process of con-arb as another means of dispute resolution. ${ }^{14}$ The con-arb process is intended to be a "one sitting" process that has "two steps", that is, conciliation followed by arbitration, if conciliation is not successful (CCMA, 2007). The con-arb is governed by the same rules as conciliation and arbitration. Legal representation is not allowed in the conciliation stage of the con-arb process but may be permitted at the arbitration stage. The legislation allows for parties to object to the same commissioner who conducted the conciliation phase to arbitrate the matter if the dispute is not resolved at the

12 For example, a dispute concerning unfair dismissals must be referred within 30 days of the date of dismissal, while an unfair labour practice dispute must be referred within 90 days of the date of the alleged unfair labour practice. With discrimination cases, a period of six months is permitted.

13 Rule 25 (1) of the rules of conduct of Proceedings before the CCMA deals with representation at conciliation hearings.

14 In 2002, section 191(5A) of the 1995 LRA was amended and the con-arb (conciliation-arbitration) process was formally introduced into the LRA. 
conciliation stage. ${ }^{15}$ The purpose of the con-arb is to avoid the delay between the conciliation and arbitration hearings and thus, reduce the costs of these processes.

Molahlehi (2005) points out that there is a consensus between academic writers and practitioners that the success of the new dispensation and the CCMA lies in the fact that workplace justice has now been made more accessible and less costly for unskilled workers. ${ }^{16}$ The absence of a requirement for formal pleadings and complicated referral procedures are one of the successful features that make the CCMA more accessible. This simplicity of the processes is often cited as an important factor in making the CCMA accessible to a large number of workers. For example, it has ensured that literacy, lack of skills and resources are not hindrances preventing entry to the system. However, the ease of access to the CCMA has also meant that the private cost of formalising a dispute, irrespective of the issue, is at the conciliation stage, zero. In this respect then, many observers have argued that the rapid rise in cases before the CCMA may reflect these zero entry costs.

In spite of these achievements, the CCMA faces several challenges. For example, as Ngcukaitobi (2004) argues, the CCMA has not been able to resolve disputes as expeditiously as had been hoped at the time of its establishment. Brand (2000) suggests that the difficulties experienced by the CCMA are due to financial and human resource constraints. ${ }^{17}$ Resource constraints also impact on the quality of the administrative service provided by the CCMA. Furthermore, as indicated by Molahlehi (2005) the CCMA commissioners in the process of narrowing issues, are under immense case load pressure and the need to meet case efficiencies. The daily efficiencies for commissioners are: two con-arbs per day, three conciliations per day, two arbitrations per day, four in limines per day or four rescissions per day. ${ }^{18}$ Based on these efficiency parameters, some have argued that this may, in some cases lead to hasty settling of disputes and possibly also in superficial settlements which fail to address the underlying causes of conflict or the real needs of the parties.

15 Different commissioners can conciliate and arbitrate at con-arb, and this is in fact encouraged. According to Molahlehi (2005) the number of objections to the con arb process has become a major challenge to the CCMA because a party may object to the con arb for no apparent reason if not only to frustrate the other party attempt at a speedy resolution of the dispute

16 This is supported by Brand (2000) who reports that the CCMA has proved to be cheap and accessible to workers at the point of entry.

17 A lack of resources leads to limited opportunities for training. Brand (2000) further indicates that caseload pressure has now forced less experienced and qualified commissioners to arbitrate. See also Roskam (2006), Cheadle (2006) and Benjamin (2006).

18 See Molahlehi (2005). A in limine hearing is a hearing on a specific legal point, which takes place before the actual case refered, can be heard. It is meant to address technical legal points, which are raised prior to getting into the merits of the case and relates to matters of jurisdiction (see http://www.ccma.org.za accessed on the 20/01/2007). 


\section{b) Bargaining Councils}

Bargaining Councils are joint employer and union bargaining institutions whose functions and powers are set out in the LRA. One of the LRA's main objectives is to promote collective bargaining as a means of regulating relations between management and labour and as a means of settling disputes between them. A Bargaining Council has the responsibility to resolve disputes between parties that arise from the collective agreements concluded in the council and other statutory instruments. Bargaining Council agreements deal with issues such as minimum wages, hours of work, overtime, leave pay, notice periods, and retrenchment pay. A bargaining council does not need to be accredited with the CCMA to perform dispute resolution services regarding parties to that council. According to Brand (2002) if a bargaining council applies to the CCMA for accreditation the CCMA may, as a term of accreditation, give council conciliators similar powers to CCMA conciliators. There are currently about 55 Bargaining Councils in South Africa. Their jurisdiction may be sectoral, regional or industrywide and hence they vary in size and quality of dispute resolution. One of the main criticisms aimed at bargaining councils is that they are fragmented in nature and poorly resourced. ${ }^{19}$

\section{c) Private Dispute Resolution Agencies}

The Independent Mediation Service of South Africa (IMSSA) was the first private dispute resolution agency that specialised in labour disputes of importance. It was formed in 1984 and set out to provide mediation arbitration services that were more expeditious, informal and less adversarial in nature than the courts (see Bosch et al 2004). In 2000 IMSSA closed down and Tokiso Dispute Settlement was formed to fill the gap. Since then, Tokiso has grown to be the largest and most active private dispute resolution service in South Africa. The CCMA has however, not accredited private agencies, despite the demand for private dispute resolution services by agencies such as Tokiso. There is an urgent need therefore, to accredit private dispute resolution agencies in order to afford parties to a dispute the choice of which institutions to assist them.

\section{d) Labour Courts}

The LRA establishes the Labour Court as a court of law and equity. It has jurisdiction in all provinces. The Labour Court can hear contractual or BCEA or EEA disputes without going through conciliation first. It can interdict strikes and lockouts without prior conciliation. If there

19 However, this is a generalisation may not apply to all Bargaining Councils, for example the Motor, Metal and Public Sector Bargaining Councils would not necessarily fit this description. 
is perfect conciliation, then not many cases will actually be referred to the Labour Court. ${ }^{20}$ The Labour Appeal Court is the court of final appeal in respect of labour disputes. The LRA created the Labour Courts to deal with complex labour issues. The Labour Courts have found it difficult to attract sufficient judges of high calibre in the field of labour law. This has resulted in the over-reliance on acting judges, some of whom have little experience in labour law (see the discussion by Roskam (2006), Cheadle (2006) and Benjamin (2006) for the nature and extent of this challenge). In addition, Benjamin (2006) points out that, it was thought that the Labour Courts would exercise a supervisory authority over the CCMA. However, this has not occurred given that both the CCMA and Labour Courts have had huge case loads and that the Labour Courts suffer from significant levels of inefficiency due to their human resource constraints. ${ }^{21}$ We should note that there is an ongoing judicial review process which is examining the role and responsibilities of specialist courts, such as the Labour Courts and the Labour Appeals Courts.

20 The Labour Court's primary tasks are to: adjudicate disputes relating to freedom of association (union- and employer- organisation membership); adjudicate automatically unfair dismissals including dismissals arising out of operation requirements (that is, redundancy/retrenchment matters) as well as strike disputes; review CCMA arbitration awards (Bhoola, 2002).

21 For a thorough review of the Labour Courts and the Labour Appeal Court see Benjamin (2006). 


\section{Data Overview}

The current labour legislation and dispute resolution processes in South Africa have recently become the focus on an intense national policy debate on labour market policy. An analysis of the effectiveness and efficiency of the dispute resolution system is therefore important. It is estimated that some 72 per cent of the employed in South Africa fall under jurisdiction of the CCMA (Van Niekerk, 2006). Hence, this institution also manages the majority of disputes that arise in the labour market. It is therefore appropriate to use the CCMA's Case Management System (CMS) database as the main data source for the analysis, as this database represents a large majority of disputes that are formally heard in South Africa.

The CMS is a national database that has been in use since the establishment of the CCMA in 1996/97.22 It is a live database capturing case details for every case referred to the CCMA, whether the case falls within jurisdiction of the CCMA or not. For all cases, general information about the case is captured, which is mostly administrative in nature. This includes the types of disputes, the regional CCMA office to which the dispute was referred, as well as the processes followed to reach an agreement (for example, pre-conciliation, conciliation, arbitration and so on). Limited information about the parties involved is also included, for example, the sector of employment and names of parties. ${ }^{23}$

Throughout the dispute resolution process, various target dates are captured. These dates are used to calculate various turnaround times ${ }^{24}$ for dispute resolution. Dates captured include the date on which the dispute arose, the date on which it was referred to the CCMA, and the date on which the case was activated by the CCMA. If a case is unresolved after the conciliation phase, the arbitration referral date is also captured. The date on which conciliation and arbitration cases are concluded is also captured, while in the case of arbitration awards being made at a later stage, an arbitration award date is captured. At various stages along the

22 The CCMA's financial year stretches from 1 April to 31 March of every year. The periods of analysis correspond to the financial years rather than calendar years.

23 Unfortunately the CMS data does not capture skills or occupation types of workers in much detail. The sector of employment is known, while some specific occupation types such as security personnel, domestic workers and agricultural workers are captured. Beyond that it is impossible to determine the skills level or income level of parties to a dispute. are calculated and reported regularly as an internal measure of efficiency, namely conciliation turnaround times and arbitration turnaround times. Later in this study we also calculate various turnaround times associated with specific types of processes (that is, conciliation and arbitration), but these may differ slightly from the CCMA's internal estimates. See further discussions in Section 4.4. 
process information is added, for example the number of hearings that have taken place up to that point, the current process at which the dispute was resolved, and so on. In the case of arbitration cases there is information on whether the award was in favour of the employer or employee, and, if applicable, an award amount.

The analysis by Benjamin and Gruen (2006) included CMS data for the periods 2001/02, 2003/04 and 2004/05, since, as they argue, these years span important events in the history of dispute resolution and the labour market. These events include amendments to the Labour Relations Act which came into effect on 1 August 2002, altering the operation of the CCMA and introducing a new set of CCMA rules. Also important are the various sectoral determinations introduced in 2002 under the Basic Condition of Employment Act. These determined minimum wages for domestic and farm workers. The Unemployment Insurance Act of 2001 came into effect on 1 April 2002. These events, it was argued, may have impacted on the labour market and on the prevalence and nature of labour market disputes, hence it is important to analyse the 'before' and 'after' data.

Since the publication of Benjamin and Gruen's (2006) paper, the CMS data for 2005/06 had also become available and is included in the analysis for this project. In order to allow analyses using a pooled dataset spanning the entire period from 2001/02 to 2005/6, we also include the 2002/03 CMS data. The CCMA also publishes an Annual Report that is used as an additional data source in this study. An internal document called the Review of Operations is also produced annually. The latter is not usually available to the general public, but was obtained for the purpose of this study. The Review of Operations is very useful for gaining an understanding of the internal and statutory operational efficiency measures that are in place at the CCMA. Essentially the Review of Operations is a twelve-month summary of the CCMA internal and statutory measures of efficiencies that are produced on a monthly basis.

As noted, roughly 72 per cent of the formal workforce (including agricultural and domestic workers) fall under jurisdiction of the CCMA. The remainder fall under jurisdiction of Bargaining Councils. By examining only the CMS datasets we are therefore, in reality, working with a restricted sample of disputes. Hence, it is important not to make too strong conclusions about the dispute resolution system in general based solely on this data. ${ }^{25}$ Preliminary estimates

25 An analysis of Bargaining Council data falls beyond the scope of this study, but may add value if included in follow-up studies. At the time of this research being conducted we were unable to obtain fully comparable datasets for all the Bargaining Councils. 
by the DPRU ${ }^{26}$ of Bargaining Council 'coverage' suggest that 40 per cent of craft and trade workers and 35 per cent of operators and assemblers (see Table 1, as well as the more detailed Figure 8 in the Appendix) fall under jurisdiction of Bargaining Councils. Given that, on average, about 28 per cent of workers fall under jurisdiction of Bargaining Councils it is evident that a disproportionate share of blue-collar workers fall under the Bargaining Council system. The CCMA, on the other hand, is the only dispute resolution institution that covers domestic workers and agricultural workers ${ }^{27}$, both of which are occupation types that often have very unique characteristics, particularly due to seasonal employment trends and the informal nature of contracts. At the other end of the internal labour market ladder, the CCMA covers a higher share of skilled, formal sector employees. Again, on the basis of Table 1 it should be clear that the CCMA coverage is relatively higher at the two extremes of the skills spectrum. ${ }^{28}$ Hence, it is evident that while we are not overly concerned about the 'representativity' of the CCMA data, it remains important to bear in mind that skills and sectoral differences between the CCMA and Bargaining Councils may render the representativity of our conclusions on the dispute resolution system for South Africa imperfect.

26 This forthcoming DPRU study (Van der Westhuizen and Goga, 2007) from which estimates of Bargaining Council coverage is obtained investigates wage differentials between Bargaining Council and non-Bargaining Council workers.

27 The ten per cent Bargaining Council coverage for 'agricultural, forestry and fisheries workers' presumably include mainly forestry and fisheries workers, although it may also include respondents defining themselves as agricultural workers but are perhaps employed in economic sectors covered by Bargaining Councils.

28 The high Bargaining Council coverage for professional workers is interesting. This is presumably because this category includes 'technical' workers, many of who are employed in manufacturing industries that also have a high Bargaining Council coverage rate (see Figure 8 in the Appendix). 
Table 1: CCMA and Bargaining Council Coverage by Main Occupation Groups

\begin{tabular}{|l|r|r|r|r|r|}
\hline & \multicolumn{1}{|c|}{ CCMA } & \multicolumn{1}{c|}{ Share } & \multicolumn{1}{c|}{ BC } & \multicolumn{1}{c|}{ Share } & \multicolumn{1}{c|}{ Total } \\
\hline Managerial & 743,458 & $99 \%$ & 4,774 & $1 \%$ & 748,232 \\
\hline Professional & 904,133 & $55 \%$ & 747,177 & $45 \%$ & $1,651,311$ \\
\hline Clerical & 883,944 & $77 \%$ & 263,842 & $23 \%$ & $1,147,786$ \\
\hline Service & 791,684 & $67 \%$ & 393,334 & $33 \%$ & $1,185,018$ \\
\hline Craft \& Trade & 706,043 & $60 \%$ & 463,908 & $40 \%$ & $1,169,951$ \\
\hline Operators \& Assembler & 650,499 & $65 \%$ & 344,820 & $35 \%$ & 995,319 \\
\hline Elementary & $1,200,867$ & $75 \%$ & 390,212 & $25 \%$ & $1,591,078$ \\
\hline Agriculture \& Fishing & 68,093 & $90 \%$ & 7,769 & $10 \%$ & 75,862 \\
\hline Domestic Workers & 858,219 & $100 \%$ & 1,042 & $0 \%$ & 859,261 \\
\hline $\begin{array}{l}\text { Total "formal" } \\
\text { employment (*) }\end{array}$ & $6,806,939$ & $72 \%$ & $2,616,878$ & $28 \%$ & $9,423,817$ \\
\hline
\end{tabular}

Note: $\quad$ This table includes selected items from the more comprehensive Figure 8 in the Appendix. The assumption here is that those workers that do not fall under jurisdiction of Bargaining Councils (as mapped by Van der Westhuizen and Goga, 2007), fall under jurisdiction of the CCMA. The estimate for total 'formal' employment includes agricultural and domestic workers also in non-formal employment contracts.

A further important issue to take note of is the type of labour market disputes referred to the CCMA. Table 2 shows the distribution of all referrals across different types of disputes as reported in the CMS database between 2001/02 and 2005/06. There are four main types of disputes or "genuine disputes" as Benjamin and Gruen (2006:10) refer to them:

- Unfair dismissal disputes: These include termination of contracts without notice, dismissals relating to incapacity, misconduct, pregnancy or operational requirements (mainly redundancies), and constructive dismissals. The latter occurs when an employer deliberately makes the work environment unbearable for an employee, thus forcing her to resign.

- Unfair labour practice disputes: This includes a variety of 'general' discrimination disputes, as well as unfair suspension or discipline and unfair conduct relating to promotion, demotion or training.

- Mutual interest: Disputes arising when employers and employees have mutual interests.

- Severance pay: This includes instances where a dismissal is deemed fair (for example, operational requirements) but employees feel that they have been treated unfairly with respect to severance pay packages offered. 
Table 2: Distribution of All Referrals across Different Dispute Types

\begin{tabular}{|l|rrrrr|}
\hline \multicolumn{1}{|c}{} & \multicolumn{1}{c}{$\mathbf{2 0 0 1 / 0 2}$} & $\mathbf{2 0 0 2 / 0 3}$ & $\mathbf{2 0 0 3 / 0 4}$ & $\mathbf{2 0 0 4 / 0 5}$ & \multicolumn{1}{c|}{$\mathbf{2 0 0 5 / 0 6}$} \\
\hline Unfair dismissal & 75,602 & 81,573 & 88,903 & 86,668 & 84,037 \\
Unfair labour & $(68.8)$ & $(69.8)$ & $(71.1)$ & $(69.3)$ & $(69.2)$ \\
practice & 7,706 & 7,582 & 7,385 & 7,798 & 6,922 \\
& $(7.0)$ & $(6.5)$ & $(5.9)$ & $(6.2)$ & $(5.7)$ \\
Mutual interest & 2,089 & 1,526 & 1,172 & 1,491 & 1,539 \\
& $(1.9)$ & $(1.3)$ & $(0.9)$ & $(1.2)$ & $(1.3)$ \\
Severance pay & 2,972 & 2,833 & 2,564 & 2,026 & 1,741 \\
& $(2.7)$ & $(2.4)$ & $(2.1)$ & $(1.6)$ & $(1.4)$ \\
Other & 21,487 & 23,374 & 25,059 & 27,043 & 27,211 \\
& $(19.6)$ & $(20.0)$ & $(20.0)$ & $(21.6)$ & $(22.4)$ \\
\hline Total & 109,856 & 116,888 & 125,083 & 125,026 & 121,450 \\
& $(100.0)$ & $(100.0)$ & $(100.0)$ & $(100.0)$ & $(100.0)$ \\
\hline
\end{tabular}

Source: CMS (various years) and Authors' Calculations.

Notes: (1) Includes all referrals, that is, cases in and out of jurisdiction, and cases that are not closed by settlement or arbitration award.

(2) Figures in brackets represent column shares.

Structurally no large shifts in the types of disputes referred to the CCMA are observable. The main dispute types accounts for between 78 and 80 per cent of all referrals in all the years under investigation. Of these main dispute types, the vast majority (between 86 and 89 per cent) are unfair dismissal cases. Unfair dismissals further make up around 70 per cent of all referrals. What the data suggests then is that the analysis of dispute resolution undertaken in this study is overwhelmingly an analysis of unfair dismissals. Within the legislative environment, of course, this also suggests that we are concerned with very specific components of South Africa's legislative architecture.

\subsection{Dispute Resolution Institutions}

We start the analysis by first reviewing some of the overall trends and patterns of dispute referrals. During its first year of operation (1996/97) the CCMA only processed 2917 cases. Thereafter the number of cases increased rapidly from 67319 in 1997/98 to just under 130000 in 2005/06 (see Figure 2). The CCMA received significantly more referrals than was originally anticipated - early projections were set at around 30000 cases per year - obviously causing strain in a system that was designed to handle a much smaller caseload (Venter, 2007). The overwhelming response from the labour market is probably indicative of the fact that workers are very well informed of their rights, and increasingly become better informed. 
Since about 2002/03 the caseload has remained between about 120000 and 130000 cases per year. The number of cases even declined marginally between 2004/05 and 2005/06. Whether the caseload will remain stable at these levels, remains to be seen.

Figure 2: Cases Referred to the CCMA, $1997 / 98$ to 2005/06

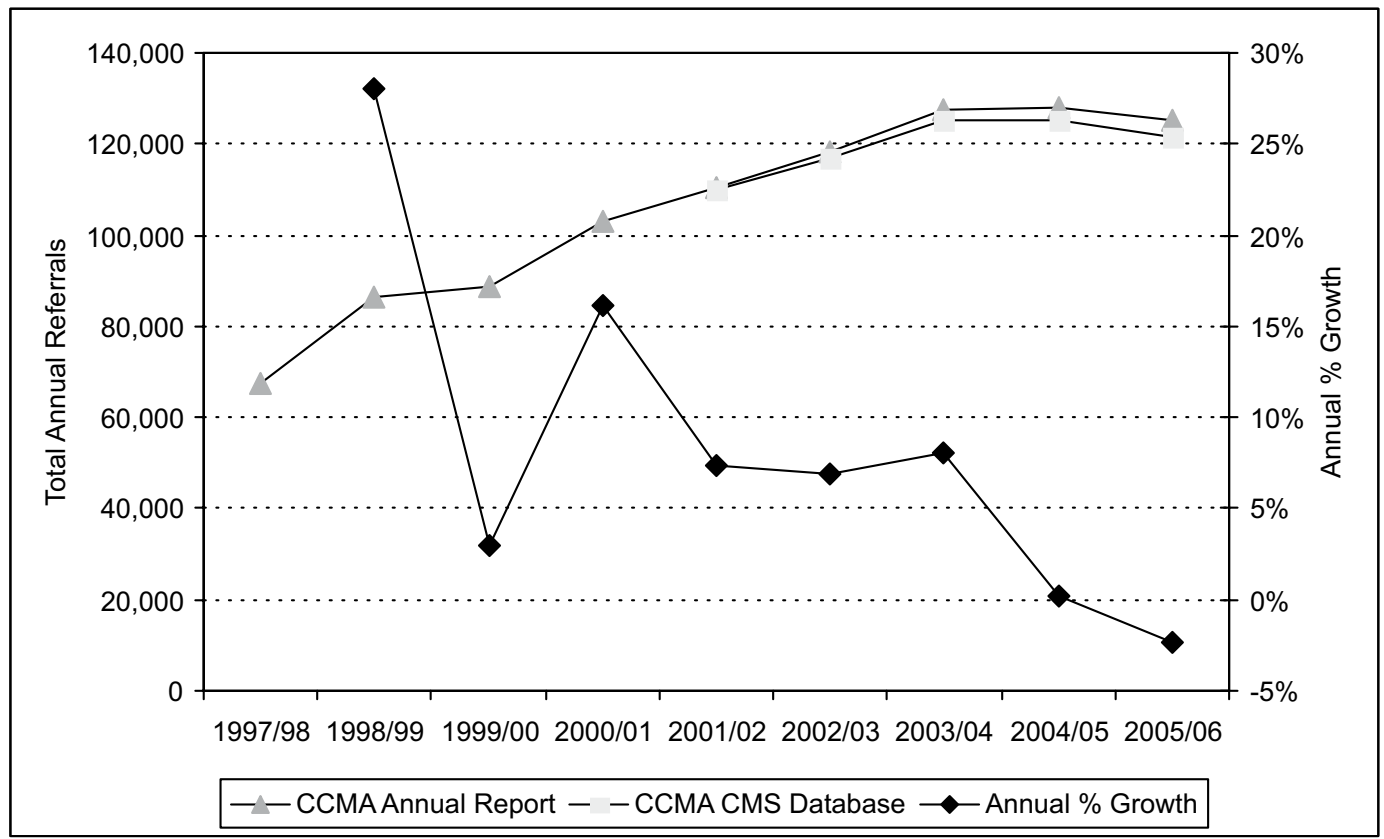

Source: CMS and CCMA Annual Reports (various years) and authors' calculations.

Notes: (1) Includes all referrals, i.e. cases in and out of jurisdiction, and cases that are not closed by settlement or arbitration award.

(2) The annual percentage growth rates are based on the Annual Report figures throughout the period.

From a labour market point of view the year 2002 was significant due to the various amendments and additions to the labour market legislation. Any significant changes in the number of referrals received by the CCMA around this time would therefore not have been unexpected. However, Figure 2 shows no significant increase in the caseload between 2001/02 and 2003/04; in fact, the growth rate declines from over 15 per cent in 2000/01 to between five and ten per cent between 2001/02 and 2003/04. A slight increase in the growth rate between 2002/03 and 2003/04 is observable, but this does not look to be a significant response to the changing labour market regime. In fact, from 2004/05 the growth rate drops below five per cent per annum. 
It can therefore be argued that the high growth rate in the first years of operation was a natural growth path of this newly formed institution. Labour market participants became better informed and more aware of the CCMA, resulting in a high growth in the caseload initially. Since then, the growth in the caseload has declined significantly, currently varying at levels more comparable with the labour force growth rate during the latter years (Figure 7 in the appendix compares the CCMA referral growth rate with the labour force growth rate over the period). Indeed, although this is only indicative evidence over a fairly short period of time, it is possible that the CCMA may be able to use labour force growth rates as a predictor for its future caseloads and hence their required future resources. At the same time, however, it also has to be said that a variety of other factors may influence or determine the caseload of the CCMA, including trends in unemployment rates, legislative changes, increased awareness among labour market participants, and an expansion in the CCMA network (for example, opening up of a new regional office). Hence, forecasting of referral rates should be done taking all of these factors into account.

Figure 3 shows the distribution of referrals across provinces. Most provinces only have a single regional office, except for Gauteng and Eastern Cape (two offices each) and KwaZuluNatal (three offices). Each province's share of the national referrals has remained fairly constant over time. According to the CCMA's Annual Report for 2005/06, this has been the case since the inception of the CCMA. Figure 3 also shows the provincial shares of formal and domestic workers across the provinces, which are derived from the Labour Force Survey for September 2005.

As noted above, there is some variation in CCMA coverage by occupation types. This is also the case for regions and economic sectors, as is shown in Figure 8 in the appendix. Thus, in Figure 3 (and also in Figure 4 and Figure 5 to follow) 're-weighted' shares are also calculated. These re-weighted shares use the CCMA coverage rates for each region, occupation and type of sector of employment to calculate the number of workers in these various cohorts that fall under jurisdiction of the CCMA (as opposed to all workers). A comparison of these re-weighted shares with the distribution of referrals gives a better indication of whether referrals originating from within specific cohorts are under- or overrepresented. In the case of the regional shares shown in Figure 3 the re-weighted shares match the original shares closely, probably due to the fact that the CCMA coverage rates do not vary significantly across provinces. ${ }^{29}$

29 These coverage rates range from about 77 per cent in Gauteng to 66 per cent in KwaZulu-Natal (Figure 8 in the Appendix). 
Figure 3: Distribution of Referrals by Province

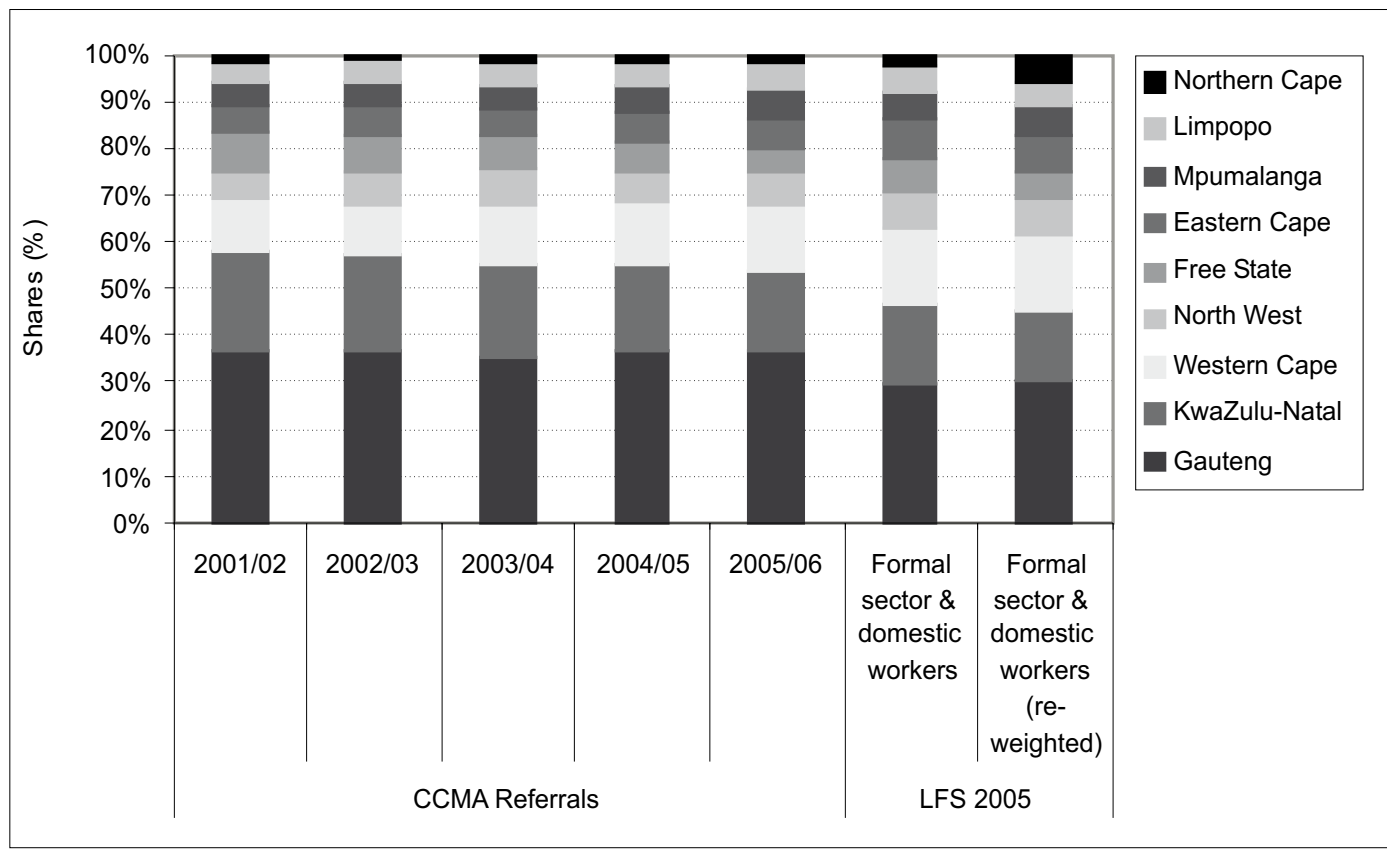

Source: CMS (various years) and LFS September 2005 (Statistics South Africa) and Authors' Calculations.

Note: Includes all referrals, that is, cases in and out of jurisdiction, and cases that are not closed by settlement or arbitration award.

Also evident from Figure 3 is the fact that the majority of cases - almost 70 per cent - are handled in three of South Africa's provinces, namely Gauteng (36 per cent), KwaZulu-Natal (17 per cent) and the Western Cape (15 per cent) (2005/06 figures). Gauteng's Pretoria office was only established in 2004/05 and currently handles about 26 per cent of the region's cases, up significantly from only 8 per cent in its first year. KwaZulu-Natal has three offices based in Durban, Pietermaritzburg and Richard's Bay, with 75 per cent of the cased referred to the Durban office. The only other province with more than one office is the Eastern Cape, with offices in East London and Port Elizabeth. This is despite the fact that the province as a whole only handles six per cent of the referrals nationwide. These two regional offices share roughly the same caseload. The Northern Cape office is by far the smallest in terms of its share of referrals. This is unsurprising given the small population of this region. However, when compared to the re-weighted LFS shares it is evident that referrals in this regions are underrepresented. Presumably many disputes are never referred to this regional office given the long distances people would have to travel to attend hearings. 
Figure 4 shows the distribution of referrals across broad economic sectors, which, clearly, has also not changed much during the last few years. There is perhaps some evidence of a marginal increase in the share of referrals originating from within the finance, insurance and business services, coupled with a decline from manufacturing and community and social services. The comparative employment figures from the LFS September 2005 are again shown. The shares are also re-weighted to reflect differences in CCMA coverage rates by sector.

\section{Figure 4: Distribution of Referrals by Economic Sector}

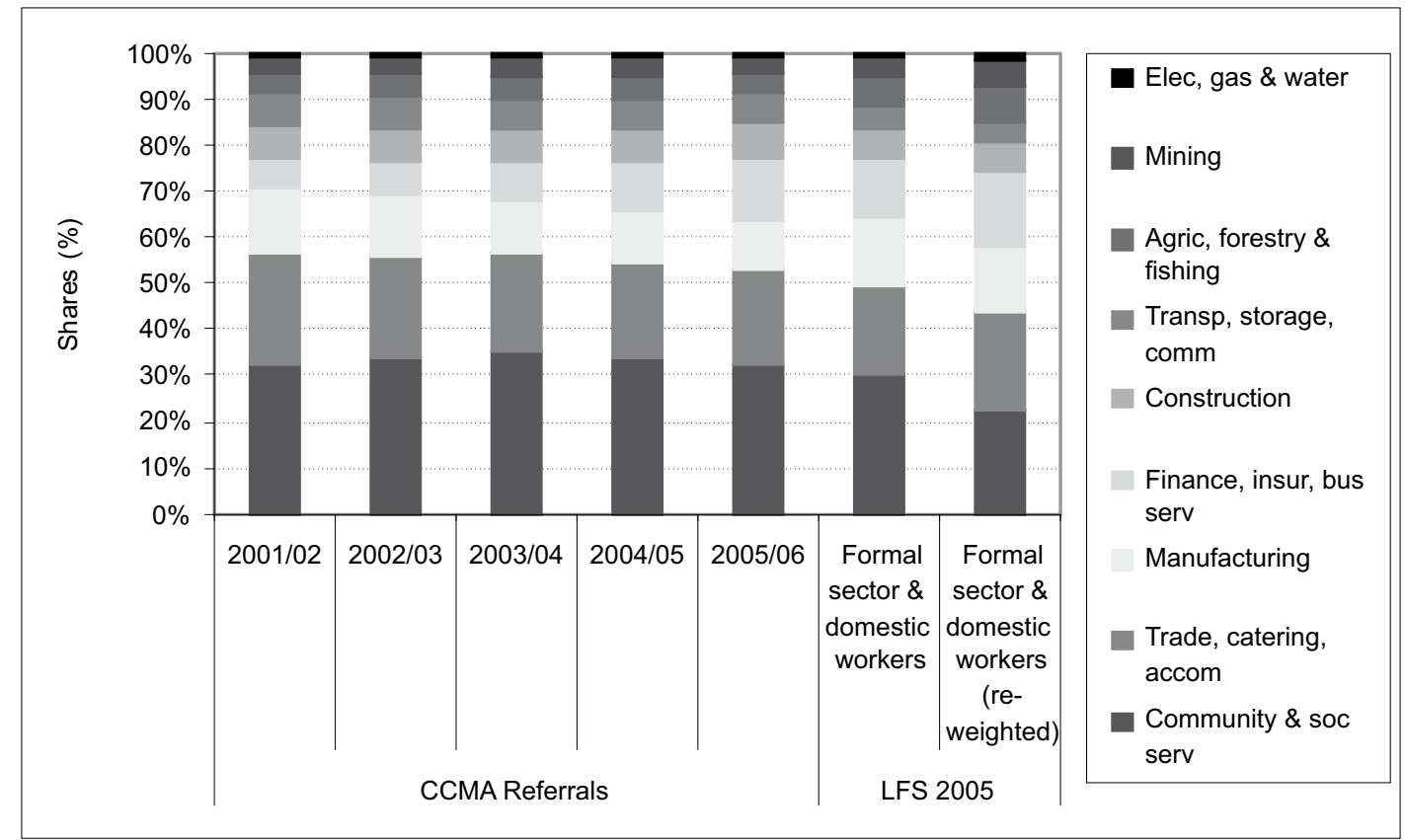

Source: CMS (various years), LFS September 2005 and Authors' Calculations.

Notes: (1) Includes all referrals, that is, cases in and out of jurisdiction, and cases that are not closed by settlement or arbitration award.

(2) Domestic workers are included under community and social services for the purpose of this analysis.

A marginal increase in the share of referrals from agricultural workers is observable from $2001 / 02$ (4.6 per cent) to $2003 / 04$ (5.1 per cent). This may be seen as a response to the sectoral determination that was introduced for agricultural workers in 2002. However, the impact has not been significant, and apparently only temporary, as shown by the subsequent decline in the share of referrals from agricultural workers. By 2005/06 this share had again reached 4.6 per cent. Compared to the labour force shares, agricultural workers are in fact 
underrepresented in the CMS database, which probably reflects the fact that many farm workers reside in rural areas and have difficulty travelling to the urban centres where the CCMA offices are located. ${ }^{30}$

The community and social services sector in Figure 4 includes domestic workers who are also protected by a minimum wage. At first glance it appears as if referrals from this sector are overrepresented, especially when comparing the 2005/06 referral share (32 per cent) to the re-weighted LFS share (23 per cent). Approximately 40 per cent of referrals in the community and social service sector are from domestic workers. Hence it would appear as if referrals from domestic workers are to blame for the disproportionate share of referrals coming from the community and social service sector. This, however, as we argue below, is a misinterpretation.

Figure 5 breaks the referrals originating from within the community and social services sector down into its various components, namely (1) domestic workers, cleaning and laundry staff, (2) private safety and security personnel, (3) public sector services, (4) other private sector services and (5) other. ${ }^{31}$ As noted, over 40 per cent of referrals in 2005/06 in this sector are from domestic workers. Security guards make up around 35 per cent of this group, while most of the remainder is made up of government and other services. Judging by Figure 5 the overall composition of referrals from this sector has not shifted much over time, although there is evidence of a relative rise in the number of referrals from domestic workers. In fact, in 2001/02 about 35 per cent of referrals were from domestic workers. This share increased to 39 per cent the following year and to 43 per cent in 2003/04. By 2005/06 the share had dropped back to around 40 per cent.

30 The CCMA is doing a great deal to overcome this problem by having multiple CCMA offices in regions such as KwaZulu-Natal and the Eastern Cape that have large and dispersed rural populations. The use of 'mobile courts' has also made the CCMA accessible.

31 Some of which include referrals from the informal sector. 
Figure 5: Distribution of Referrals within the Community and Social Services Sectors

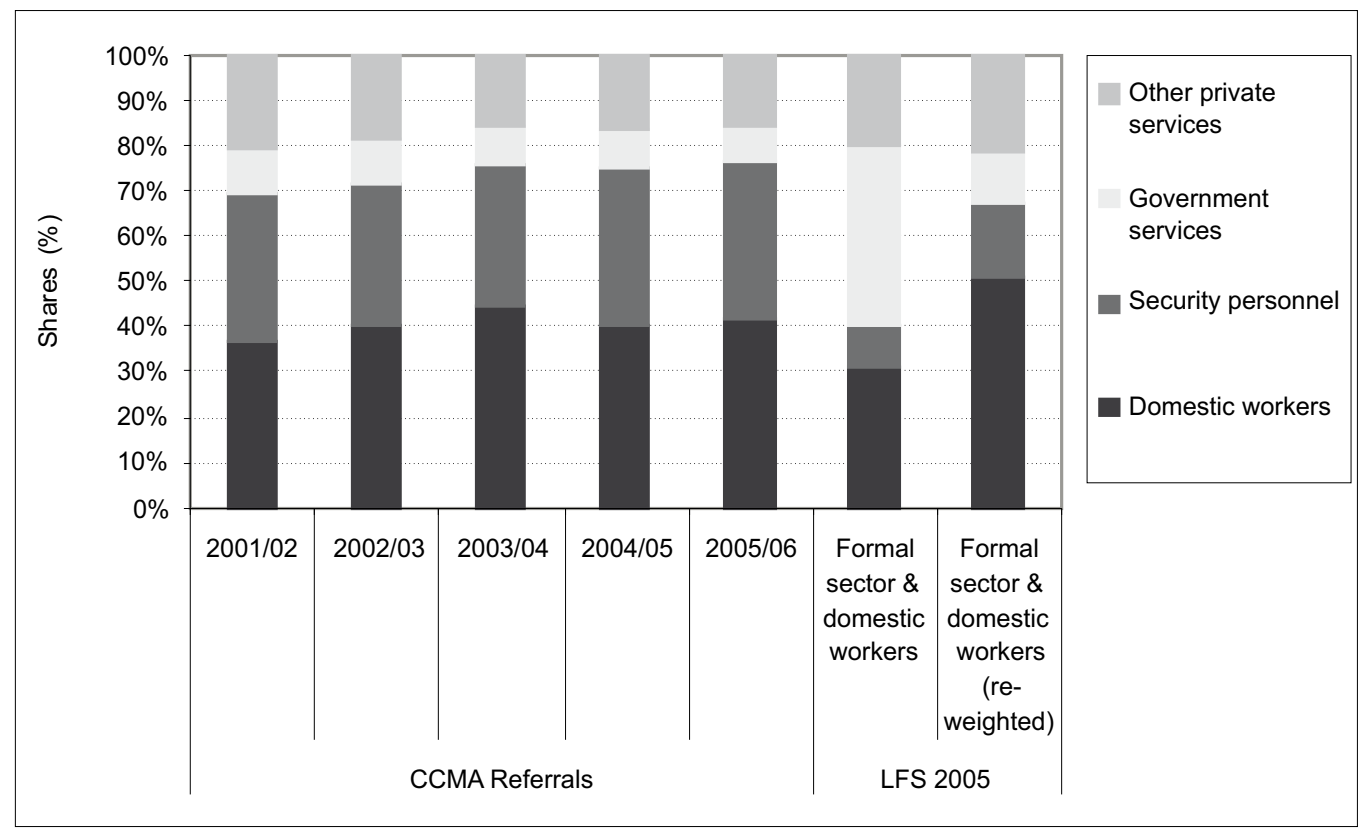

Source: CMS (various years) and Authors' Calculations.

Notes: Includes all referrals, that is cases in and out of jurisdiction, and cases that are not closed by settlement or arbitration award.

When compared to the LFS employment shares for this sector, domestic workers still appear to be overrepresented. However, given the large differences in CCMA coverage between the different types of workers or sectors represented here, the re-weighted shares suggest otherwise. In fact, domestic workers are underrepresented as the expected share of referrals is closer to 50 per cent. Most public sector workers fall under the Public Sector Coordinating Bargaining Council (PSCBC) (see Figure 8 in the Appendix), and judging by the re-weighted shares the low number of referrals from this group is to be expected. Security workers, however, appear to be hugely overrepresented in this sector. ${ }^{32}$ From this evidence there appears to be no justification for the assumption that domestic workers 'clog' the system. Simply put, domestic worker cases are not overrepresented within the CCMA. Indeed, it is more likely that security worker disputes are disproportionate in the caseload of the CCMA. Venter (2007) is, however, still of the opinion that domestic and also agricultural workers, due

$32 \quad$ A cautionary note: Security workers in the LFS September 2005 are randomly distributed across a variety of sectors. Presumably security workers report that sector in which they perform their task, even though in reality most security workers are employed by security companies (in the service sector). This basically implies that the Bargaining Council coverage data for security workers may be incorrect, which in turn affects the reliability of the other (re-weighted) labour force shares as well. 
to the nature of their employment contracts, really require an alternative system to handle their disputes. She does not argue that these workers should have their own Bargaining Councils, but rather that the CCMA should perhaps have a special division dealing with cases from these sectors. As for the security sector, Venter feels that disputes from this sector should still be dealt with by the CCMA despite the disproportionate share of referrals coming from this sector. This sector, she argues, is well organised and most workers are employed on formal work contracts. This allows the dispute resolution process to be more straightforward than is typically the case for domestic and agricultural workers. The reason for the disproportionate share of referrals originating from this industry probably has more to do with unfavourable working conditions (leading to unfair labour practice disputes) and the high incidence of strikes (as was seen in 2006), which possibly impact on the relative share of dismissals in this industry.

The CCMA (2007) disagrees about the need to treat agricultural, domestic or security worker disputes separately, arguing that this would be impractical and unnecessary, while impacting adversely on resources and the budget. They acknowledge that in the past cases involving domestic or agricultural workers were characterised by longer turnaround times, various simple measures have been introduced to rectify this problem. ${ }^{33} \mathrm{~A}$ typical example would be that a default award is made in favour of the plaintiff due to non-attendance. Upon hearing this news the employer would challenge the outcome, leading to the case being rescinded and the process starting over again. Recently a system was introduced whereby parties involved in a dispute receive notification of hearings via cellular phone messenger services. There is also now the option of Saturday or Sunday hearings. These innovations have, according to the CCMA, greatly reduced turnaround times.

From this cursory overview of the CCMA dispute referral trends a number of preliminary conclusions can be drawn. Firstly, it was argued that the growth in the number of referrals received by the CCMA, while initially high, appears to have stabilised. In recent years, therefore, a decline in the measured efficiency of a particular CCMA office, for example, should not be viewed as a function of high or unexpected growth in referrals. It is also important to note that the growth in referrals appears to be converging with the labour force growth

33 This report looks at turnaround times in more detail in Sections 4.3 (see Table 6 in particular) and 4.4. While estimates of mean turnaround times for conciliation and arbitration cases shown in Table 6 suggest that turnaround times for domestic workers, for example, are generally above the average across all sectors, we show in the econometric models in Section 4.4 that, when controlling for other factors, domestic workers actually have lower than average turnaround times. See related discussions for clarity. 
rate, which should make future planning easier for the CCMA. Secondly, it is evident that no significant structural changes in dispute patterns (types of disputes) or the share of referrals across regions and economic sectors have occurred since the inception of the CCMA. While we observed slight compositional shifts for agricultural and domestic workers shortly after the 2002 sectoral determinations were enacted, none of these were lasting in nature. A deduction from the above evidence therefore is that significant structural or compositional shifts are unlikely to explain any large variations in efficiency of the CCMA.

The above conclusions are, however, preliminary, and in an effort to provide a more exhaustive empirical analysis, we conduct a series of statistical tests to determine whether our hypotheses are in fact correct. Hence in what follows below the CCMA's statutory and internal efficiency parameters and turnaround times are estimated, before moving on to a discussion of the econometric model developed to analyse these issues further. Thus far the analysis has focused on all referrals received by the CCMA, that is, both those referrals that fall under jurisdiction of the CCMA and the 'out of jurisdiction' or non-jurisdictional cases. Generally, non-jurisdictional cases are screened out during an initial screening stage. If at this stage it is ruled that a case falls under the jurisdiction of, say, the Labour Court or one of the Bargaining Councils, the case is dismissed immediately. These cases are excluded from all further analysis in this report (and by the CCMA). In some instances non-jurisdictional cases are only detected during conciliation or arbitration hearings. These cases are also terminated with immediate effect, but since at least one hearing has already taken place some time has lapsed since the activation of the case and the scheduling of the hearing, these cases are included in the CCMA's internal analyses of efficiency and the calculation of turnaround times. In our own analyses to follow we also generally include these non-jurisdictional cases, unless otherwise indicated.

Two further points of interest: Firstly, it can of course be argued that non-jurisdictional cases screened out prior to a conciliation hearing taking place may in fact impact on efficiency in an indirect way as these represent cases that should not have been referred to the CCMA in the first place. Although not central to the analysis of efficiency, we do look at out of jurisdiction trends in the Appendix (Section 7.2) in more detail. Secondly, an analysis based solely on CMS data may draw criticism. As explained, this is not a perfect representation of dispute resolution in South Africa in general, and further research should ideally include an analysis also of data from various Bargaining Councils. We argue further (Section 4.4) that disputes that make it to the CCMA are already subject to so-called sample bias given that these represent disputes that could not be resolved at the firm level. We attempt to correct for this 
sample bias in the econometric models employed. Something that cannot be controlled for but has been raised by researchers working with the CMS data is the concern about the quality of the data (Benjamin and Gruen, 2006 and Venter, 2007). This has implications for the accuracy of results and the policy conclusions drawn. Some of these data problems are discussed in Section 7.3 in the Appendix and some suggestions for improvements are made. 


\section{Measuring the Efficiency of the CCMA}

\subsection{Efficiency and Dispute Resolution Processes}

In this section we analyse the efficiency of the CCMA. The CCMA uses various internal and statutory efficiency parameters to measure its efficiency as well as the variation of efficiency across regions. Most of these efficiency measures, which are discussed in section 4.2 , are defined for specific processes (mainly conciliation and arbitration) that form part of the dispute resolution system. In CCMA jargon, the 'determinative process' of a dispute is defined as the process at which a case is closed or resolved. For example, if closure is reached at the end of the conciliation phase then conciliation would be the determinative process.

Table 3 shows the determinative processes for all dispute types between 2001/02 and 2005/06. These include pre-conciliation, conciliation, con-arb (broken down into conciliation and arbitration), arbitration, in limine, rescission and other. Pre-conciliation basically involves CCMA officials phoning the parties involved in dispute prior to a hearing being scheduled, with the aim of resolving the dispute prior to a formal conciliation hearing take place. The conciliation and arbitration processes are as described previously in Section 2. The con-arb process was introduced as an efficiency-enhancing measure as it makes provision for a conciliation and arbitration hearing to run back to back in a single sitting or hearing. ${ }^{34}$ This significantly reduces the turnaround times of the traditional conciliation and arbitration processes combined, although the conciliation and arbitration processes that form part of a con-arb are legally speaking no different from 'pure' conciliation and arbitration hearings. Finally, in limine refers to cases that are dismissed on technical grounds, while rescinded cases are those withdrawn or repealed after an arbitration ruling was made. These are the processes that were current at the time the case was closed. Of course the natural path of a case would be to go through conciliation (either a pure conciliation hearing or as part of the con-arb process), and, if unresolved, to go through arbitration.

As shown in Table 3, the share of cases resolved at the pre-conciliation phase remained close to five per cent during the entire period. As a general rule of thumb the CCMA aims to conduct pre-conciliations for ten per cent of cases (see efficiency targets discussed further below).

34 This is of course subject to considerations of the legislation providing for objection to con-arb, objection to the same commissioner arbitrating both processes, and attendance of parties. 
At present the average is closer to 15 per cent (Review of Operations, 2005/06). In previous years the related efficiency measure was defined differently, stating that five per cent of cases had to be resolved at the pre-conciliation phase. Clearly in terms of this measure they have been fairly efficient. The CCMA (2007) notes that the intention is for only certain types of cases to be subjected to the pre-conciliation process, hence, the reason for changing the definition of the efficiency target. Pre-conciliation "is not intended as a screening mechanism, nor as a process to be applied to most cases", while "there are important natural justice issues and other factors that need to be taken into account when applying the pre-conciliation provision, pointing towards pre-conciliation only being used under specific circumstances". (CCMA, 2007) In short, all people have a right to a fair and formal conciliation hearing, and hence only clear-cut cases are dealt with in this manner. Increases in successful pre-conciliations, although drastically reducing turnaround times, is not in the interest of the parties involved in a dispute.

Table 3: Determinative Processes

\begin{tabular}{|c|c|c|c|c|c|}
\hline & $2001 / 02$ & $2002 / 03$ & $2003 / 04$ & $2004 / 05$ & $2005 / 06$ \\
\hline \multirow[t]{2}{*}{ Pre-conciliation } & 3,607 & 4,988 & 3,733 & 2,800 & 5,655 \\
\hline & $(5.1)$ & (6.6) & $(4.6)$ & (3.5) & (6.5) \\
\hline \multirow[t]{2}{*}{ Conciliation } & 37,108 & 31,964 & 23,432 & 19,466 & 19,354 \\
\hline & $(52.5)$ & (42.3) & (28.7) & (24.6) & (22.4) \\
\hline \multirow[t]{2}{*}{ Con/Arb - Conciliation } & 1 & 1,959 & 13,208 & 18,287 & 17,969 \\
\hline & $(0.0)$ & (2.6) & (16.2) & (23.1) & (20.8) \\
\hline \multirow[t]{2}{*}{ Con/Arb - Arbitration } & 2 & 464 & 2,968 & 6,485 & 6,737 \\
\hline & $(0.0)$ & $(0.6)$ & (3.6) & (8.2) & (7.8) \\
\hline \multirow[t]{2}{*}{ Arbitration } & 25,257 & 27,614 & 28,901 & 22,652 & 26,899 \\
\hline & (35.8) & (36.5) & (35.4) & $(28.6)$ & (31.1) \\
\hline \multirow[t]{2}{*}{ In limine } & 3,490 & 6,248 & 6,108 & 7,200 & 7,056 \\
\hline & (4.9) & (8.3) & (7.5) & (9.1) & (8.2) \\
\hline \multirow[t]{2}{*}{ Rescinded } & 1,094 & 2,193 & 2,898 & 1,997 & 2,554 \\
\hline & (1.6) & (2.9) & (3.6) & (2.5) & (3.0) \\
\hline \multirow[t]{2}{*}{ Other } & 76 & 155 & 304 & 229 & 277 \\
\hline & $(0.1)$ & $(0.2)$ & $(0.4)$ & $(0.3)$ & (0.3) \\
\hline \multirow[t]{2}{*}{ Total } & 70,635 & 75,585 & 81,552 & 79,113 & 86,501 \\
\hline & $(100.0)$ & $(100.0)$ & $(100.0)$ & $(100.0)$ & $(100.0)$ \\
\hline
\end{tabular}

Source: CMS (various years) and Authors' Calculations.

Note: (1) Includes only closed cases, that is, cases that have either been settled, dismissed or ruled out of jurisdiction during conciliation or arbitration, or those for which an arbitration award was made. The numbers exclude those cases that were ruled out of jurisdiction during the initial screening stage. Roughly two-thirds of in limine cases are out of jurisdiction.

(2) Con-arb cases are disaggregated into those settled or closed during conciliation and those that continue to arbitration, eventually resulting in an arbitration award. The case outcome detail in the CMS database is used for this breakdown. Con-arb cases that are ruled out of jurisdiction (see Note 1 above), dismissed, settled or withdrawn are all allocated to conciliation. Only con-arb cases resulting in arbitration awards (default or 'normal') are allocated to the arbitration row. Figures in brackets represent column shares in percentages. 
Turning to conciliation, we note that this was by far the most common determinative process in the first two years analysed here. The share of 'pure' conciliation as the determinative process has dropped from 53 per cent in 2001/02 to 22 per cent in 2005/06. This fall coincides with a rapid rise in cases resolved through con-arb. Con-arb was introduced in 2001/02 and increased from close to zero per cent (three cases) to around 29 per cent in 2005/06 (as a joint process). This rapid rise in the share of con-arb cases is to be expected. Under the provisions in the LRA, con-arb should be conducted for all dismissal and unfair labour practice disputes relating to probation, dismissal disputes relating to conduct and capacity (excluding dismissal arising from participation in an unprotected strike), constructive dismissal, dismissal where the employee does not know the reason for the dismissal and unfair labour practices, subject to objection by the parties. Clearly, these disputes make up the majority of disputes (see Table 2). The only disputes that cannot be handled using the con-arb process are disputes relating to organisational rights, interpretation and application of collective agreements, workplace forums, non-renewal of contracts or renewal on terms less favourable, automatically unfair dismissals, operational requirement dismissals and entitlement to severance pay.

Of course, cases settled during the conciliation process of a con-arb should also be included as conciliation settlements, as should (theoretically) cases settled during pre-conciliation, as these processes do not differ from a legal context. The sum of these shares initially stood at 58 per cent in 2001/02, but thereafter dropped to about 51 to 52 per cent and remained stable at this level. Thus, although the con-arb has replaced the conciliation process, it has not detracted much from the share of cases resolved through conciliation; in fact, the share seems to have remained constant in the last four years.

Con-arb was introduced fairly recently and showed rapid growth. It is perhaps too soon to try and analyse trends in the share of con-arb cases resolved at the conciliation phase. Nevertheless, in the last two years (2004/05 and 2005/06) about three-quarters of con-arb cases were resolved at the conciliation stage. In this regard the CCMA have found that the settlement rate (at conciliation) of con-arb is "significantly higher" than the settlement rate of conciliations conducted separately (CCMA, 2007). While there are no clear reasons why this should be the case, it does allude to increased efficiency of con-arb over pure conciliation, given that arbitration cases generally have much longer turnaround times (see Section 4.3). The CCMA conclude that "con-arb benefits all role players, and the more extensive use of con-arb needs to be facilitated" (CCMA, 2007). 
The share of cases concluded at the arbitration stage declined from 36 to 31 per cent during the period of analysis. This drop has coincided with an increase in the share of cases resolved at the arbitration process of con-arb, from zero per cent in 2001/02 to about eight per cent in 2005/06. The joint share of cases resolved through 'pure' arbitration or the arbitration process of a con-arb remained stable, at between 36 per cent in 2001/02 and 29 per cent in 2005/06.

The shares of in limine and rescinded cases remains fairly stable from 2002/03 onwards. It is unclear whether the initial rise in rescinded or in limine should be regarded as a concern. Benjamin and Gruen (2006), whose study covers the period up until 2004/05, attributes the rise to the changing nature of employment relationships. They cite a study by the International Labour Organisation (ILO) that suggests that employers increasingly aim to disguise employment contracts through 'outsourcing' or 'contracting out' certain services, or by continuously rolling over short-term contracts. If employers can prove that a standard employment relationship did not exist, any case brought against them can be rescinded or dismissed on technical grounds. This effectively means that employers can sidestep any regulations when it comes to dismissals or other labour market disputes.

In response to this notion, the CCMA (2007) notes that in limine cases are not a strong predictor of atypical forms of employment: "the in limine process typically deals with various issues such as jurisdiction ${ }^{35}$, referral defects and condonation; our statistics reflect that atypical employment accounts for 0.1 per cent of the issues identified in limine cases at present". However, the rise in atypical employment contracts is a global phenomenon. South Africa follows this trend, with various research on the subject finding evidence that firms are relying more on subcontracting in order to meet skills needs and to reduce the costs associated with recruitment and training of permanent staff members (see Lundall et al, 2004 for a review of the literature). Also in this regard Bhorat and Hinks (2005) find that the labour regulatory environment has resulted in firms hiring fewer workers and substituting permanent workers for casual or contract workers. The key issue arising here is that if atypical forms of employment may significantly alter the nature of dispute resolution, and it is crucial to either regulate such labour market changes if they are deemed undesirable, or to adapt the relevant legislation to these altering labour market conditions. Ultimately the CCMA should be responsible for monitoring the impact of atypical forms of employment on the incidence and nature of labour

35 Our estimates show that, on average, about 72 per cent of cases with determinative process stated as in limine are classified as out of jurisdiction. 
market disputes, and also on the way in which such disputes can be handled within the legislative context.

\subsection{Internal and Statutory Measures of CCMA Efficiency}

The CCMA has an extensive list of internal and statutory measures of efficiency. Outcomes are compared against targets on a monthly basis to measure the efficiency of each of the regional offices. The results and ranking of regional offices or provinces are published annually in the Review of Operations. The efficiency parameters are not necessarily comparable over time as dispute resolution processes adapt and evolve, which leads to new measures being introduced periodically, sometimes replacing older or obsolete measures. Efficiency targets are also revised regularly as information becomes available that are grounds for efficiency targets to be revised. A comprehensive list of efficiency parameters with descriptions, target levels and actual outcomes appears in Table 11 in the Appendix.

Below we highlight what we consider as five of the most important efficiency parameters and outcomes over the last three years:

- Conciliations conducted outside 30 days: This statutory requirement (as noted in the LRA) provides that that no conciliation may be conducted outside the 30-day statutory period unless agreed upon by both parties. The related efficiency measure is purely a count of cases that were conducted outside the 30 days; hence, it differs fundamentally from the internal efficiency measure that calculates the turnaround time for conciliations (see below). The target of zero per cent has never been reached, and actually increased from three per cent in 2003/04 to seven per cent in 2005/06.

- Settlement rate: At least 70 per cent of cases referred to the CCMA have to be 'settled', that is, resolved during the conciliation or arbitration process or withdrawn by the plaintiff. This target has also not been reached in any of the last three financial years, with outcomes ranging from 56 to 62 per cent between 2003/04 and 2005/06.

- Postponements: A trend that has emerged at the CCMA in recent years is a seemingly increasing tendency for part-time commissioners to postpone cases. While concrete evidence is lacking, there is a concern that this is being done for financial reasons given that they work on a contract/hourly basis. In order to reduce the occurrence of 
postponements, the CCMA (as an internal measure ${ }^{36}$ ) limits the number of cases that any commissioner may postpone. In 2003/04 the target was one per cent, but this was increased to three and five per cent in the following two years. The target was never reached, with postponements reaching eight per cent in each of the last three years.

Of course, the postponements by part-time commissioners have to be viewed against the number of cases handled by them. The use of part-time commissioners has increased from around 62 per cent in 2003/04 to 73 per cent in 2005/06. In all three years under investigation part-time commissioners were more likely to issue postponements. While this is understandably a worrying trend, the CCMA should perhaps consider the overall efficiency of part-time commissioners relative to full-time commissioners. In KwaZulu-Natal, for example, 69 per cent of commissioners were part-time in 2003/04, the highest of any province. Yet, this province consistently ranks as one of the most efficient provinces when taking into account all the efficiency parameters (see below). It remains true, however, that the significant rise in postponements within the CCMA may be a key marker for the perverse incentives that potentially operate amongst the cohort of commissioners.

- Turnaround times for conciliations: This is an internal efficiency measure which states that conciliation cases must be finalised within 30 days of activating the case. The efficiency measure therefore calculates the time taken from activation to the end date of the case, that is, when an outcome has been reached. The target was missed in both 2004/05 and 2005/06, with the outcome actually increasing from 33 days to 45 days. In 2005/06 not a single regional office met the target. ${ }^{37}$

- Turnaround times for arbitrations: This is an internal efficiency measure that states that arbitration cases must be finalised within 60 days of the arbitration referral date. As with the conciliation turnaround time the measure is calculated as the time lapsed between these two dates. The target was missed in both 2004/05 and 2005/06, although an improvement is observable (88 days to 79 days). In 2005/06 not a single regional office met the target. ${ }^{38}$

36 Commissioner usage was listed as a formal but non-statutory (internal) efficiency target in 2003/04. See Table 11 in the Appendix.

37 Our own estimates of turnaround times for conciliation cases (all jurisdictional cases) are 40 days in 2004/05 and 33 days in 2005/06. Benjamin and Gruen (2006) also note that it is sometimes difficult to replicate figures and estimates reported in the Reviews of Operations or Annual Reports. Of course, the CMS is a live database, which may explain differences depending on the time at which a calculation is done. Furthermore, the measure is sensitive to the inclusion or exclusion of cases, for example pre-conciliation cases, conciliation cases and con-arb cases settled at conciliation, or jurisdictional and non-jurisdictional cases. 
Clearly the CCMA has not been highly successful at reaching their efficiency targets. This either suggests that they are aiming too high or that, by their own standards, they are not performing as well as they should be. The outcomes of all efficiency parameters (Table 11) show that in 2003/04 only six out of 14 measures were achieved (43 per cent). In 2004/05 the success rate declined to three out of 15 (20 per cent). This picked up again with five out of 13 targets achieved in 2005/06 (38 per cent). In all the years (where applicable) none of the efficiency parameters that we consider as the most important were, in fact, achieved.

A more detailed examination of Table 11 indicates in turn, that it is often the same offices that perform badly. Each year the CCMA ranks offices and/or provinces according to their overall efficiency using a weighted ranking process. Table 4 shows the results as published in the annual Review of Operations in the last three years. We use this information to construct a simple index to determine which provinces, on average, performed the best over the years. This index is shown in Figure 6, with a lower number indicating better performance,that is, higher average placing in the annual ranking.

Table 4: Efficiency Ranking of Regions or Provinces, 2003/04 to 2005/06

\begin{tabular}{|c|c|c|c|c|c|}
\hline Rank & $2003 / 04$ & Rank & $2004 / 05$ & Rank & $2005 / 06$ \\
\hline 1 & $\begin{array}{l}\text { KwaZulu-Natal }(\mathrm{KZN}) \text { - } \\
\text { classified as single region in } \\
2003 / 04 \text {. }\end{array}$ & 1 & $\begin{array}{l}\text { KwaZulu-Natal Durban } \\
\text { (KZNDB) }\end{array}$ & 1 & Northern Cape (NC) \\
\hline 2 & Northern Cape (NC) & 2 & $\begin{array}{l}\text { KwaZulu-Natal Richard's Bay } \\
\text { (KZNRB) }\end{array}$ & 2 & Gauteng Pretoria (GAPT) \\
\hline 3 & North West (NW) & 3 & $\begin{array}{l}\text { KwaZulu-Natal } \\
\text { Pietermaritzburg (KZNPM) }\end{array}$ & 3 & $\begin{array}{l}\text { KwaZulu-Natal }(\mathrm{KZN}) \text { - } \\
\text { classified as single region in } \\
2005 / 06 \text {. }\end{array}$ \\
\hline 4 & Limpopo (LP) & 4 & Northern Cape (NC) & 4 & Western Cape (WE) \\
\hline 5 & Mpumalanga (MP) & 5 & Limpopo (LP) & 5 & North West (NW) \\
\hline 6 & Western Cape (WE) & 6 & $\begin{array}{l}\text { Eastern Cape - Port Elizabeth } \\
\text { (ECPE) }\end{array}$ & 5 & Free State (FS) \\
\hline 7 & $\begin{array}{l}\text { Gauteng (GA) - classified as a } \\
\text { single region in 2003/04 }\end{array}$ & 7 & Mpumalanga (MP) & 7 & Limpopo (LP) \\
\hline 8 & Free State (FS) & 8 & North West (NW) & 8 & Mpumalanga (MP) \\
\hline 9 & $\begin{array}{l}\text { Eastern Cape - Port Elizabeth } \\
\text { (ECPE) }\end{array}$ & 9 & Western Cape (WE) & 9 & $\begin{array}{l}\text { Eastern Cape (EC) - classified } \\
\text { as a single region in 2005/06 }\end{array}$ \\
\hline \multirow[t]{3}{*}{10} & $\begin{array}{l}\text { Eastern Cape - East London } \\
\text { (ECEL) }\end{array}$ & 10 & $\begin{array}{l}\text { Eastern Cape - East London } \\
\text { (ECEL) }\end{array}$ & 10 & $\begin{array}{l}\text { Gauteng Johannesburg } \\
\text { (GAJB) }\end{array}$ \\
\hline & & 10 & Free State (FS) & & \\
\hline & & 12 & $\begin{array}{l}\text { Gauteng }(G A) \text { - classified as a } \\
\text { single region in 2004/05. }\end{array}$ & & \\
\hline
\end{tabular}

Source: CCMA Review of Operations, 2003/04 to 2005/06 
Figure 6: Average Ranking for the Period 2003/04 to 2005/06 (Index)

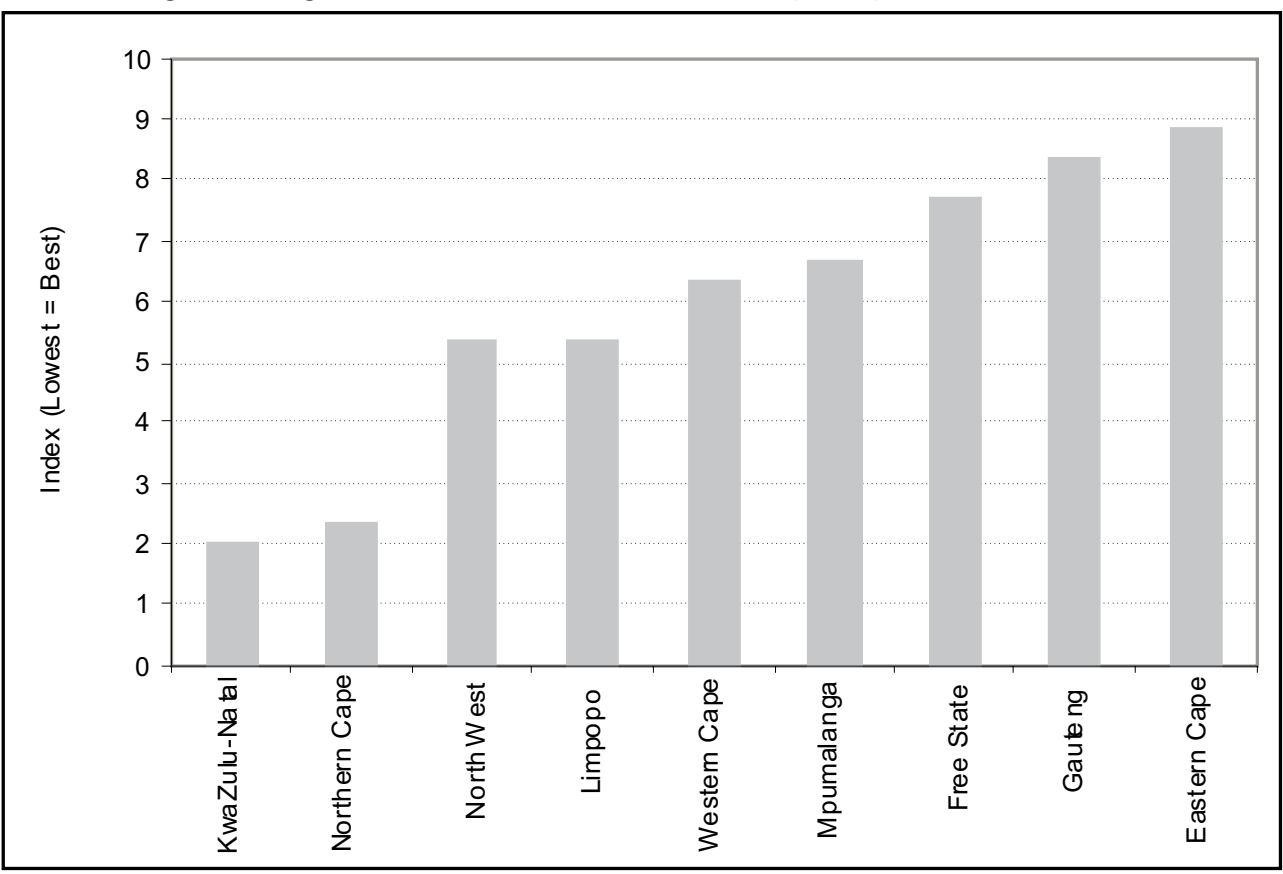

Source: Authors' Calculations based on CCMA Review of Operations, 2003/04 to 2005/06

As shown in Figure 6, KwaZulu-Natal as a region performed the best over the period 2003/04 to $2005 / 06$. Unfortunately it is not possible here to distinguish between different offices within a region over the entire period, as the Review of Operations was inconsistent in its disaggregations over the years (see Table 4). However, even in 2004/05, when KwaZulu-Natal was disaggregated, the three regional offices were at the top of the list. In the second place is the Northern Cape office, the smallest CCMA office in terms of number of referrals. The Northern Cape has a small population but is also the largest province in South Africa in terms of area. Further analysis of this region would be interesting, particularly to determine whether referrals are concentrated only in Kimberley, the main urban area, or whether the office also manages to service far-off customers. Certainly, judging by Figure 3 previously, referrals in this region are underrepresented when compared to the weighted LFS shares, presumably since people live far from the CCMA office. If proximity to a CCMA office affects referral rates the issue should certainly be addressed.

At lower end of the ranking are the Free State, Gauteng and Eastern Cape regional offices. The poor performance in Gauteng is problematic, especially in the light of the fact that this province handles the largest share of cases of all the provinces, obviously related to the fact 
that Gauteng also has the largest working population. However, poor performance in Gauteng affects the overall performance of the CCMA. The Eastern Cape is also consistently a poor performer, perhaps justifying closer investigations into processes in this province. A mitigating circumstance, perhaps, is the fact that large parts of the Eastern Cape have poor infrastructure and are situated in deep rural areas. It is unclear, however, what share of referrals would necessarily originate from these isolated areas. It may well be that the mobile courts used in those provinces that serve rural areas (see footnote 30 ) adds to the efficiency rating of such provinces. However, the Northern Cape and KwaZulu-Natal, for example, would then stand out as exceptions - these provinces also serve large rural areas through mobile courts, but they are consistently the most efficient provinces.

Clearly, a better understanding of the management, referrals received and other unique circumstances that exist in each province is needed to fully explain differences in efficiency across provinces. The CCMA itself is perhaps best placed to investigate this further. In the following sections (Sextions 4.3 and 4.4), however, we do investigate variation in turnaround times in more detail in order to better understand efficiency levels. In particular we are concerned about explaining variations in efficiency across dispute types, economic sectors and regions for various determinative processes.

\subsection{A Descriptive Overview of Turnaround Times}

The CMS dataset records various dates during the conciliation and arbitration processes. An analysis of the variation in time lapsed between the various steps in the process is useful for gauging the efficiency of the CCMA. The CCMA sets itself various efficiency targets in terms of turnaround times against which they can measure performance. Below we analyse trends in three key turnaround times, namely the referral-to-activation date turnaround time, the activation-to-end date turnaround time for conciliation cases and the arbitration referral-toend date turnaround time for arbitration cases. These estimates are not necessarily entirely comparable with the conciliation and arbitration turnaround times calculated internally by the CCMA.

\subsubsection{Referral to Activation Date}

When a case is referred to the CCMA a case number is assigned. As soon as the required information (case details, party details and so on) is captured, the case is activated. In about two-thirds of the cases the activation date is the same as the referral date, that is, the turnaround time from referral to activation is zero. However, if there is any missing information 
in the referral, the applicant is requested to produce the required information, thus resulting in delays. These delays are analysed in detail in Benjamin and Gruen (2006). Long delays in referral to activation times are not necessarily a reflection of poor performance by the CCMA office, as the client is responsible for supplying information.

Using the pooled dataset (2001/02 to $2005 / 06$ data inclusive) we compare some referral to activation date turnaround times for across dispute types, sectors, regions and determinative processes across various years. Observations included in the calculation of turnaround times include all dispute types but only for pre-conciliation, conciliation, arbitration and con-arb as determinative processes. ${ }^{39}$ This means that only cases that are not ruled as out of jurisdiction cases at the initial screening stage are included. Only valid (positive and non-missing) turnaround times are included in the calculation. In order to control for outliers we exclude any observations with turnaround times exceeding 365 days (one year). Negative turnaround times are probably due to incorrect dates being captured, while 'missing' values (in the statistical context) appear in the dataset when the date format is incorrect and hence calculations cannot be done with that specific date.

Table 5 shows the average referral to activation turnaround times. A brief discussion follows. The national average referral to activation date turnaround time is 6.3 days, which is fairly high considering that about 60 per cent of the observations record a turnaround time of zero. The yearly data shows that relatively speaking 2003/04 was the least efficient year as measured by referral to activation turnaround times. Since then a significant improvement can be observed. Variation across dispute type appears to be quite high, but as shown in the previous section, the majority of cases are unfair dismissal cases; hence the national average is driven largely by the turnaround time for unfair dismissal cases.

There is also substantial variation in turnaround times across economic sectors. One sector that stands out with its high turnaround time is the public service sector. This suggests that public sector cases are disproportionate contributors to the CCMA inefficiency, at least as far as referral to activation is concerned. This may be attributed to a number of things; for example, it may be that government officials referring disputes to the CCMA take a very long time to submit all the

39 It was found that in limine cases had referral to activation turnaround times of between 20 and 35 days over the period of analysis. In contrast the average among the other determinative processes ranged between five and eight days. As a result the in limine cases were excluded from the calculations since they bias mean estimates upwards. Most in limine cases are out of jurisdiction cases (see footnote 35). 
relevant data before a case can be activated. It may also relate to the fact that most public sector cases do not fall under jurisdiction of the CCMA and, hence, perhaps more time is needed to determine the jurisdictional status of such cases before they are activated.

The turnaround times vary significantly across regions. A recurring result is that the KwaZulu-Natal offices are by far the best performers, also in terms of the referral to activation turnaround times. This result also holds for individual years. The Eastern Cape (in particular the East London office) has a very poor performance, with the highest referral to activation date turnaround time on average. In theory referral to activation dates for different determinative processes should not differ. For example, at the referral stage it is unknown to the parties involved whether a case will be settled at conciliation or whether it will be referred for arbitration. However, as shown here, there are some substantial differences in turnaround times across determinative processes, with arbitration cases typically taking longer to activate. ${ }^{40}$ 
Table 5: Average Referral to Activation Date Turnaround Times, 2001/02 - 2005/06

\begin{tabular}{|c|c|c|c|c|c|c|}
\hline & $2001 / 02$ & $2002 / 03$ & $2003 / 04$ & $2004 / 05$ & $2005 / 06$ & Total \\
\hline \multicolumn{7}{|l|}{ By type of dispute } \\
\hline \multirow{2}{*}{ Unfair dismissal } & 6.3 & 5.5 & 8.3 & 5.6 & 4.9 & 6.1 \\
\hline & $(50,480)$ & $(51,428)$ & $(57,682)$ & $(53,822)$ & $(55,547)$ & $(268,959)$ \\
\hline \multirow[t]{2}{*}{ Unfair labour practice } & 7.1 & 5.7 & 8.0 & 6.6 & 5.7 & 6.6 \\
\hline & $(3,732)$ & $(3,963)$ & $(4,218)$ & $(4,167)$ & $(4,364)$ & $(20,444)$ \\
\hline \multirow[t]{2}{*}{ Mutual interest } & 4.3 & 4.2 & 4.5 & 2.4 & 3.3 & 3.8 \\
\hline & $(1,667)$ & $(1,208)$ & $(1,020)$ & $(1,226)$ & $(1,133)$ & $(6,254)$ \\
\hline \multirow{2}{*}{ Severance pay } & 5.2 & 5.6 & 8.5 & 5.5 & 3.7 & 5.8 \\
\hline & $(2,089)$ & $(1,985)$ & $(1,773)$ & $(1,434)$ & $(1,294)$ & $(8,575)$ \\
\hline \multirow{2}{*}{ Other } & 9.6 & 8.1 & 9.0 & 8.6 & 7.5 & 8.5 \\
\hline & $(3,655)$ & $(3,412)$ & $(4,023)$ & $(4,061)$ & $(4,823)$ & $(19,974)$ \\
\hline \multirow[t]{2}{*}{ Total } & 6.4 & 5.6 & 8.3 & 5.8 & 5.1 & 6.3 \\
\hline & $(61,623)$ & $(61,996)$ & $(68,716)$ & $(64,710)$ & $(67,161)$ & $(324,206)$ \\
\hline \multicolumn{7}{|l|}{ By sector } \\
\hline \multirow{2}{*}{$\begin{array}{l}\text { Agriculture, forestry } \\
\& \text { fishing }\end{array}$} & 8.7 & 6.6 & 9.0 & 6.4 & 5.6 & 7.3 \\
\hline & $(2,769)$ & $(2,849)$ & $(3,229)$ & $(2,771)$ & $(2,651)$ & $(14,269)$ \\
\hline \multirow[t]{2}{*}{ Mining } & 9.8 & 6.4 & 8.1 & 8.5 & 7.2 & 8.0 \\
\hline & $(2,136)$ & $(2,493)$ & $(3,145)$ & $(2,644)$ & $(2,474)$ & $(12,892)$ \\
\hline \multirow[t]{2}{*}{ Manufacturing } & 6.9 & 5.6 & 8.7 & 6.0 & 6.4 & 6.7 \\
\hline & $(7,628)$ & $(7,204)$ & $(6,302)$ & $(6,138)$ & $(5,900)$ & $(33,172)$ \\
\hline \multirow[t]{2}{*}{ Electricity, gas \& water } & 7.5 & 7.7 & 12.0 & 8.0 & 5.6 & 8.2 \\
\hline & $(547)$ & $(481)$ & (471) & (409) & $(468)$ & $(2,376)$ \\
\hline \multirow[t]{2}{*}{ Construction } & 5.2 & 5.1 & 8.2 & 5.4 & 4.3 & 5.6 \\
\hline & $(4,051)$ & $(4,284)$ & $(4,608)$ & $(4,715)$ & $(5,159)$ & $(22,817)$ \\
\hline \multirow{2}{*}{$\begin{array}{l}\text { Trade, catering, } \\
\text { accommodation }\end{array}$} & 5.9 & 5.4 & 7.1 & 5.2 & 4.7 & 5.7 \\
\hline & $(16,188)$ & $(14,687)$ & $(16,802)$ & $(14,872)$ & $(14,627)$ & $(77,176)$ \\
\hline \multirow{2}{*}{$\begin{array}{l}\text { Transport, storage, } \\
\text { communication }\end{array}$} & 9.2 & 6.9 & 9.5 & 7.4 & 6.5 & 8.0 \\
\hline & $(3,001)$ & $(2,715)$ & $(2,606)$ & $(2,327)$ & $(2,323)$ & $(12,972)$ \\
\hline \multirow{2}{*}{$\begin{array}{l}\text { Finance, insurance, } \\
\text { bus service }\end{array}$} & 6.8 & 7.0 & 11.0 & 6.2 & 5.4 & 7.0 \\
\hline & $(4,464)$ & $(4,832)$ & $(5,843)$ & $(6,972)$ & $(10,020)$ & $(32,131)$ \\
\hline \multirow[t]{2}{*}{ Community \& Social Service } & 6.9 & 6.4 & 8.0 & 6.1 & 5.7 & 7.0 \\
\hline & $(5,469)$ & $(5,187)$ & $(13,930)$ & $(4,823)$ & $(4,310)$ & $(33,719)$ \\
\hline \multirow[t]{2}{*}{ Domestic workers } & 4.4 & 4.2 & 8.1 & 5.2 & 4.1 & 4.7 \\
\hline & $(7,655)$ & $(9,252)$ & $(2,289)$ & $(9,780)$ & $(9,894)$ & $(38,870)$ \\
\hline \multirow[t]{2}{*}{ Security personnel } & 5.5 & 4.6 & 7.7 & 4.9 & 4.2 & 5.4 \\
\hline & $(6,483)$ & $(6,960)$ & $(8,143)$ & $(8,379)$ & $(8,418)$ & $(38,383)$ \\
\hline \multirow[t]{2}{*}{ Public service } & 10.2 & 11.9 & 9.9 & 10.0 & 8.1 & 10.1 \\
\hline & $(1,228)$ & $(1,051)$ & $(1,343)$ & $(871)$ & $(914)$ & $(5,407)$ \\
\hline Total & $\begin{array}{r}6.4 \\
(61.619)\end{array}$ & $\begin{array}{r}5.6 \\
(61.995)\end{array}$ & $\begin{array}{r}8.3 \\
(68.713)\end{array}$ & $\begin{array}{r}5.8 \\
(64702)\end{array}$ & $\begin{array}{r}5.1 \\
(67161)\end{array}$ & $\begin{array}{r}6.3 \\
(3241901\end{array}$ \\
\hline
\end{tabular}


Table 5 continued...

\begin{tabular}{|c|c|c|c|c|c|c|}
\hline & $2001 / 02$ & $2002 / 03$ & $2003 / 04$ & $2004 / 05$ & $2005 / 06$ & Total \\
\hline \multicolumn{7}{|l|}{ By province } \\
\hline \multirow{2}{*}{ Western Cape } & 9.7 & 7.2 & 7.7 & 5.5 & 4.3 & 6.8 \\
\hline & $(7,979)$ & $(8,141)$ & $(8,986)$ & $(9,007)$ & $(10,075)$ & $(44,188)$ \\
\hline \multirow[t]{2}{*}{ Eastern Cape } & 5.5 & 9.1 & 7.1 & 8.2 & 6.3 & 6.9 \\
\hline & $(4,067)$ & $(2,395)$ & $(2,106)$ & $(1,908)$ & $(2,820)$ & $(13,296)$ \\
\hline \multirow[t]{2}{*}{ Northern Cape } & 8.2 & 5.3 & 5.4 & 8.1 & 6.6 & 6.7 \\
\hline & $(1,068)$ & $(1,115)$ & $(1,316)$ & $(1,414)$ & $(1,524)$ & $(6,437)$ \\
\hline \multirow[t]{2}{*}{ Free State } & 5.4 & 6.7 & 7.2 & 8.0 & 6.8 & 6.6 \\
\hline & $(4,358)$ & $(4,058)$ & $(4,296)$ & $(1,144)$ & (440) & $(14,296)$ \\
\hline \multirow[t]{2}{*}{ KwaZulu-Natal } & 2.5 & 0.5 & 1.1 & 1.5 & 1.5 & 1.4 \\
\hline & $(11,215)$ & $(12,214)$ & $(14,934)$ & $(13,829)$ & $(13,500)$ & $(65,692)$ \\
\hline \multirow[t]{2}{*}{ North West } & 11.0 & 6.6 & 9.7 & 10.6 & 9.4 & 9.4 \\
\hline & $(4,050)$ & $(4,564)$ & $(4,835)$ & $(4,229)$ & $(4,445)$ & $(22,123)$ \\
\hline \multirow[t]{2}{*}{ Gauteng } & 5.8 & 6.5 & 12.9 & 6.8 & 6.3 & 7.7 \\
\hline & $(22,751)$ & $(23,854)$ & $(25,974)$ & $(27,157)$ & $(27,785)$ & $(127,521)$ \\
\hline \multirow[t]{2}{*}{ Mpumalanga } & 14.5 & 8.6 & 6.5 & 5.1 & 3.2 & 7.3 \\
\hline & $(3,211)$ & $(3,726)$ & $(4,060)$ & $(3,580)$ & $(3,987)$ & $(18,564)$ \\
\hline \multirow[t]{2}{*}{ Limpopo } & 4.6 & 6.7 & 9.6 & 7.0 & 6.2 & 6.7 \\
\hline & $(2,924)$ & $(1,929)$ & $(2,209)$ & $(2,442)$ & $(2,585)$ & $(12,089)$ \\
\hline \multirow[t]{2}{*}{ Total } & 6.4 & 5.6 & 8.3 & 5.8 & 5.1 & 6.3 \\
\hline & $(61,623)$ & $(61,996)$ & $(68,716)$ & $(64,710)$ & $(67,161)$ & $(324,206)$ \\
\hline \multicolumn{7}{|c|}{$\begin{array}{l}\text { By determinitive } \\
\text { process }\end{array}$} \\
\hline \multirow{2}{*}{ Pre-conciliation } & 4.0 & 5.2 & 5.9 & 4.5 & 2.6 & 4.4 \\
\hline & $(3,312)$ & $(4,629)$ & $(3,427)$ & $(2,394)$ & $(4,746)$ & $(18,508)$ \\
\hline \multirow[t]{2}{*}{ Conciliation } & 6.1 & 4.8 & 8.3 & 6.6 & 5.7 & 6.2 \\
\hline & $(34,574)$ & $(29,541)$ & $(21,862)$ & $(17,385)$ & $(17,008)$ & $(120,370)$ \\
\hline \multirow[t]{2}{*}{ Con-Arb } & 0.0 & 6.2 & 6.7 & 4.7 & 3.9 & 5.0 \\
\hline & (2) & $(2,332)$ & $(15,901)$ & $(23,612)$ & $(21,594)$ & $(63,441)$ \\
\hline \multirow[t]{2}{*}{ Arbitration } & 7.3 & 6.6 & 9.4 & 6.4 & 6.2 & 7.3 \\
\hline & $(23,735)$ & $(25,494)$ & $(27,526)$ & $(21,319)$ & $(23,813)$ & $(121,887)$ \\
\hline \multirow[t]{2}{*}{ Total } & 6.4 & 5.6 & 8.3 & 5.8 & 5.1 & 6.3 \\
\hline & $(61,623)$ & $(61,996)$ & $(68,716)$ & $(64,710)$ & $(67,161)$ & $(324,206)$ \\
\hline
\end{tabular}

Source: CMS (various years) and Author's Calculations.

Notes: (1) The numbers in brackets show the number of observations on which the estimate is based.

(2) This table only includes cases referred and activated, and eventually being resolved at one of the 'main' determinative processes, that is, pre-conciliation, conciliation, con-arb or arbitration. The sample is truncated by dropping all observations with turnaround times exceeding 365 days. This ensures that estimates of the mean are not biased upwards by outliers. 


\subsubsection{Conciliation and Arbitration Turnaround Times to End Date}

It is only once a case has been activated that the CCMA begins to monitor turnaround times to the point of closure of a case. As discussed previously the internal efficiency target for the closing of cases where conciliation is the determinative process is 30 days, and 60 days for an arbitration case. In the case of conciliation cases the measurement is taken from the activation date, while for arbitration cases, the turnaround time is calculated from the arbitration referral date to the end date.

Table 6 shows the conciliation turnaround times based on two alternative definitions. The first set of results shows the average activation to end date turnaround times for conciliation cases. These include all cases that were concluded (closed) at conciliation stage or in the conciliation stage of the con-arb process. This is also the turnaround time variable for conciliation cases that is used in the econometric analyses to follow, and, to our knowledge, closely approximates the approach used by the CCMA to calculate their conciliation turnaround times. The second set of results shows the same turnaround times, only now including preconciliation cases. About a quarter of pre-conciliation cases are resolved or closed on the activation date and hence the turnaround time is zero. As a result estimates in this second set are slightly lower than the first. Since pre-conciliation is not seen as a possible efficiency enhancing option (see earlier discussion), these lower turnaround times may be misleading. In the discussion that follows we only consider the first set of results. 


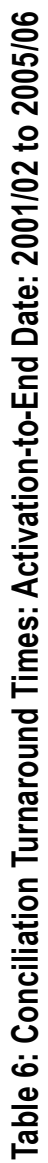

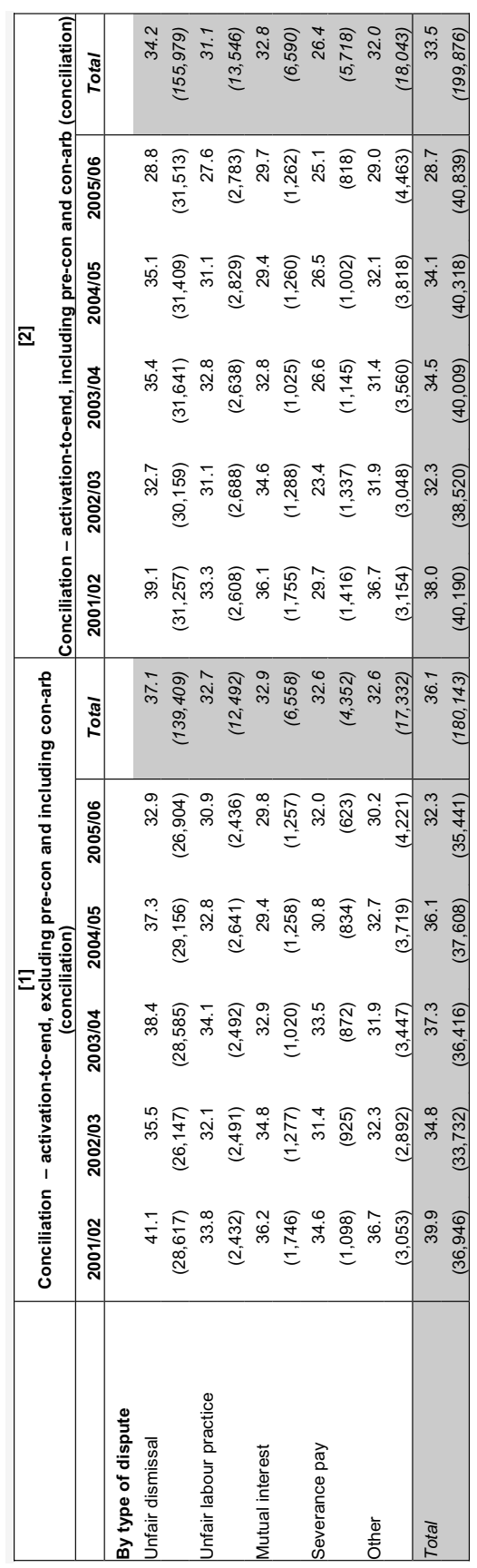




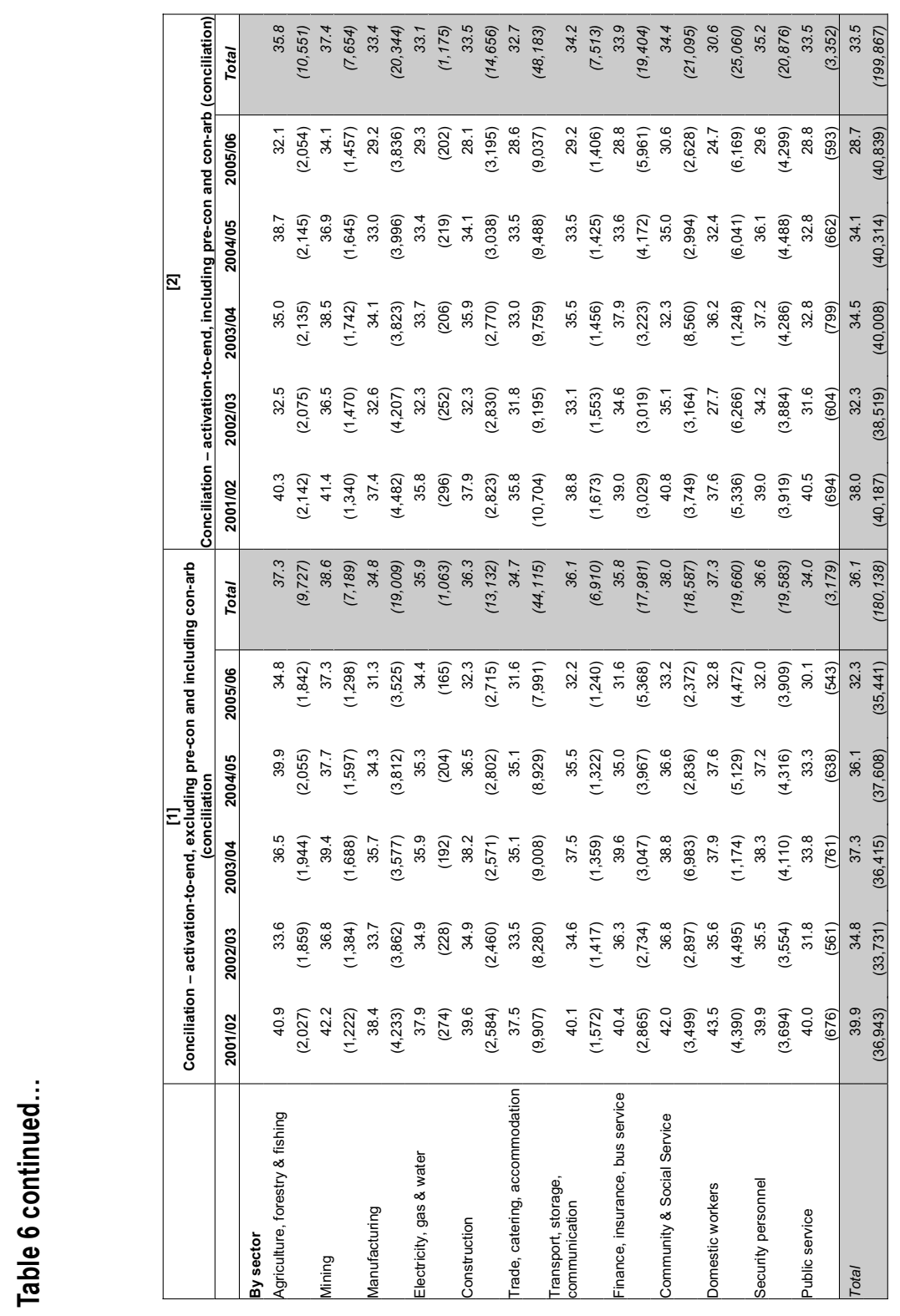




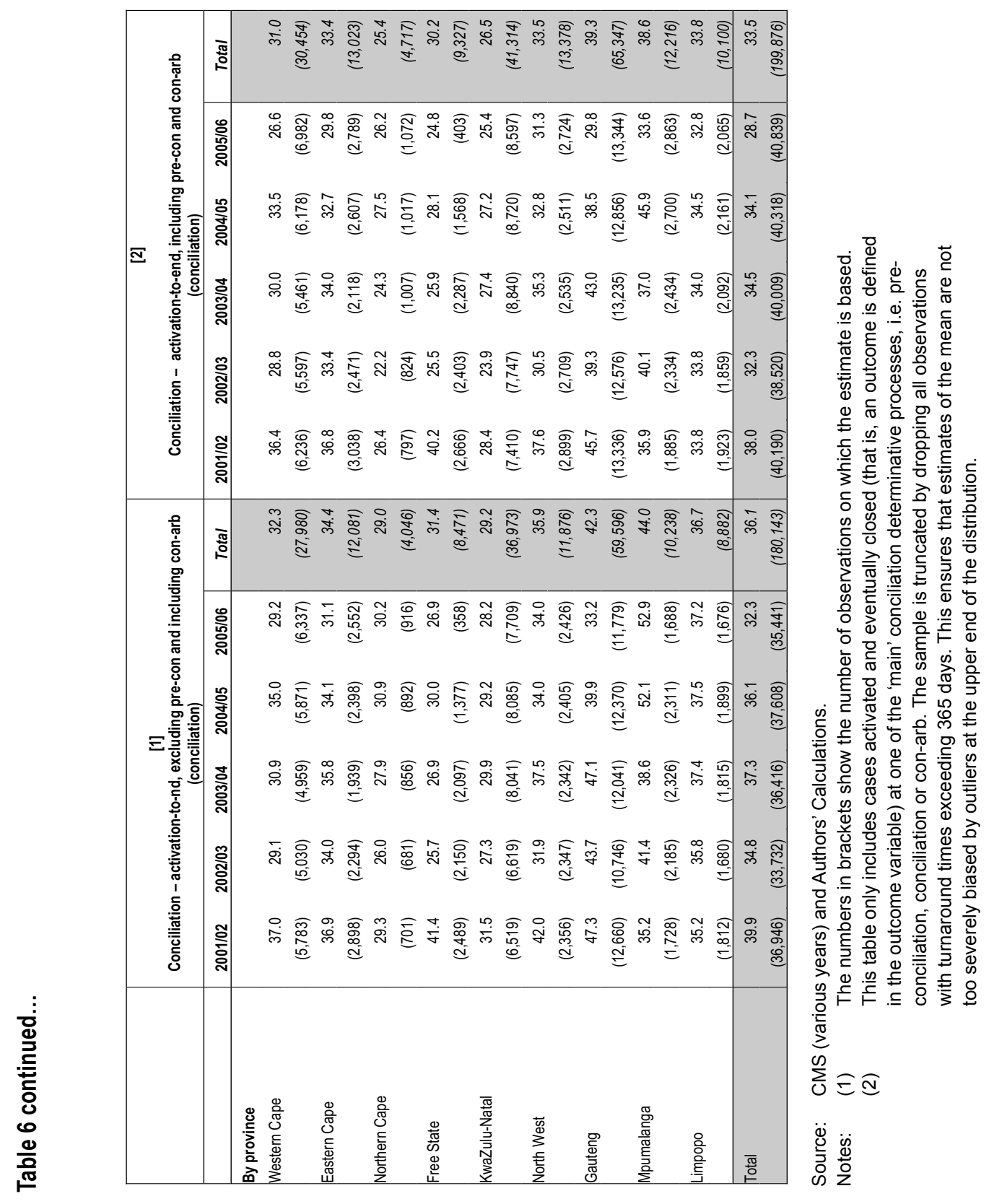


The average conciliation turnaround time for the pooled sample is 36 days, which is well above the internal requirement of 30 days. Although there is substantial variation across the years, the turnaround time appears to have declined from 40 days in 2001/02 to 32 days in 2005/06. The average turnaround time for unfair dismissal disputes, at 37 days for the 2001/02 to $2005 / 06$ period, is significantly higher than that of other dispute types. Since the majority of cases are unfair dismissal disputes it is evident that the turnaround time for unfair dismissals drives the overall turnaround time.

Table 6 shows that the sectoral variation appears to be quite low, ranging from 34 days for the public sector to almost 39 days for mining workers. The regional variation is quite high, with Mpumalanga faring worst with an average of 44 days across the period. As usual the KwaZuluNatal offices and the Northern Cape do particularly well, all coming in at below 30 days for the entire period.

For arbitration cases, which include con-arb concluded at the arbitration stage, two approaches are used to calculate the turnaround time (see Table 7). In the first instance the calculation is based on the time lapsed between the activation and end dates of these cases. This is not comparable with the arbitration turnaround time calculated by the CCMA. In the second set of results we use the arbitration referral to end date as the measure of turnaround time for the portion of 'pure' arbitration cases, while using the activation to end date for con-arb cases resolved at arbitration. ${ }^{41}$ To our knowledge this is a similar approach to the one used by the CCMA. In the econometric analyses that follow in Section 4.4, however, we use the first set of turnaround times for the arbitration model. This is done mainly due to the large number of missing values for arbitration referral date, which, as shown in Table 7, reduces the number of observations that can be studied (compare sample size in the second and third set of results in theory these should be the same). A brief discussion follows directly below the table.

41 Given the way in which con-arb is conducted there is no arbitration referral date, hence this approach. This is similar to the approach used by the CCMA for calculating arbitration turnaround times. 


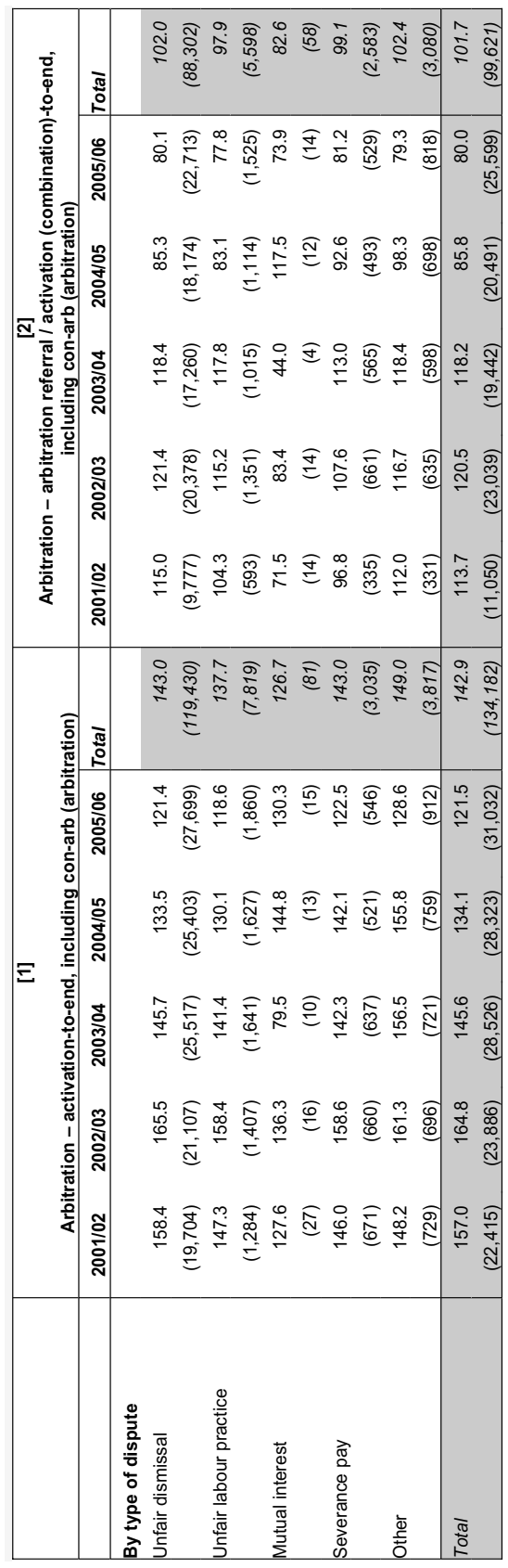




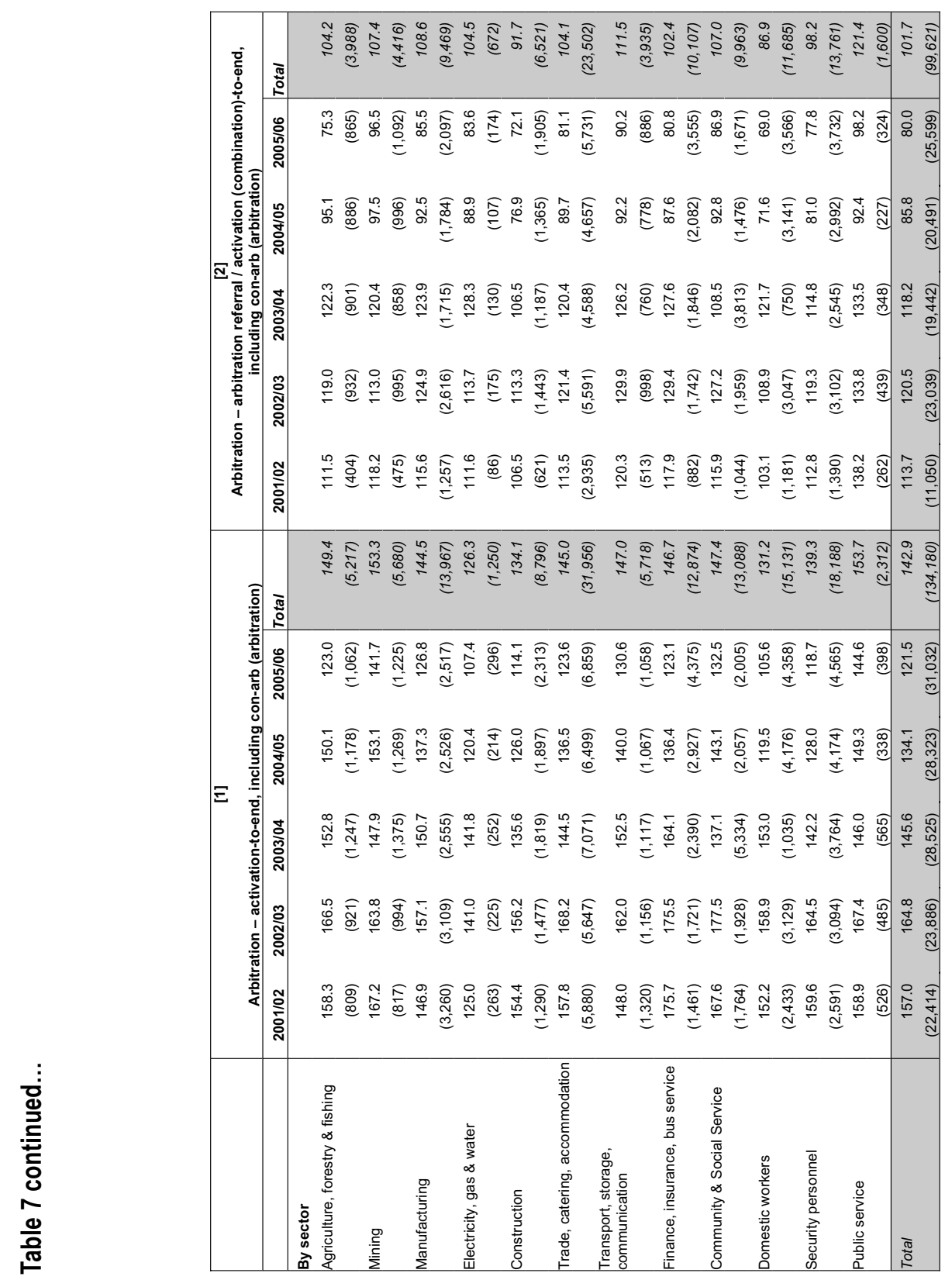




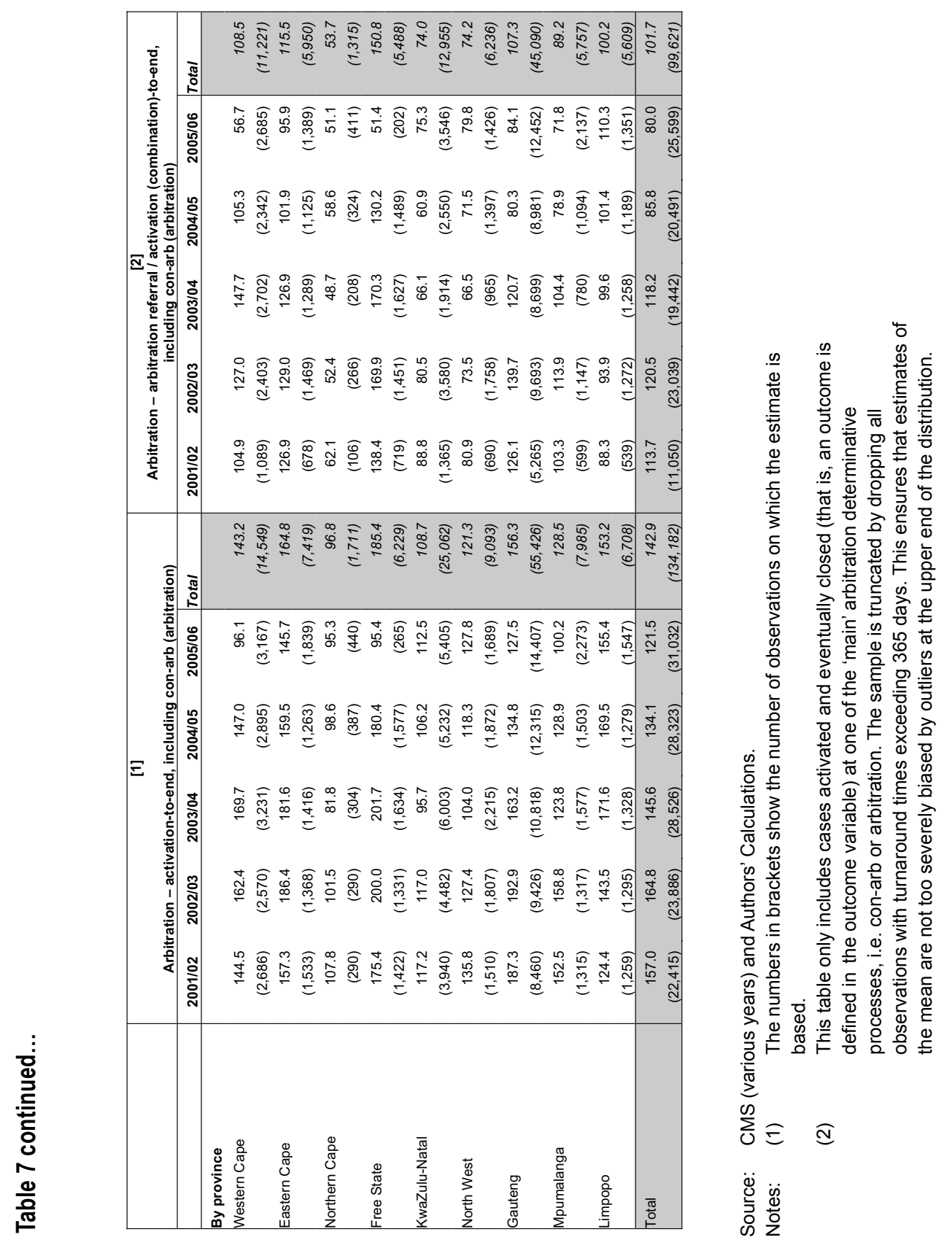


In the first set of results the average turnaround time for arbitration cases over the entire period was 143 days, declining significantly over the period from around 157 in the first year to 122 in 2005/06. As expected, the average turnaround time for unfair dismissal cases is again close to the overall average given the large share of unfair dismissal disputes. However, in contrast to the conciliation turnaround times, unfair dismissals do not have the highest turnaround time. The public service sector has the highest average turnaround time (153 days). Gauteng, Eastern Cape and the Free State are at the top of the distribution, with average turnaround times ranging between 156 and 185 days.

In the second set of results we find that the way in which turnaround times are now calculated brings the averages down to levels that are more comparable with the CCMA's internal estimates. By 2005/06 the turnaround time had dropped significantly to around 80 days. The distribution across dispute types, sectors and provinces is similar to the estimates in the first set of results, although now at lower levels.

The next section analyses the determinants of these turnaround times in an econometric model. In doing so we will hopefully be able to determine, within a multivariate context, how the different independent variables, such as province, sector, type of dispute and so on, may simultaneously impact on average turnaround times for different types of processes.

\subsection{Determinants of Variation in Turnaround Times}

\subsubsection{Estimation Approach}

In order to assess the efficiency of the CCMA we analyse the turnaround time for the conciliation and arbitration processes to be finalised. Our estimate of turnaround time for a case should not be confused with the "turnaround times" used by the CCMA as internal and statutory measures of efficiency, although they are very similar. We define the turnaround time as the number of days from the activation of the case ${ }^{42}$ up to the end date of the case. Disputes are referred to the CCMA as noted in detail above, only after all the intra-firm dispute resolution procedures have been exhausted and the dispute remains unresolved. Therefore, within the context of our estimation approach here, the conciliation and con-arb processes at the CCMA are conditional on a dispute not being resolved at the firm level and consequently the parties to the dispute deciding to bring the case to the attention of the CCMA.

42 This activation date is on or after the case referral date. 
Unfortunately, however, we do not have access to intra-firm dispute resolution data and therefore we do not know the characteristics or extent of the underlying population. Specifically, the underlying population is unobserved and we effectively rely solely on the CMS database, which is not a random sample of labour disputes. This data limitation results in a selection bias problem that we acknowledge from the outset, but cannot control for. Sample selection bias arises given that we only observe a restricted, non-random sample of disputes referred to the CCMA. We are therefore implicitly analysing more intractable disputes that have failed to be resolved within the firm. Empirically therefore, the measured turnaround times for disputes in our sample, are upwardly biased estimates of the true measures of mean turnaround time.

A further limitation relates to the fact that we only analyse disputes referred to the CCMA. While the CCMA handles the majority of labour market disputes in South Africa, the exclusion of disputes referred to and handled by the various Bargaining Councils detracts from the analysis in terms of it being truly representative of dispute resolution in South Africa. Our analysis is then also only based on the referred cases that also fall within the jurisdiction of the CCMA, as these are the only cases for which detailed data exists at all stages of the dispute resolution process.

Given the above problems, our estimation approach is set up in two stages. In the first stage, we start with a full sample of cases referred to the CCMA for dispute resolution and estimate a semi-logarithmic turnaround time function for conciliation at both the conciliation or at the con-arb processes. Because the CMS database does not have information on whether con-arb cases that are settled prior to an arbitration award being made were settled during the conciliation phase or the arbitration phase. We assume that all settled cases at the con-arb process are settled during a conciliation hearing and therefore represent the conciliation cases of this process and that cases that are not settled at the conciliation hearing proceed to the arbitration hearing where they may be settled during the formal arbitration process or dismissed. In the second stage, we estimate a Heckman selection model for arbitration using a reduced sample of cases that were not settled during the conciliation processes. Our conciliation equation can be represented as:

$$
\begin{aligned}
& Y_{j}^{T}=Z_{j} \theta+\varepsilon_{j} \\
& \varepsilon_{j} \approx N I D\left(0, \sigma^{2}\right) \text { and } \mathrm{j}=1, \ldots, \mathrm{n}
\end{aligned}
$$


Where $Y_{j}^{T}$ is the natural log of turnaround time of the conciliation or the settled con-arb case $j$ that is brought to the CCMA. $Z_{j}$ is a vector of the case characteristics and $\varepsilon_{j}$ is an independent and identically distributed error term with mean zero and variance $\sigma^{2}$. We use a normal OLS estimation approach for this stage of the estimation process.

Equation (1), however, only captures conciliation and settled con-arb cases. Unresolved conciliation disputes are referred to arbitration. The main problem with adopting Equation (1) for the arbitration process is that the sample actually observed at the arbitration stage is not random, and the application of OLS regressions will yield potentially biased estimates. If we model the selection process that governs observing the potentially non-random sample of cases going to the arbitration process then we may be able to provide a solution to the problem. We adopt the Heckman selection model to cope with the sample selection bias and estimate the following model for the arbitration process ${ }^{43}$ :

$A_{j}^{T}=X_{j} \beta+\mu_{l j}$

$A_{j}^{T}$ is the natural log of turnaround time for an arbitration case $j$ multiplied by the number of hearings and $X_{j}$ are the case characteristics that determine the dependent variable. Equation (3) shows the selection equation. We assume then that the dependent variable $\left(A_{j}^{T}\right)$ in the outcome equation for the case $j$ is observed if:

$s_{j}=\left\{\frac{1 \text { if } s_{\mathrm{j}}^{*}>0 \text { and } \mathrm{s}_{\mathrm{j}}^{*}=\mathrm{S}_{\mathrm{j}} \mathrm{Y}+\mu_{2 \mathrm{j}}}{0 \text { otherwise }}\right\}$

$\mu_{1} \approx N(0, \sigma), \mu_{2} \approx \mathrm{N}(0,1)$ and $\operatorname{corr}\left(\mu_{1}, \mu_{2}\right)=\rho$

The dependent variable in Equation (3), $s_{j}$ is a dummy variable equal to one if the case proceeds to arbitration and 0 , if there is no progress to arbitration and the case is resolved through conciliation. The vector of case characteristics, $X_{j}$, included in the outcome equation can include some of the same independent variables as those included in $S_{j}$ in the selection

$43 \quad$ For an introduction into the Heckman selection model see Heckman (1979) and Greene (2003). Although, we use the Heckman selection model to cope with the sample selection bias problem, it has some important weaknesses as well. For example, such models are very sensitive to the assumption of bivariate normality and rely heavily on the distributional assumptions. 
equation, but in order to identify the equations, they cannot overlap completely. The correlation between the error terms $\left(\mu_{1}, \mu_{2}\right)$ is given by $\rho$, and the two decisions (that is, to proceed to arbitration and how long to take in order to reach a settlement) are related if $\rho$ is not equal to zero. In such a case, estimating the semi-logarithmic function of arbitration turnaround time would induce a sample selection bias, which we are controlling for by estimating both equations as proposed by Heckman (1979).

Consistent estimation requires that we include an additional variable called the inverse Mills ratio. Thus, the process of correction for sample selection can be viewed as including an omitted variable. We interpret the omitted variable also as a proxy for unobserved private information. We suggest that the omitted variable controls for, and tests for, the significance of private information in explaining the ex-post outcomes of choices to proceed to arbitration. This private information set would for example make the employee or employer more willing to proceed to arbitration if he knew for sure that he would win perhaps because costs of the conciliation process are lower than those of the arbitration process.

\subsubsection{Estimation Results}

As already mentioned in the estimation approach, our discussion of the empirical results will commence first with a presentation of the conciliation results from the conciliation and the settled con-arb processes. These results will then be followed by a summary presentation of the results from the arbitration processes.

Table 8 shows the estimated estimation results for the conciliation and the settled con-arb processes. For all the conciliation and the settled con-arb cases, ${ }^{44}$ we estimated Equation (1) using a pooled sample of all jurisdictional disputes brought to the CCMA from 2001/02 to 2005/06. The dependent variable, the natural log of turnaround time, is used here as a proxy for efficiency. The time taken in order to reach a settlement may indicate how complex the issues are and how thoroughly the CCMA deals with these issues. However, it is costly to the parties involved and may indicate poor performance on the part of the CCMA.

$44 \quad$ We assume that the settled disputes at the con-arb process are essentially conciliation cases and are governed by the same rules as a conciliation case in a conciliation process. 
The independent variables include a set of regional CCMA office dummy variables to which the dispute is referred:

- A set of economic sector dummy variables which indicate where the dispute originated.

- A set of year dummy variables which identify the year in which the dispute took place.

- A set of type of dispute dummy variables that describe the four main types of disputes (that is, unfair dismissal, unfair labour practice, mutual interest and severance pay).

- A dummy variable for the outcome of a dispute (that is, one if the case was dismissed and zero if the case was settled).

- A dummy variable Con that represents a conciliation case from the con-arb process.

- A continuous variable that represents the number hearings that a particular case had for it to be resolved.

The regional dummy variables can be used to test whether differences in efficiency and other regional characteristics (unobserved labour market or CCMA office characteristics) explain the variation in the dependent variable. The sector and dispute type dummy variables can be used to test the hypothesis that there are marked differences in patterns of dispute resolution outcome of disputes in the different economic sectors or for different types of disputes. ${ }^{45}$ The referent variables are Western Cape (for region), unfair dismissal disputes (for type of dispute) and domestic workers (for economic sector), 2006 (for individual years) and case dismissed (for outcome of the dispute).

The results show that the Pretoria, Northern Cape, Limpopo and all the KwaZulu-Natal regions have negative and significant coefficients. We interpret these results to mean that Pretoria, Northern Cape, Limpopo and all the KwaZulu-Natal, when controlling for other variables, the offices in these particular regions are, significantly more efficient than the Western Cape office. What is useful about the semi-logarithmic functional form underlying the estimation

$45 \quad$ Benjamin and Gruen (2006) conclude that there are marked differences in patterns of dispute resolution and the outcome of disputes in the CCMA's different provincial region. They suggest that these regional variations are significantly greater than those between different economic sectors. 
approach here is that the coefficients can be interpreted as a 'percentage point differential'. Thus, the differential for the Pretoria is about nine per cent, which implies that Pretoria has a mean turnaround time which is nine per cent greater than the Western Cape, holding other variables constant. Mpumalanga, North West, Johannesburg and East London regions all have significant and positive coefficients. This finding reflects that these regions have turnaround times greater than the Western Cape region, holding other factors fixed. The differential ranges from about two per cent in East London to about 19 per cent in Mpumalanga. 
Table 8: Determinants of Turnaround time of the CCMA Conciliation Processes: 2001-2006

\begin{tabular}{|c|c|c|}
\hline \multirow{2}{*}{$\begin{array}{l}\text { Dependent Variable: Log (Turnaround Time) } \\
\text { East Cape (East London) }\end{array}$} & \multicolumn{2}{|l|}{ Coef. } \\
\hline & 0.0231 & $* * *$ \\
\hline East Cape (Port Elizabeth) & 0.0014 & \\
\hline Free State & 0.0021 & \\
\hline Gauteng (Pretoria) & -0.0887 & $* * *$ \\
\hline Gauteng (Johannesburg) & 0.1468 & *** \\
\hline Limpopo & -0.0580 & $* * *$ \\
\hline Mpumalanga & 0.1863 & $* * *$ \\
\hline Northern Cape & -0.0526 & $* * *$ \\
\hline North West & 0.0843 & *** \\
\hline KwaZulu-Natal (Durban) & -0.0918 & $* * *$ \\
\hline KwaZul-Natal (Pietermaritzburg) & -0.0789 & *** \\
\hline KwaZulu-Natal (Richards Bay) & -0.0803 & *** \\
\hline Unfair Labour Practice & -0.0007 & \\
\hline Mutual Interest & -0.0964 & $* * *$ \\
\hline Severance Pay & -0.0534 & *** \\
\hline Other Type Dispute & -0.0357 & $* * *$ \\
\hline Agriculture & 0.0783 & $* * *$ \\
\hline Mining & 0.0295 & *** \\
\hline Manufacturing & 0.0232 & $* * *$ \\
\hline Construction & 0.0143 & $* * *$ \\
\hline Trade & 0.0208 & $* * *$ \\
\hline Transport & 0.0238 & $* * *$ \\
\hline Finance & 0.0244 & $* * *$ \\
\hline Social Services & 0.0208 & *** \\
\hline Electricity, Gas \& Water & 0.0257 & * \\
\hline Security (Private) & 0.0233 & $* * *$ \\
\hline Public Service & 0.0349 & $* * *$ \\
\hline Dismissed & 0.0282 & $* * *$ \\
\hline Number of Hearings & 0.7660 & $* * *$ \\
\hline Con & -0.0058 & ** \\
\hline 2001_02 & 0.0951 & $* * *$ \\
\hline 2002_03 & -0.0113 & $* * *$ \\
\hline 2003_04 & 0.0699 & $* * *$ \\
\hline 2004_05 & 0.0500 & $* * *$ \\
\hline _cons & 2.4740 & $* * *$ \\
\hline Number of obs $=$ & 157573 & \\
\hline R-squared = & 0.4463 & \\
\hline Root MSE = & 0.3635 & \\
\hline
\end{tabular}

Notes: $\quad{ }^{* * *}$ Significant at the one per cent level, ${ }^{* *}$ Significant at the five per cent level and * Significant at the ten per cent level 
The type of dispute variables show a strong and clear pattern: Relative to unfair dismissal disputes the coefficients on all the other types of dispute are significant and negative apart from unfair labour practice disputes. Hence, the CCMA resolves disputes about mutual interest, severance pay and other types of disputes more speedily relative to unfair dismissal disputes at the conciliation process. The differential ranges from about four per cent for all other types of disputes to about ten per cent for mutual interest disputes. Put differently then, when controlling for other factors such as province and sector, unfair dismissal disputes are associated with the highest turnaround times. Notably, issues of mutual interest appear to be resolved most speedily. The sectoral results show that disputes from domestic workers sector have the lowest turnaround times, holding other factors constant. In fact disputes from all the other sectors have turnaround times greater than the domestic worker sector. The differential ranges from about one per cent in the construction sector to about eight per cent in the agriculture sector.

The coefficient on the Con dummy implies that, for the same region, type of dispute, sector, outcome and number of hearings, conciliation disputes at the con-arb process have turnaround times that are approximately one per cent less than conciliation disputes at the conciliation process. The coefficient on the number of hearings is significant and positive. This is a key result, suggesting that conciliation undertaken as part of the con-arb process are in fact marginally more efficient than those outside of con-arb. This coefficient can be interpreted as the percentage increase in the turnaround times for each additional hearing. Therefore, ceteris paribus, each additional hearing is predicted to increase the turnaround time by about 77 per cent. For a given region, type of dispute and sector, the difference in log (turnaround time) between a case that is dismissed and a case that is settled is 0.0282 . This means that a dismissed case is predicted to have turnaround times that are approximately three per cent higher than a settled case, holding other factors constant.

Table 9 shows the results from the arbitration processes. The sample of cases going to arbitration is not a random selection of cases drawn from the pool of disputes at the CCMA. We therefore follow the Heckman selection model described in the estimation approach above to control for the sample selection problem and assume that natural log of arbitration turnaround time is the dependent variable and that the variables listed in the outcome equation, are the determinants of turnaround time. The variables specified in the selection equation are assumed to determine whether the arbitration process is observed. 
As in the conciliation equation our independent variables include a set of regional CCMA office dummy variables to which the dispute is referred:

- A set of economic sector dummy variables that indicate where the dispute originated.

- A set of year dummy variables that identify the year in which the dispute took place.

- Type of dispute dummy variables describe the four main types of disputes, while a dummy variable Arb represents an arbitration case from the con-arb process.

- A continuous variable represents the number of hearings that a particular case had for it to be resolved.

- A set of dummy variables capture the outcome of a dispute (that is, settled, pure arbitration award and default arbitration award).

The difference between a pure and default award is that unlike a pure award, a default award in an arbitration proceeding occurs if one of the parties to the dispute does not attend the hearings and a decision is thus made in favour of the party that attends. A settled arbitration occurs when parties at arbitration arrive at mutually acceptable solution to their dispute before the arbitrator makes his or her decision.

Unlike the conciliation process, legal representation is allowed at arbitration proceedings. ${ }^{46}$ We therefore include a set of representation dummy variables for both the worker and employer. Representation as captured in the CMS database is not a mandatory field. As a result information on representation is missing for the majority of cases. Thus we need to interpret to interpret the representation results with caution. We also note that trade unions and employer organisations often hire 'consultant' organisations to advise them. We choose rather to include dummy variables for professional representation, for example, professional representation for workers would include both legal and trade union representation instead of using dummies for legal and trade union representation individually. We also include an interaction dummy between a worker having professional representation and professional representation for the employer in a given dispute. The referent variables are Western Cape (for region), unfair dismissal disputes (for type of dispute) and domestic workers (for economic sector), 2006 (for

$46 \quad$ However, it should be clearly noted that legal representation is not automatically allowed in all cases. For example, in cases where the reason for dismissal relates to misconduct and capacity, legal representation is not allowed. A party may make an application for legal representation in terms of Rule 25(1)(c) of the Rules for the Conduct of Proceedings before the CCMA (CCMA, 2007). 
individual years), pure arbitration award (for outcome of the dispute) and no representation (for type of representation).

Consider first the parameter estimates of the selection equation in Table 9. Notice that only the Northern Cape region has a significant and negative coefficient. Interestingly, this finding suggests that a case from the Northern Cape region has a decreased probability (about four per percent) of proceeding to arbitration relative to a case from the Western Cape which is the same in all other respects (including the type of dispute and the sector ). On the other hand, all the other regions have significant and positive coefficients. This means that all other regions apart from the Northern Cape have an increased probability of proceeding to arbitration relative to the Western Cape. The differential ranges from about 12 per cent in East London to about 75 per cent in Pretoria.

Another important observation from the selection equation is that unfair labour practice, mutual interest, severance pay and other dispute types are all significant and negative. In other words, the dispute type dummies suggest that the probability of arbitration decreases for all disputes relative to unfair dismissal disputes, holding the sector and region of the case constant. Put differently, an unfair dismissal case has the highest conditional probability of proceeding to arbitration. The coefficients on agriculture and construction are negative and significant which indicates that holding the type of dispute and the region constant, the agriculture and construction sectors have a decreased probability (about ten per cent and five per cent respectively) of proceeding to arbitration relative to the domestic workers sector while all the sectors have an increased probability. Of interest from the sector dummies is that the utilities and public service sector have the highest increased probability of proceeding to arbitration, holding the other variables constant. These two sectors are also more likely to have the largest share of essential workers who under the LRA are prohibited from industrial action. The Mills ratio is shown to be significant and negative, thus suggesting that sample selection bias was detected and subsequently corrected for. 
Table 9: Determinants of Turnaround time of the CCMA Arbitration Processes: 2001-2006

\begin{tabular}{|c|c|c|c|c|c|}
\hline $\begin{array}{l}\text { Dependent Variable: } \\
\text { Log (Turnaround Time) } \\
\text { Selection Equation }\end{array}$ & Coef. & & $\begin{array}{l}\text { Dependent Variable: } \\
\text { Arbitration } \\
\text { Outcome Equation }\end{array}$ & Coef. & \\
\hline East Cape EL & 0.1241 & *** & East Cape EL & 0.3011 & *** \\
\hline East Cape PE & 0.2917 & $* * *$ & East Cape PE & -0.0167 & $\star \star$ \\
\hline Free State & 0.1787 & $* * *$ & Free State & 0.3651 & $* * *$ \\
\hline Gauteng PT & 0.7543 & $* * *$ & Gauteng PT & -0.1402 & $\star \star \star *$ \\
\hline Gauteng JB & 0.4119 & $\star \star \star *$ & Gauteng JB & 0.1741 & $\star \star \star *$ \\
\hline Limpopo & 0.1392 & $* * *$ & Limpopo & -0.0852 & $* * *$ \\
\hline Mpumalanga & 0.5143 & $* * *$ & Mpumalanga & -0.1676 & $* \star \star$ \\
\hline Northern Cape & -0.0447 & $* *$ & Northern Cape & -0.3930 & 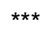 \\
\hline North West & 0.3458 & $* * *$ & North West & -0.2378 & $* * *$ \\
\hline KwaZulu-Natal DB & 0.4268 & *** & KwaZulu-Natal DB & -0.3844 & *** \\
\hline KwaZulu-Natal PM & 0.1264 & $* * *$ & KwaZulu-Natal PM & -0.3693 & $* * *$ \\
\hline KwaZulu-Natal RB & 0.2517 & *** & KwaZulu-Natal RB & -0.3451 & 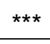 \\
\hline Unfair Labour Practice & -0.2200 & $* * *$ & Unfair Labour Practice & -0.0125 & ** \\
\hline Mutual Interest & -2.5120 & $* * *$ & Mutual Interest & -0.2914 & $* \star \star$ \\
\hline Severance Pay & -0.3236 & $* * *$ & Severance Pay & 0.0103 & \\
\hline Other Type Dispute & -1.0821 & $* * *$ & Other Type Dispute & 0.0565 & $* * *$ \\
\hline Agriculture & -0.0993 & $* * *$ & Agriculture & 0.1220 & $* * *$ \\
\hline Mining & 0.0991 & $* * *$ & Mining & 0.1023 & $* \star \star$ \\
\hline Manufacturing & 0.1063 & $* \star *$ & Manufacturing & 0.0391 & $* \star *$ \\
\hline Construction & -0.0495 & $* \star *$ & Construction & 0.0204 & $* * *$ \\
\hline Trade & 0.0369 & $* * *$ & Trade & 0.0532 & $* \star *$ \\
\hline Transport & 0.1385 & $* * *$ & Transport & 0.0474 & $* * *$ \\
\hline Finance & -0.0055 & & Finance & 0.0678 & $* \star \star$ \\
\hline Social Services & 0.0065 & & Social Services & 0.0276 & $* \star \star$ \\
\hline Electricity, Gas \& Water & 0.3163 & $* * *$ & Electricity, Gas \& Water & -0.0731 & $* * *$ \\
\hline Security (Private) & 0.1564 & $* * *$ & Security (Private) & 0.0235 & *** \\
\hline Public Service & 0.4360 & $* * *$ & Public Service & 0.0606 & 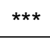 \\
\hline \multirow[t]{2}{*}{ _cons } & \multirow[t]{2}{*}{-0.1353} & \multirow[t]{2}{*}{ *** } & Number of Hearings & 0.3267 & 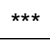 \\
\hline & & & Prof- Rep-Worker & 0.0237 & $* \star \star$ \\
\hline lathrho & 0.0085 & * & Prof- Rep -Employer & 0.0066 & * \\
\hline \multirow[t]{2}{*}{ /Insigma } & \multirow[t]{2}{*}{-0.7797} & \multirow[t]{5}{*}{$* * *$} & Prof Worker * Employer & -0.0083 & * \\
\hline & & & Award Employee & -0.0322 & $* * *$ \\
\hline rho & 0.0085 & & Arb & -1.3669 & $* * *$ \\
\hline sigma & 0.4585 & & Settled & 0.0139 & $* \star *$ \\
\hline \multirow[t]{7}{*}{ lambda } & 0.0039 & & Default Arb_awrd & 0.0214 & $* \star \star$ \\
\hline & & & Dismissed & 0.0626 & $* \star *$ \\
\hline & & & 2001_02 & 0.1282 & $* * *$ \\
\hline & & & 2002_03 & 0.2117 & $* \star \star$ \\
\hline & & & 2003_04 & 0.0529 & $* \star *$ \\
\hline & & & 2004_05 & 0.1085 & $* * *$ \\
\hline & & & _cons & 4.0739 & $\star \star \star *$ \\
\hline Number of obs $=$ & 269121 & & Wald chi2(40) & 368534.67 & \\
\hline Censored obs & 124228 & & Prob > chi2 & 0.0000 & \\
\hline
\end{tabular}

Notes: $\quad{ }^{* * *}$ Significant at the one per cent level, ${ }^{* *}$ Significant at the five percent level and ${ }^{*}$ Significant at the ten percent level 
In terms of the outcome equation results, Pretoria, Port Elizabeth, Limpopo, Mpumalanga, Northern Cape, North West, and the KwaZulu-Natal region all have significant and negative coefficients, suggesting that these regions have turnaround times less than the Western Cape, holding the other variables constant. The differential for these regions ranges from about two per cent in Port Elizabeth to about 40 per cent in the Northern Cape. To interpret the coefficients on the type of dispute dummy variables, recall that the estimates on the four dummy variables measure the proportionate difference in the turnaround time relative to unfair dismissal disputes. Therefore, the results by type of dispute suggest that unfair labour practice and mutual interest disputes have turnaround times less (about one per cent and 30 per cent respectively) than unfair dismissal disputes, holding all the other variables constant. Other types of disputes have turnaround times greater (about five per cent) than unfair dismissal disputes, holding all the other variables constant.

As in the conciliation equation the coefficient on the number of hearings is positive and significant which means that the effect of an additional hearing is predicted to increase the turnaround time by about 33 per cent, holding other factors constant. The increase in turnaround times associated with number of hearings may represent an opportunity cost for parties in dispute and the CCMA. These costs relate to costs arising from preparing for and attending hearings. It is worth noticing that a case with professional representation for the worker (but not for the employee) has a turnaround time of about two per cent more than when a worker has no representation at all. Similarly, having professional representation for the employer (but not for the worker) increases the turnaround times by about one per cent over not having any representation at all, holding other factors constant. The differential between those cases with professional representation for both workers and employers, relative to those when there is no representation at all, is about two per cent. Hence, the results suggest that formalised representation for either workers or employers result in a marginal increase in the turnaround time for arbitration cases.

This is a potentially important result given that it may reflect the high presence of legal and procedural technicalities within the CCMA resulting in a protracted arbitration process in some cases. The fact that when a worker is represented by other forms of representation such as a co-worker, the arbitration proceedings are more efficient relative to a worker not having any representation at all indeed buttresses the view that over-proceduralisation and a growing tendency toward technicalities in disputes may be frustrating attempts at increased 
efficiency within the CCMA. ${ }^{47}$ The coefficient on the arbitration dispute at the con-arb process suggests that, holding other factors constant, arbitration disputes at the con-arb process have turnaround times that are approximately 137 per cent less than arbitration disputes at the arbitration process. This indeed reinforces the efficiency-enhancing impact realised through the con-arb innovation.

The award employee award dummy is significant and negative. If the award is made in favour of the worker, then the turnaround time of the arbitration proceedings is about three per cent less than when the award is made in favour of the employer. One possible explanation for this observation is that a risk-averse employer upon realising early that he has a weak case, may decide to move to a speedy outcome instead of a protracted arbitration preceding which can only raise costs to the employer. As an indication of the effect of the outcome of a dispute on the turnaround times we included a set of outcome dummy variables to measure the proportionate difference in the turnaround times for the different outcomes at the arbitration proceedings. Table 9 shows that disputes that are settled at arbitration, disputes with a default award or dismissed disputes all have significant and positive coefficients, which suggests turnaround times of these cases are higher than pure arbitration cases that eventually result in a formal arbitration award being rendered. This result is consistent with that of dismissed cases in the conciliation equation. While at first this may seem counterintuitive - dismissed cases are thrown out before any formal arbitration ruling has to be made, which in itself is a time-consuming process - it perhaps points at the fact that cases that are dismissed (on technical grounds) or due to parties not arriving at hearing (default awards) often take longer to be closed due to technicalities that have to be resolved first. Those cases that eventually lead to an arbitration award are probably more likely to be the straightforward ones that can be resolved more speedily.

\subsubsection{Concluding Remarks}

In light of the overview and the patterns of dispute resolution described in Section 4, how do we explain some of the key results presented above? First and foremost, the provincial results suggest that the descriptive evidence as shown in Figure 6 and Table 6, illustrating that KwaZulu-Natal and the Northern Cape offices, were the most efficiently provinces corroborated in the econometric results. Although in the econometric results KwaZulu-Natal is disaggregated into three regional offices, these three regional offices and the Northern

$47 \quad$ See Table 12 in the Appendix. 
Cape office are significantly more efficient relative to the Western Cape at both the conciliation and arbitration processes. Our results have also shown that disputes of mutual interest are the most efficiently resolved relative to unfair dismissal disputes at both conciliation and arbitration proceedings due to the sense of urgency in these matters. It is possible that with such disputes there is the inability or perhaps the lack thereof, to resort to an effective strike action that persuades parties to speedily resolve their dispute at conciliation. Unfair dismissal disputes account for the largest share of referrals at the CCMA. However, with unfair dismissal disputes, parties will only settle at conciliation after assessing their risk of losing at arbitration, and costs associated with arbitration. Our results have shown that professional representation at the arbitration hearings leads to less efficient arbitration proceedings relative to not having any representation at all, holding all the other factors fixed. We suggest that because each party may believe that having professional representation moves the arbitrator's perception of a just settlement close to that party's position and that the gain of professional representation (in terms of a greater award) exceeds the costs, both the employers and workers may have private incentives to have professional representation. Finally, the econometric work illustrates that the con-arb innovation is in fact associated with an increase in efficiency both in terms of conciliation and arbitration turnaround times. 


\section{Conclusions and Policy Recommendations}

The above has provided a deliberately clinical, and non-legalistic interpretation of the efficiency and effectiveness of the CCMA since its inception. The study is groundbreaking in that it employs advanced statistical techniques and models to analyse labour dispute referral trends and investigate variations in efficiency across regions, sectors and types of disputes.

A number of key conclusions can be drawn from the statistical analysis and econometric models. Firstly, while the growth in the number of referrals received by the CCMA was initially high, it appears to have stabilised in recent years. It is also evident that no significant structural changes in dispute patterns (types of disputes) or the share of referrals across regions and economic sectors have occurred since the inception of the CCMA. While we observed slight compositional shifts for agricultural and domestic workers shortly after the 2002 sectoral determinations were enacted, none of these were lasting in nature. The stability in referral rates and patterns should, in theory, aid regional CCMA offices in their planning processes. Variations in measured efficiency across regions and financial years cannot be viewed as resulting from unexpected structural or compositional shifts in dispute referrals, nor high or unexpected growth in referrals. Instead, we believe, regional variations in turnaround times or other efficiency measures are a function primarily of regional differences in organisational effectiveness and management.

Secondly, the analysis paid some attention to dispute referrals originating from domestic and agricultural workers. A perception that has developed is that referral rates from these types of workers are overrepresented and pose an undue burden on the CCMA's resources. Furthermore, given the informal nature of occupational contracts of domestic and agricultural workers, some have called for the introduction of separate dispute resolution processes within the CCMA for these workers. The analysis here has shown that, given labour market statistics and jurisdictional information, referral rates from domestic and agricultural workers are not abnormally large or dominant. Furthermore, the statistical analysis has provided no significant evidence that disputes involving these types of workers are necessarily less efficiently resolved (as measured in terms of turnaround times for disputes) than other dispute types. As discussed in the document, the CCMA has introduced measures that have seemingly been successful in dealing with matters that have caused turnaround times for disputes from these types of workers to be high in the past. 
The third main finding relates to the introduction of the con-arb process. The process of con-arb, through 'replacing' conciliation and arbitration cases heard in separate hearings and on separate days, made allowance for conciliation and arbitration cases to be run back-to-back in a single hearing. The actual conciliation and arbitration processes that form part of a con-arb process are no different from 'pure' conciliation and arbitration processes. The perception may arise that more people would now opt to continue on to arbitration after the conciliation hearing of a con-arb, simply because there is no real time delay, which reduces the cost of arbitration. Since arbitrations are generally more resource intensive this would have been an undesirable outcome. However, the results show that the share of cases settled at conciliation (either during a 'pure' conciliation or during the conciliation phase of a con-arb) has remained stable over the years, hence there is no evidence that the introduction of con-arb has caused a shift towards arbitration. Early indications are that the settlement rate for con-arb is in fact higher than for pure conciliation. Further, as the econometric evidence indicates, the introduction of con-arb is associated with a drop in turnaround times for both conciliation and arbitration cases.

A fourth conclusion pertains to atypical forms of employment and dispute resolution. A key aspect of the post-1994 labour market environment in terms of employment trends has been, as noted, the rise in the incidence of atypical employment - marked by work arrangements such as outsourcing, labour brokering, part-time contracts and so on. While the CCMA data, in its present format, has limited information on the nature of work contracts, the institution should perhaps take a bigger responsibility for monitoring the impact of atypical forms of employment on the incidence and nature of labour market disputes. It is also important to formalise processes that would allow such disputes to be handled efficiently and effectively within the legislative context.

Fifth, although it remained at the margins of this particular analysis, a worrying trend that has emerged at the CCMA in recent years is a seemingly increased tendency for part-time commissioners to postpone cases and utilise other mechanisms for delaying cases. While concrete evidence is lacking, there is a concern that this is being done for financial reasons given that they work on a contract/hourly basis. This is of course a sensitive issue and one that we do not deal with in depth. It does, however, for the purposes of this study, point to the importance of possibly including more detail on the commissioners themselves in order to incorporate this evidence into any future econometric modelling. 
Sixth, the econometric evidence is both strong and consistent with regard to disputes of mutual interest at both the conciliation and arbitration proceedings. Disputes of mutual interest are most efficiently resolved relative to unfair dismissal disputes when controlling for other factors due to the sense of urgency in the matters (industrial action). However, with rights disputes (such as unfair dismissal disputes) parties will only settle at conciliation after assessing their risk of losing at arbitration, and costs associated with arbitration. Furthermore, arbitration cases with professional representation for both workers and employers have higher turnaround times, relative to no representation at all when controlling for all the other factors. This is a particularly powerful result. On the one hand it could indicate the complexity of the issues and how thorough the CCMA deals with issues taking into account the social justice issues related to a legal person's right to be heard. On the other hand, it is indicative of the importance of examining the role and functions of professional representation within the CCMA.

Finally, and related to the first conclusion, the econometric evidence suggests that KwaZuluNatal and the Northern Cape offices, when controlling for a range of factors, are the most efficient provinces. In addition the descriptive evidence illustrating that the Eastern Cape is the least efficient province is also supported by the empirical evidence. While variations in efficiency can not be explained by case load pressures and resource constraints alone, perhaps the CCMA is better placed to investigate issues around management and other unique circumstances that exist in each province to explain differences in efficiency across the provinces.

The study's attempts at broadening our understanding of dispute resolution in South Africa are, understandably, somewhat restricted by the availability of reliable and relevant data. The study only uses CCMA case data. About 72 per cent of the South African workforce falls under jurisdiction of the CCMA, while the rest, for all practical purposes, fall under any one of the various Bargaining Councils. Cases referred to Bargaining Councils are excluded in the analysis here given data compatibility and availability problems. While we believe that our findings present an accurate reflection of dispute resolution in South Africa in general, this hypothesis can only be tested once a comprehensive study is conducted using Bargaining Council data as well. Although many non-jurisdictional cases are also referred to the CCMA and recorded as such, the majority of these cases are dismissed during an initial screening stage, and no further data is captured for these cases. For this reason these non-jurisdictional cases are also largely excluded from the analysis here. A further limitation mentioned is the fact that we only have data on those cases that are not resolved at the workplace. Hence the 
sample of cases that are observable already suffer from so-called selection bias, which cannot be corrected in the econometric models used.

In summary, this paper has attempted, through the use of official CCMA data, to provide both a descriptive and econometric analysis of the institutionalised dispute resolution system. As noted, an analysis based solely on CCMA data may draw criticism. In addition the lack of sufficient variable coverage, and possibly the difficulty in converting some of the qualitative case evidence into quantitative information may have militated against a more exhaustive analysis. It is hoped, however, that such a study provides for a point of departure for a more informed debate on the role of dispute resolution in improving the economy's labour regulatory environment. 


\section{References}

Benjamin, P. 2006. The Impact of the Decisions of the Labour Courts on the Operation of the CCMA. Development Policy Research Unit, Draft Paper, November 2006.

Benjamin, P. and Gruen, C. 2006. The Regulatory Efficiency of the CCMA: A Statistical Analysis of the CCMA's Database, DPRU Working Paper No 06/110.

Bhoola, U. 2002. National Labour Law Profile: South Africa. International Labour Organisation. Accessed at: http://www.ilo.org/public/english/dialogue/ifpdial/info/ national/sa.htm.

Bhorat, H. and Hinks, T. 2005. Changing Patterns of Employment and Employer-Employee Relations in Post-Apartheid South Africa, Mimeo.

Bosch, D., Molahlehi, E. and Everett, W. 2004. The Conciliation and Arbitration Handbook: A Comprehensive Guide to Labour Dispute Resolution Procedures. LexisNexis Butterworths: Durban.

Brand, J. 2000. CCMA: Achievements and Challenges - Lessons from the First Three Years, Industrial Law Journal, 21(1-3).

Brand, J. 2002. Bargaining Council Dispute Resolution under the LRA as Amended, Industrial Law Journal, 23 (10-12) 1737.

CCMA. 2007. CCMA Commentary and Input on "Understanding the Efficiency and Effectiveness and Efficiency of the Dispute Resolution System in South Africa". Comments on an earlier draft of this paper, submitted by the CCMA, June 2007.

Cheadle, H. 2006. Regulated Flexibility and Small Business: Revisiting the LRA and the BEA. Development Policy Research Unit Working Paper 06/109. 
Collier, D. 2003. The right to legal representation under the LRA, Industrial Law Journal, 24: 757 .

Du Toit, D., Woolfrey, D., Godfrey, S., Bosch, D., Christie, S., Giles, G. and Rossow, J. 2003. Labour Relations Law - A Comprehensive Guide, 4th Edition. LexisNexis Butterworths Durban.

Greene, W. 2003. Econometric Analysis, 5th. Upper Saddle River, NJ: Prentice: 5th Edition.

Heckman, J. (1979). "Sample Selection Bias as a Specification Error," Econometrica, 47.

ILO. 2001. The Labour Legislation Guidelines, Substantive Provisions of Labour Legislation: Settlement of Collective Labour Disputes. International Labour Organisation. Accessed at: http://www.ilo.org/public/english/dialogue/ifpdial/llg/index.htm (20 November 2006).

Lundall, P., Majeke, A. and Poswell, L. 2004. Atypical Employment and Labour Market Flexibility: Experiences of Manufacturing Firms in the Greater Cape Town Metropolitan Area. Development Policy Research Unit, Cape Town. July 2004.

Molahlehi, E.M. 2005. CCMA Developments: Review of Operations During 2004/2005. Commission for Conciliation, Mediation and Arbitration. Accessed at: http://www. lexisnexis.co.za/ServicesProducts/presentations/18th/EdwinMolahlehi.doc (21 November 2006).

Ngcukaitobi, T. 2004. Sidestepping the Commission for Conciliation, Mediation and Arbitration: Unfair Dismissal Disputes in the High Court, Industrial Law Journal, 25.

Roskam, A. 2007. An Exploratory Look into Labour Market Regulation. DPRU Working Paper 07/116 
Van der Westhuizen, C. and Goga, S. 2009. Analysing Wage Formation in the South African Labour Market: The Role of Bargaining Councils. DPRU Working Paper 09/135

Van Niekerk, A. 2005. In search of Justification, Industrial Law Journal, 25.

Van Niekerk, A. 2007. Regulating Flexibility and Small Business: Revisiting the LRA and BCEA - A Response to Halton Cheadle's Draft Concept Paper. DPRU Working Paper 07/119

Venter, T. 2007. Personal Communication, 15 March 2007.

Young, L.K. 2004. CCMA arbitration awards: An update, Contemporary Labour Law, 14:2. 


\section{Technical Appendix}

\subsection{Additional Graphs and Tables}

Figure 7: Comparison of Growth in Total Employment and CCMA Referrals

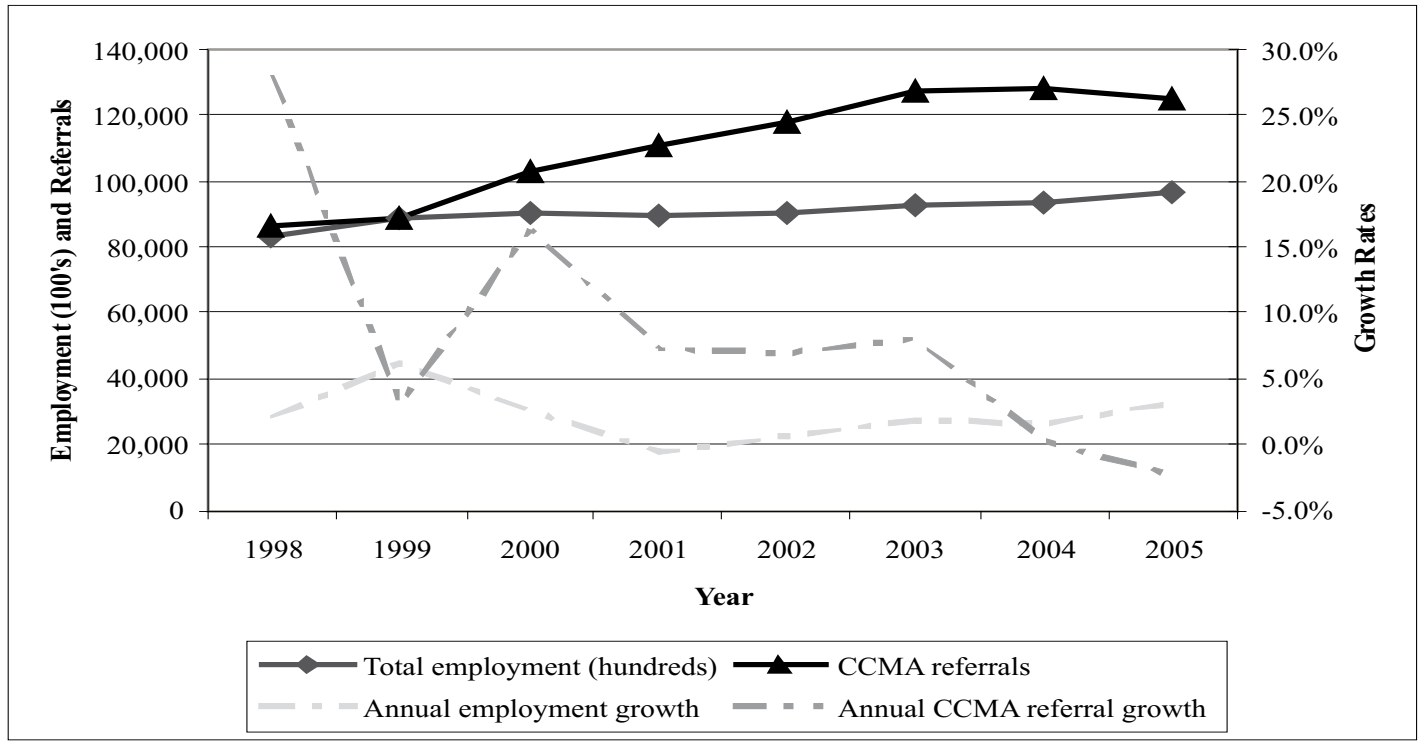

Source: CCMAAnnual Reports and OHS/LFS Employment Figures (Statistics South Africa). OHS/LFS series obtained from Marlé van Niekerk, University of Stellenbosch. 
Table 10: List of Accredited Bargaining Councils

\begin{tabular}{|l|l|}
\hline Furniture Manufacturing Industry (KZN) & Contract Cleaning Industry \\
Restaurant Catering and Allied Trades & Metal and Engineering Industry \\
Canvas Goods Industry & Motor Industry \\
New Tyre Manufacturing Industry & Road Freight Industry \\
Grain Industry & Laundry Industry of South Africa \\
Entertainment Industry of South Africa & Furniture Manufacturing Industry \\
Hairdressing and Cosmetology Trade (PTA) & Electrical Industry Bargaining Council (National) \\
Sugar Manufacturing and Refining Industry & Fishing Industry \\
Building Industry (Bloemfontein) & Furniture Bedding and Upholstery \\
Tearoom Restaurant and & \\
Catering Trade (PTA) & Transnet \\
Hairdressing and Cosmetology & \\
Trade (National) & Amanzi Statutory Council \\
Building Industry (South-Eastern) & South African Local Government \\
Building Industry (East London) & General Public Service Sectoral Bargaining Council \\
Retail Meat Trade & \\
Building Industry (Cape of Good Hope) & Pablic Health and Welfare Sector Sectoral \\
Packaging Industry & \\
Clothing Industry & Pecting Bargaining Council \\
\hline
\end{tabular}

Source: CCMA Annual Report 2005/06 
Figure 8: Bargaining Council Coverage by Region, Economic Sector and Occupation (2005)
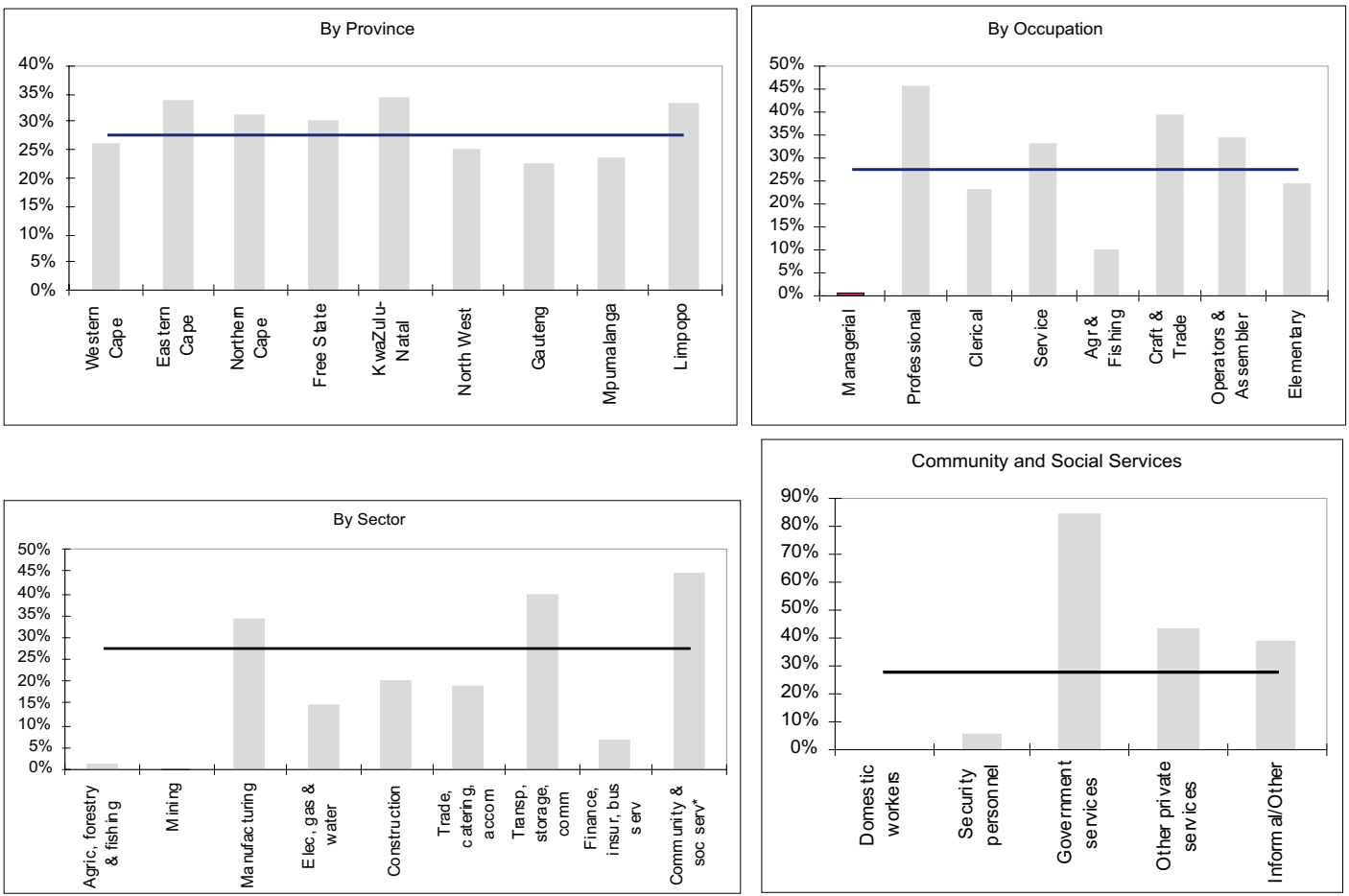

Source: LFS September 2005. Coverage estimates by Van der Westhuizen and Goga (2007).

Note: $\quad$ The balance between the Bargaining Council coverage and 100 per cent can be used as a proxy for the CCMA coverage rate. Note that in the bottom left-hand panel the community and social services coverage rate is shown including $\left(^{*}\right)$ and excluding domestic workers. 


\begin{tabular}{|c|c|c|c|c|c|}
\hline \multirow[b]{3}{*}{ 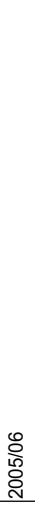 } & 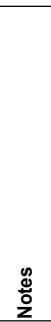 & 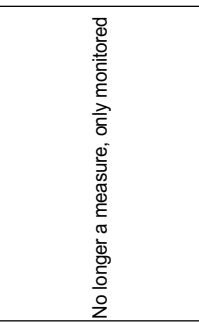 & 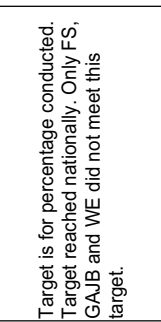 & 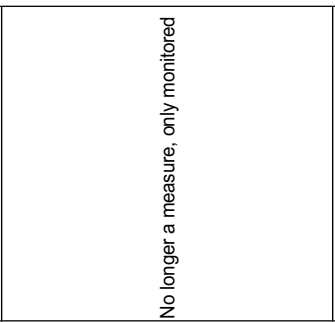 & 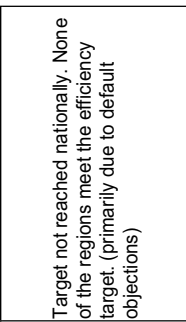 \\
\hline & 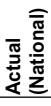 & $\bar{\Sigma}$ & 웅 & $\frac{\varsigma}{z}$ & ஓे \\
\hline & 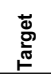 & $\frac{\pi}{z}$ & @을 & $\frac{s}{z}$ & ڤे \\
\hline \multirow[b]{3}{*}{$\begin{array}{l}\text { o. } \\
\text { के } \\
\text { क्रे }\end{array}$} & $\begin{array}{l}\frac{\mathscr{g}}{2} \\
z\end{array}$ & 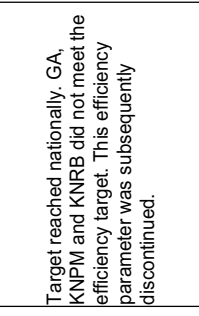 & 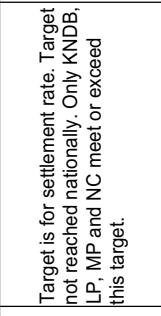 & 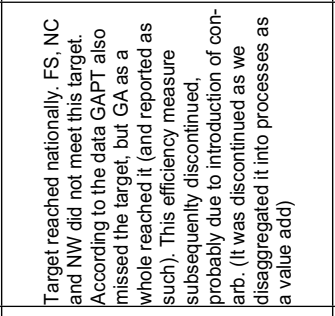 & 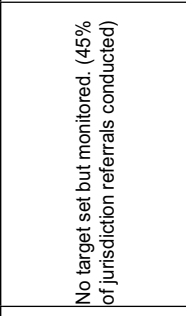 \\
\hline & 产 & 犬ें & ळे & ळें & $\frac{\pi}{z}$ \\
\hline & 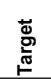 & 户े & ஸे & ठे & $\frac{s}{z}$ \\
\hline \multirow[b]{3}{*}{ 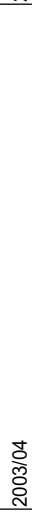 } & 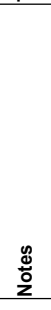 & 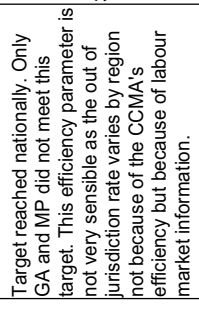 & 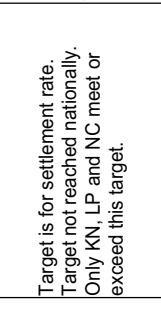 & 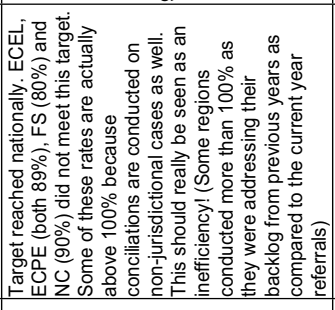 & 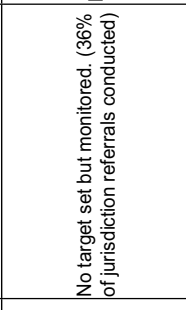 \\
\hline & 产 & ڤ్ & $\stackrel{\circ}{\circ}$ & ஃ & $\underline{\Sigma}$ \\
\hline & 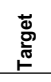 & 户े & i̊ & ळે & $\frac{\pi}{z}$ \\
\hline & 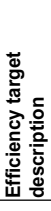 & 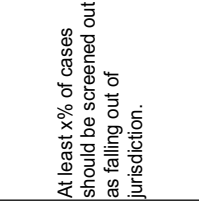 & 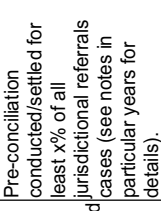 & 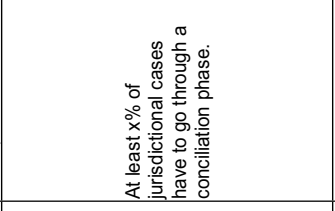 & 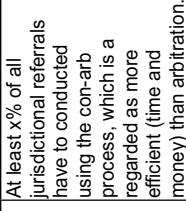 \\
\hline & 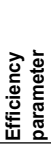 & 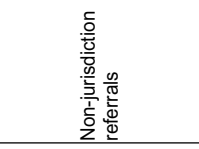 & 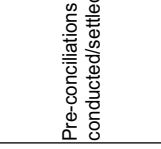 & 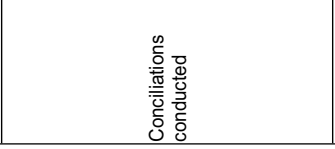 & 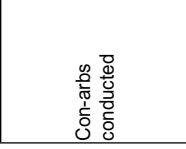 \\
\hline
\end{tabular}




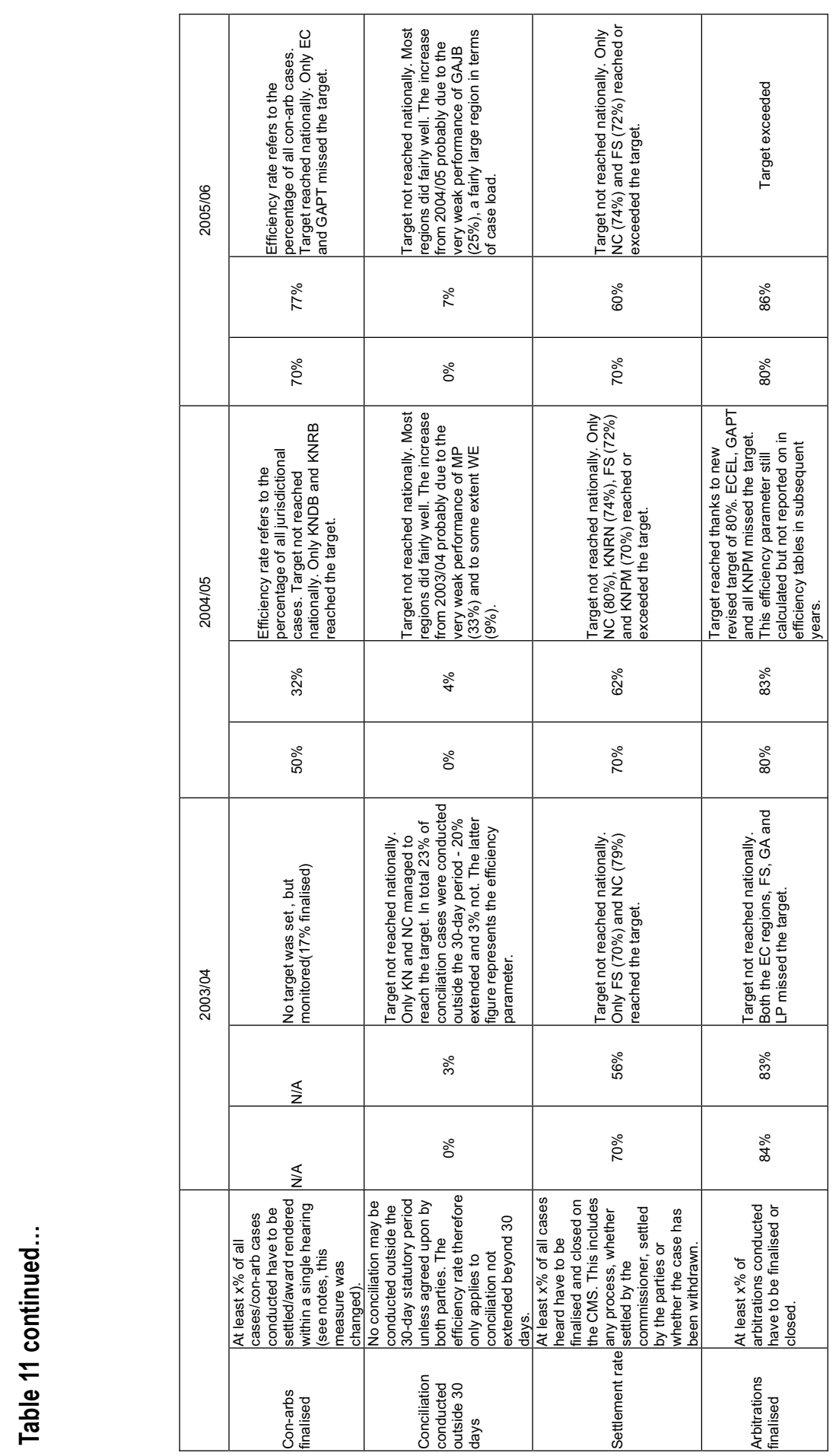




\begin{tabular}{|c|c|c|c|c|}
\hline & \multirow[t]{3}{*}{$\begin{array}{l}\stackrel{8}{\circ} \\
\text { 윰 }\end{array}$} & 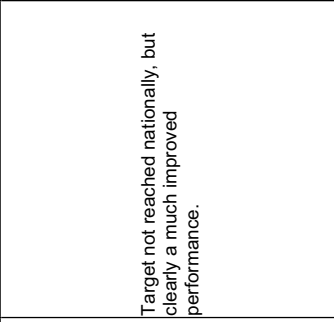 & 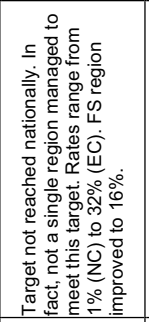 & $\widehat{s}$ \\
\hline & & 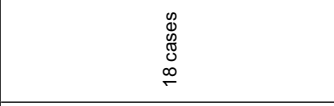 & ஃे & $\frac{s}{z}$ \\
\hline & & 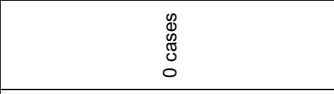 & 今े & $\frac{s}{z}$ \\
\hline & 㝘 & 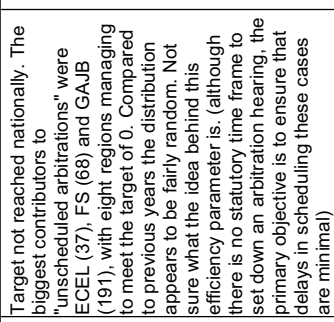 & 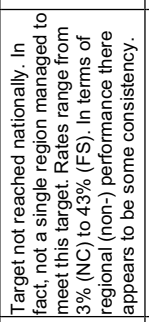 & $\frac{\bar{s}}{z}$ \\
\hline & & 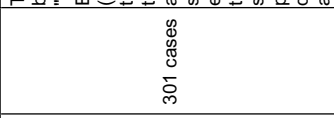 & $\stackrel{\circ}{\stackrel{\circ}{\infty}}$ & $\frac{\bar{z}}{z}$ \\
\hline & & $\begin{array}{l}\mathscr{\mathscr { D }} \\
\mathbb{0} \\
\mathbb{8} \\
0 \\
\end{array}$ & ○े & $\frac{\pi}{z}$ \\
\hline & 蒿 & 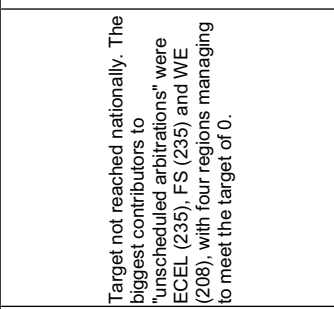 & 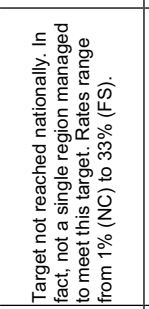 & 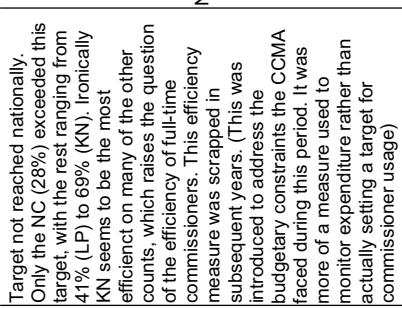 \\
\hline & & 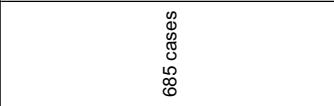 & ஃ̊ & ๙ิे \\
\hline & & $\begin{array}{l}0 \\
\mathscr{8} \\
\mathbb{8} \\
\mathbb{8} \\
0 \\
0\end{array}$ & $\stackrel{\circ}{\circ}$ & ஓे \\
\hline 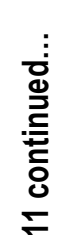 & & 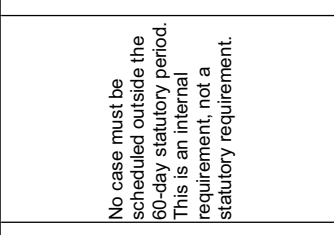 & 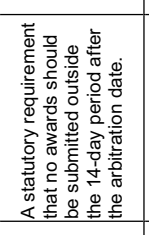 & 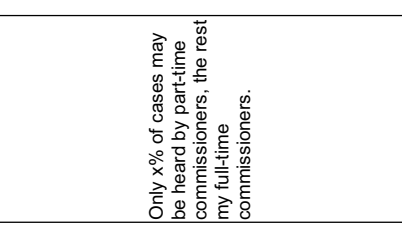 \\
\hline$\frac{5}{\frac{0}{0}}$ & & 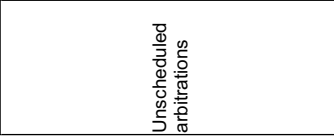 & 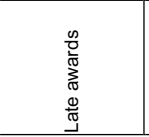 & 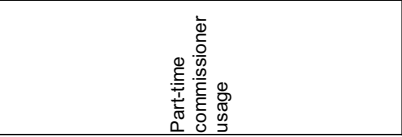 \\
\hline
\end{tabular}




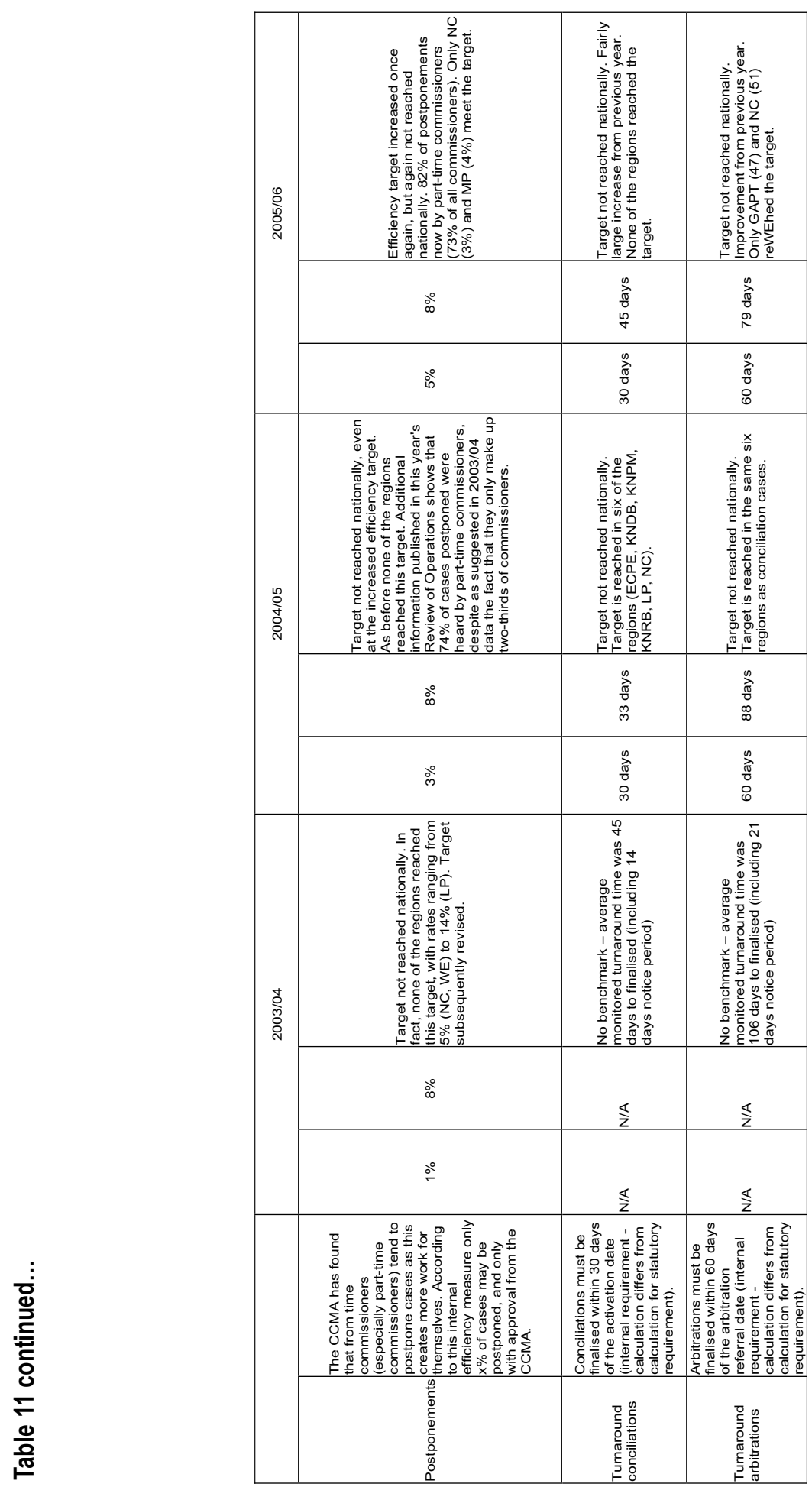




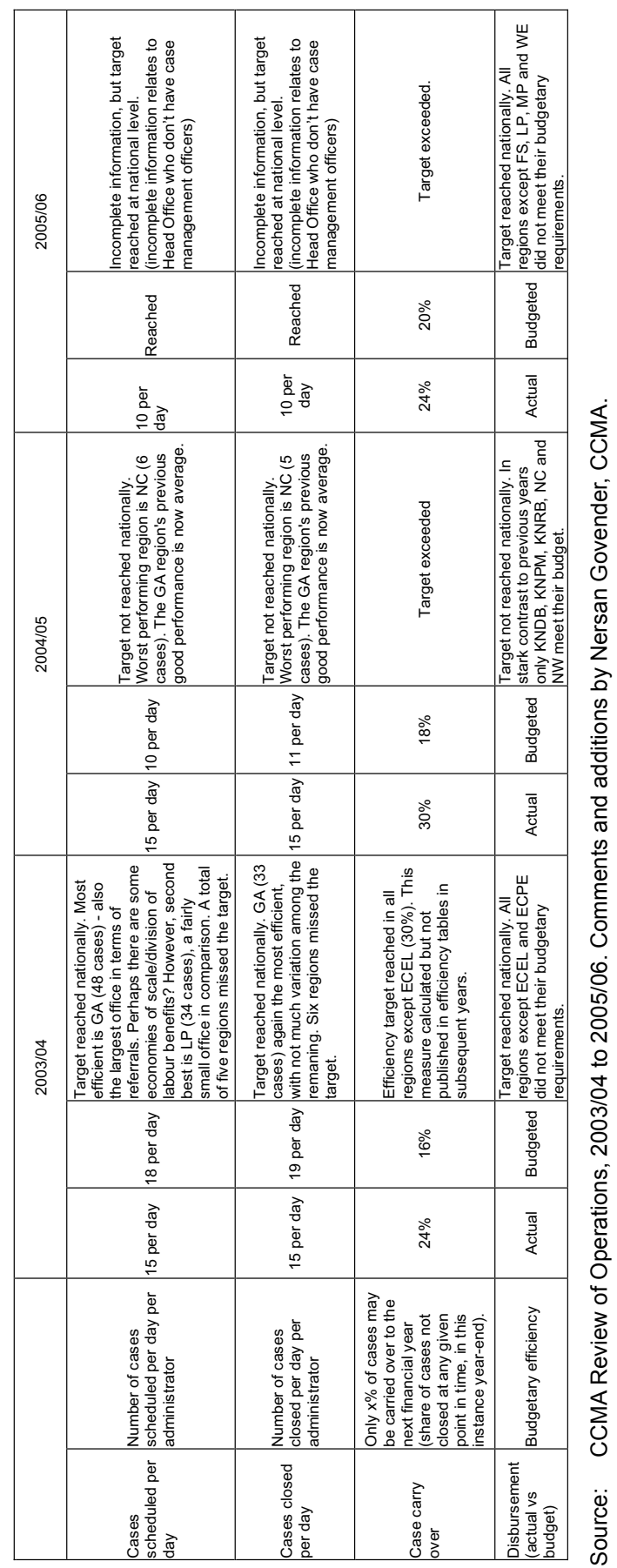


Table 12: Determinant of Turnaround time of the CCMA Arbitration Processes: 2001-2006

\begin{tabular}{|c|c|c|c|c|c|}
\hline $\begin{array}{l}\text { Log (Turnaround Time) } \\
\text { Selection Equation }\end{array}$ & Coef. & & $\begin{array}{l}\text { Arbitration } \\
\text { Outcome Equation }\end{array}$ & Coef. & \\
\hline East Cape EL & 0.1241 & $* * *$ & East Cape EL & 0.3066 & *** \\
\hline East Cape PE & 0.2917 & $* * *$ & East Cape PE & -0.0150 & * \\
\hline Free State & 0.1787 & $* * *$ & Free State & 0.3650 & *** \\
\hline Gauteng PT & 0.7543 & $* * *$ & Gauteng PT & -0.1406 & *** \\
\hline Gauteng JB & 0.4119 & $* * *$ & Gauteng JB & 0.1732 & *** \\
\hline Limpopo & 0.1392 & $* * *$ & Limpopo & -0.0857 & $* * *$ \\
\hline Mpumalanga & 0.5143 & $* * *$ & Mpumalanga & -0.1677 & $* * *$ \\
\hline Northern Cape & -0.0447 & $* *$ & Northern Cape & -0.3920 & *** \\
\hline North West & 0.3458 & $* * *$ & North West & -0.2382 & *** \\
\hline KwaZulu-Natal DB & 0.4268 & $* * *$ & KwaZulu-Natal DB & -0.3835 & $* * *$ \\
\hline KwaZulu-Natal PM & 0.1264 & $* * *$ & KwaZulu-Natal PM & -0.3511 & $* * *$ \\
\hline KwaZulu-Natal RB & 0.2517 & $* * *$ & KwaZulu-Natal RB & -0.3449 & $* * *$ \\
\hline Unfair Labour Practice & -0.2200 & $* * *$ & Unfair Labour Practice & -0.0125 & * \\
\hline Mutual Interest & -2.5120 & $* * *$ & Mutual Interest & -0.2911 & $* * *$ \\
\hline Severance Pay & -0.3236 & $* * *$ & Severance Pay & 0.0101 & \\
\hline Other Type Dispute & -1.0821 & $* * *$ & Other Type Dispute & 0.0566 & $* * *$ \\
\hline Agriculture & -0.0993 & $* * *$ & Agriculture & 0.1218 & *** \\
\hline Mining & 0.0991 & $* * *$ & Mining & 0.1026 & *** \\
\hline Manufacturing & 0.1063 & $* * *$ & Manufacturing & 0.0391 & *** \\
\hline Construction & -0.0495 & $* * *$ & Construction & 0.0204 & $* * *$ \\
\hline Trade & 0.0369 & *** & Trade & 0.0533 & *** \\
\hline Transport & 0.1385 & $* * *$ & Transport & 0.0474 & *** \\
\hline Finance & -0.0055 & & Finance & 0.0676 & $* * *$ \\
\hline Social Services & 0.0065 & & Social Services & 0.0275 & *** \\
\hline Electricity, Gas \& Water & 0.3163 & $* * *$ & Electricity, Gas \& Water & -0.0726 & $* * *$ \\
\hline Security (Private) & 0.1564 & $* * *$ & Security (Private) & 0.0236 & $* * *$ \\
\hline Public Service & 0.4360 & $* * *$ & Public Service & 0.0607 & *** \\
\hline \multirow[t]{5}{*}{ _cons } & \multirow[t]{5}{*}{-0.1353} & \multirow[t]{5}{*}{ *** } & Number of Hearings & 0.3265 & *** \\
\hline & & & w_union & 0.0125 & * \\
\hline & & & w_legal & 0.0471 & *** \\
\hline & & & w_other & -0.0539 & $* * *$ \\
\hline & & & e_empor & 0.0042 & \\
\hline lathrho & 0.0086 & * & e_legal & -0.0049 & \\
\hline \multirow[t]{2}{*}{ /Insigma } & \multirow[t]{2}{*}{-0.7798} & \multirow[t]{5}{*}{$* * *$} & e_other & 0.0005 & \\
\hline & & & Award Employee & -0.0325 & *** \\
\hline rho & \multirow{3}{*}{$\begin{array}{l}0.0086 \\
0.4585 \\
0.0039\end{array}$} & & Arb & -1.3660 & $* * *$ \\
\hline sigma & & & Settled & 0.0122 & *** \\
\hline lambda & & & Default Arb_awrd & 0.0612 & *** \\
\hline \multirow[t]{5}{*}{+2} & & & Dismissed & 0.0223 & *** \\
\hline & & & 2001_02 & 0.1297 & $* * *$ \\
\hline & & & 2002_03 & 0.2124 & $* * *$ \\
\hline & & & 2003_04 & 0.0536 & $* * *$ \\
\hline & & & 2004_05 & 0.1088 & *** \\
\hline Number of obs & \multicolumn{2}{|l|}{269121} & & & \\
\hline
\end{tabular}

Source: $\quad$ *** Significant at the one per cent level, ${ }^{* *}$ Significant at the five per cent level and * Significant at the ten per cent level 


\subsection{A Note on CCMA Jurisdiction}

One of the issues identified as impacting on service delivery and efficiency of the CCMA is the large number of cases that are being referred to this institution when they should have been referred to the Labour Court, the Department of Labour or one of the Bargaining Councils. All cases referred to the CCMA, including those that are out of jurisdiction, have to be recorded and captured in the CMS database, which is administratively burdensome. It is nevertheless important to screen the out of jurisdiction cases, if possible already at the referral stage, as it reduces the administrative burden on the CCMA in the conciliation or arbitration phases.

It can be argued that the out of jurisdiction rate, that is, the percentage of total referrals that are out of jurisdiction, is largely beyond control of the CCMA. Anyone can refer a case to the CCMA and this case has to be processed by them, whether it falls within their jurisdiction or not. For this reason it appears strange that a minimum out of jurisdiction rate of 34 per cent was initially used as an efficiency target of the CCMA until 2004/05 (see Table 11). This may have created perverse incentives for CCMA offices to be overly technical in deciding whether cases are out of jurisdiction simply in order to meet the out of jurisdiction target.

Instead, as we argue here, a high out of jurisdiction rate actually has negative consequences for efficiency, and hence the CCMA should strive to reduce the number of out of jurisdiction referrals. The out of jurisdiction rate is really a reflection of the degree to which the labour force lacks of information about jurisdictional matters. Part of the task of the CCMA, and of course the Bargaining Councils and the Department of Labour, is to inform the public of their labour rights, but also to educate them about how they should go about dealing with any disputes that may arise. Therefore, if the CCMA is successful in educating the labour market in this regards, the out of jurisdiction rate is likely to drop, resulting in lower administrative costs for the institution.

Table 13 shows the out of jurisdiction rates by regional office for the years 2001/02, 2003/04 and 2005/06. In the early years the out of jurisdiction rate varied substantially between regions, possibly since some regional offices at that stage had only just started operating and had few cases. The national average in that year was 32.5 per cent. It subsequently rose to 35.3 per cent, thus reaching the efficiency target of 34 per cent in that year. By 2005/06 the efficiency 
target had been removed, and the national average had also declined back to 32.0 per cent. Variation between regions is also much lower, which suggest that an out of jurisdiction rate of about one-third is probably a fair indication of the 'natural' out of jurisdiction rate of CCMA referrals. 


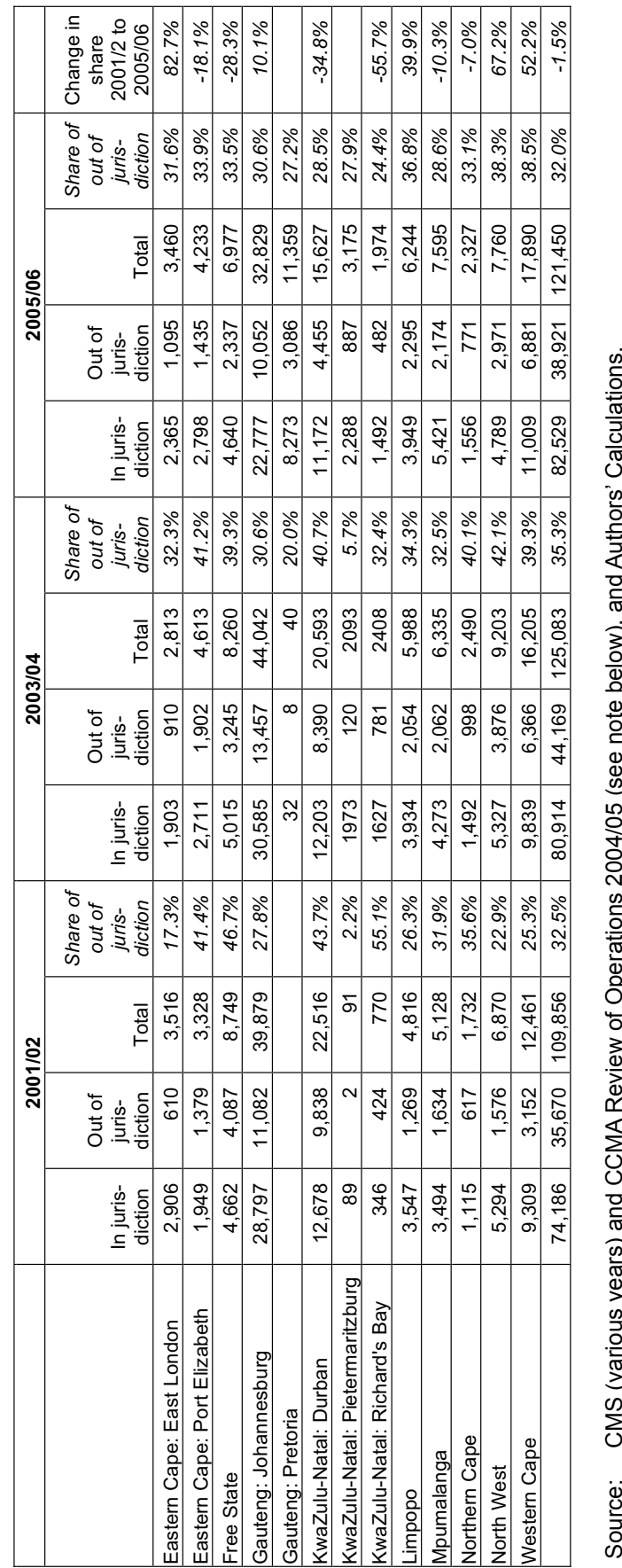


Figure 9 shows the percentage of referrals by dispute type (see Table 2) that are out of jurisdiction. Generally the trend appears to be that of a declining out of jurisdiction rate for the main dispute types. This is especially true for unfair labour practice disputes, which accounted for just over seven per cent of the main disputes in 2005/06, and declined from over 40 per cent in 2001/02 to below 30 per cent in 2005/06. The overall out of jurisdiction rate for the main dispute types declined marginally from 21 per cent to 20 per cent during the period. This corresponds roughly with the pattern observed for unfair dismissal disputes, which is not surprising given that unfair dismissals make up almost 90 per cent of all the main dispute types.

Figure 9: Share of Cases Out of Jurisdiction, by Types of Disputes (Selected Years)

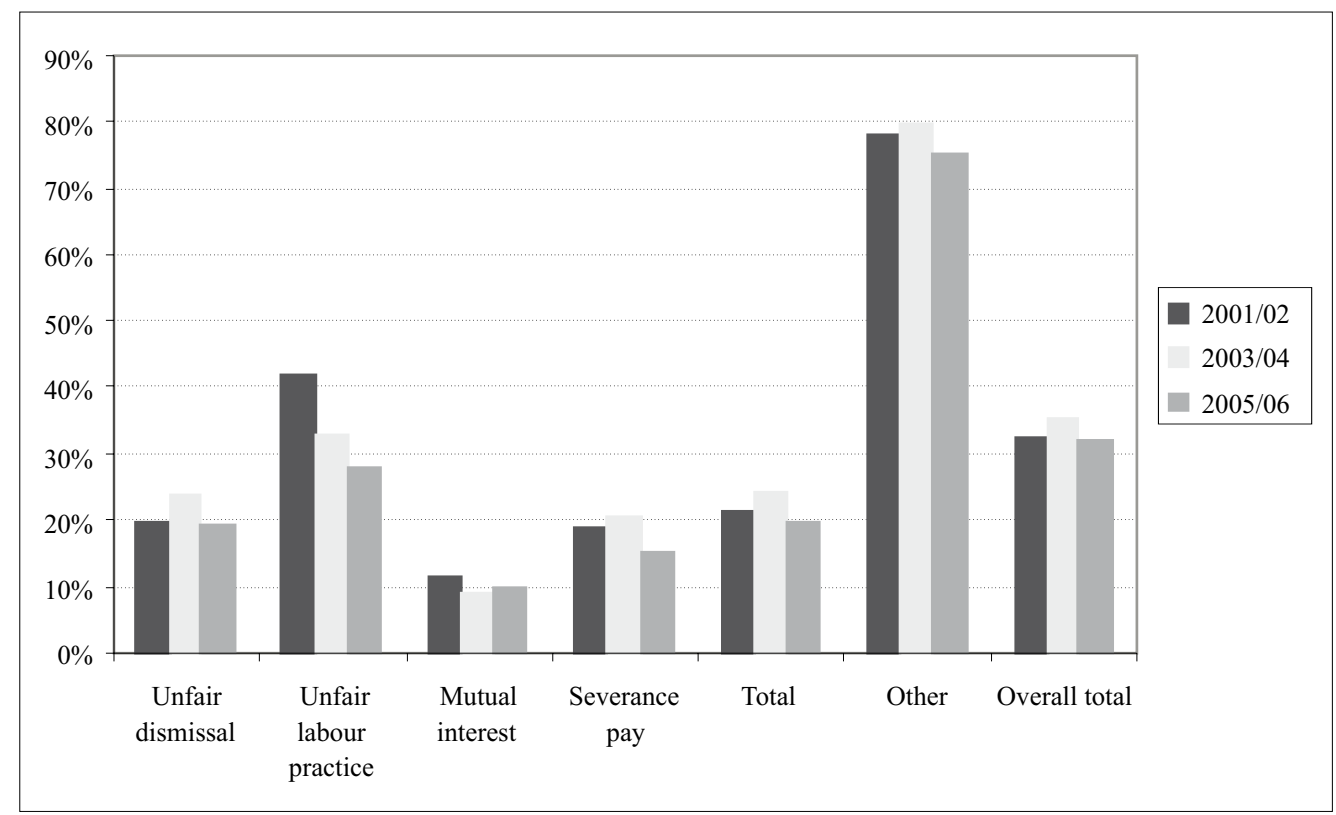

Source: CMS (various years) and Authors' Calculations.

The overall or total out of jurisdiction rate is somewhat higher than the total for the main disputes, but this is largely due to the very high out of jurisdiction rate in the 'other' dispute type category, which accounted for over 20 per cent of all disputes in 2005/06 (see Table 2). However, as shown later in Figure 13, about half of the 'other' disputes are classified as out of jurisdiction (the Department of Labour, Bargaining Councils or other organisations have jurisdiction). This data problem or oddity needs to be addressed. The problem is, suppose, for example, that someone brings an unfair dismissal claim to the CCMA when it should have been brought to a Bargaining Council. The CMS administrators will now either capture the case type as 'Bargaining Council jurisdiction' or as 'unfair dismissal'. A separate variable in the CMS database (the one used to construct Figure 9) now records the case as being out of 
jurisdiction. This means that the real dispute type for such cases cannot be determined from the CMS database, thus also potentially skewing the estimates obtained for the main dispute types. This is just one of the instances where a 'catch-all' category in one of the CMS variables makes analyses difficult and often inaccurate (see Section 7.3 for more on data issues).

Figure 10 shows the out of jurisdiction rate by economic sector (compare Figure 4 ). For all sectors the out of jurisdiction rate initially increases between 2001/02 and 2003/04, but then decreases in 2005/06. This pattern seems to reflect the overall change in the out of jurisdiction rate as reflected in Figure 9. Although out of jurisdiction rates vary between sectors - probably largely due to differences in CCMA/Bargaining Council coverage rates ${ }^{48}$ - there is no suggestion that changes in the overall out of jurisdiction rate can be attributed to structural changes in out of jurisdiction rates across sectors.

Figure 10: Share of Cases Out of Jurisdiction, by Sector (Selected Years)

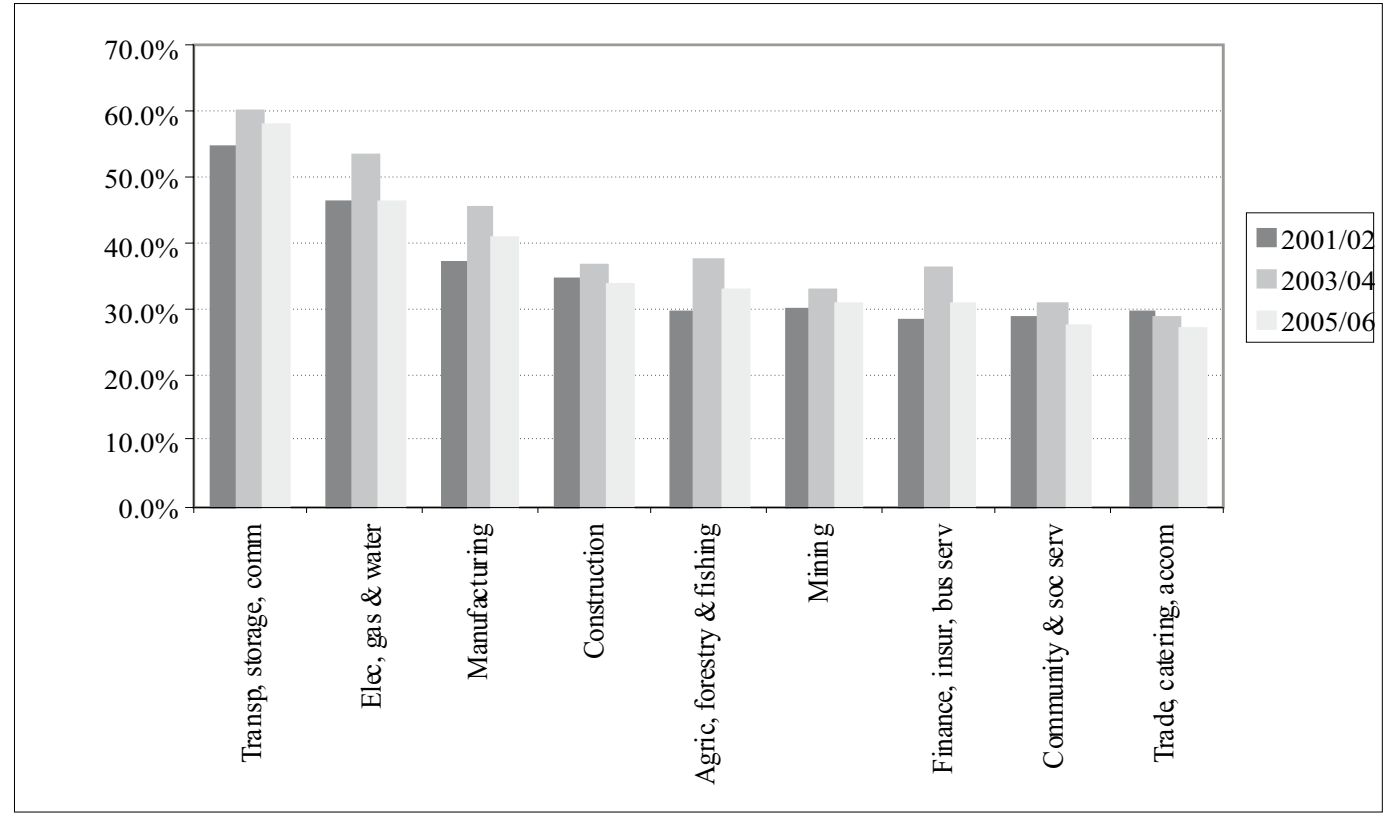

Source: CMS (various years) and authors' calculations.

Note: Industries sorted from highest to lowest out of jurisdiction rate in 2005/06.

48 A comparison of Figure 10 and Figure 8 reveals that a high out of jurisdiction rate for a sector is typically matched by a high CCMA coverage rate for that sector. 


\subsection{Proposals for Data Improvements}

The CMS was designed as an internal tool to monitor the effectiveness and efficiency of the CCMA. As such it is basically an administrative database and hence not entirely useful to analyse dispute resolution issues in much detail. This is understandable, as much of the information that is required to do better labour market research is not the kind of information needed by the CCMA in order to improve performance. However, a strong case can be made for the fact that a better understanding, broadly speaking, of how specific labour market issues impact on the efficiency and effectiveness of the CCMA will also assist this institution in improving their administrative processes.

\subsubsection{Summary of Benjamin and Gruen's Data Proposals}

Benjamin and Gruen (2006) discuss a range of variables that they feel should be included in the CMS data that would enable better analysis of labour market regulatory issues in the future. Some of these proposals include the following:

- Length of service of employees: there is a perception that a large proportion of the unfair dismissal cases concern employees with a short length of service.

- $\quad$ Nature of employment contracts: an identifier of non-standard employment contracts is needed in order to investigate the issue of in limine cases in more depth.

- Earnings and skills levels of applicants: Many feel that the CCMA services, which are free of charge, should be reserved for lower-skilled or low-income workers who cannot afford private arbitration. Knowledge of the skills or income levels of applicants would enable the CCMA to determine whether high-skilled applicants really congest the system. It may also be that high-skilled workers typically have more complex employment contracts, which may impact on the conciliation ruling or calculation of arbitration awards.

- $\quad$ Size of employer: Often Small, Medium and Micro Enterprises (SMMEs) are mooted as the drivers of employment in developing countries. SMMEs are by nature sensitive to non-wage labour costs imposed by labour market regulation and legislation. Information in this regard may be useful for analysing the economic implications of dispute resolution processes for small firms.

- Representation at arbitration cases: At present representation is a non-mandatory field in the CMS database. This makes analyses of the impact of representation on 
outcomes, turnaround times and so on difficult. It also makes it difficult to assess claims that, for example, trade unions and employer organisations representing parties are simply consultancies operating under a guise. Better information about representation will also be useful to assess the cost implications of dispute resolution.

While scrutinising the CMS databases we also came across a number of oddities, data problems and inconsistencies in the way in which information is captured. While the CMS is clearly an enormously powerful and impressive database, we believe some further proposals below would ensure improved analyses of the data.

\subsubsection{Types of Unfair Dismissal or Unfair Labour Practice Cases}

Figure 11 shows how different types of unfair dismissal cases are recorded in the CMS database. This breakdown in the figure is based on 2005/06 data, and only includes jurisdictional cases. Clearly unfair dismissal cases are not properly described in the CMS database, with about 63 per cent of unfair dismissal disputes recorded as 'reason for dismissal unknown' or 'dismissal disputes not further classified'. This makes any analysis of the types of unfair dismissal cases difficult. A further 25 per cent of unfair dismissal cases related to misconduct, while the remainder are related to operational requirements and constructive dismissals (both four per cent), incapacity (two per cent) and termination of contracts without notice (one per cent). A variety of other categories exist in the CMS database, but these only amount to about one per cent of all unfair dismissal disputes. 
Figure 11: Types of Unfair Dismissal Cases, 2005/06

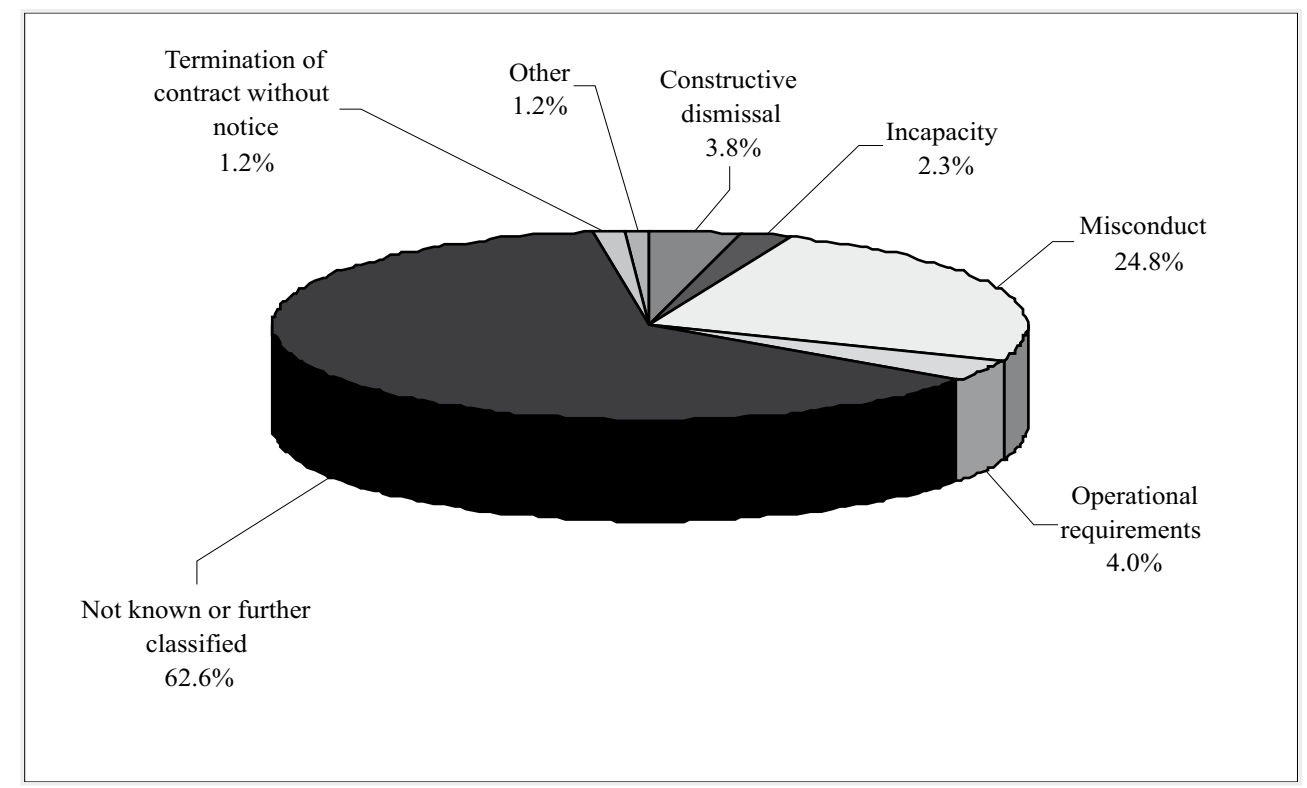

Source: CMS (2005/06) and Authors' Calculations.

Note: Only cases in jurisdiction included.

Similarly, unfair labour practice is also not very well coded in the CMS database. About 29 per cent of cases are recorded under the default 'unfair labour practice' category, thus making further analysis of the types of unfair labour practice cases pointless (see Figure 12). Other relatively large categories include unfair suspension or discipline (40 per cent) and unfair conduct relating to promotion, demotion or training (31 per cent). If the types of unfair dismissal or unfair labour practice disputes that are referred to the CCMA for conciliation or arbitration are important in determining, for example, variations in turnaround times, it is important that the CMS database is improved to properly capture this information. 
Figure 12: Types of Unfair Labour Practice Cases, 2005/06

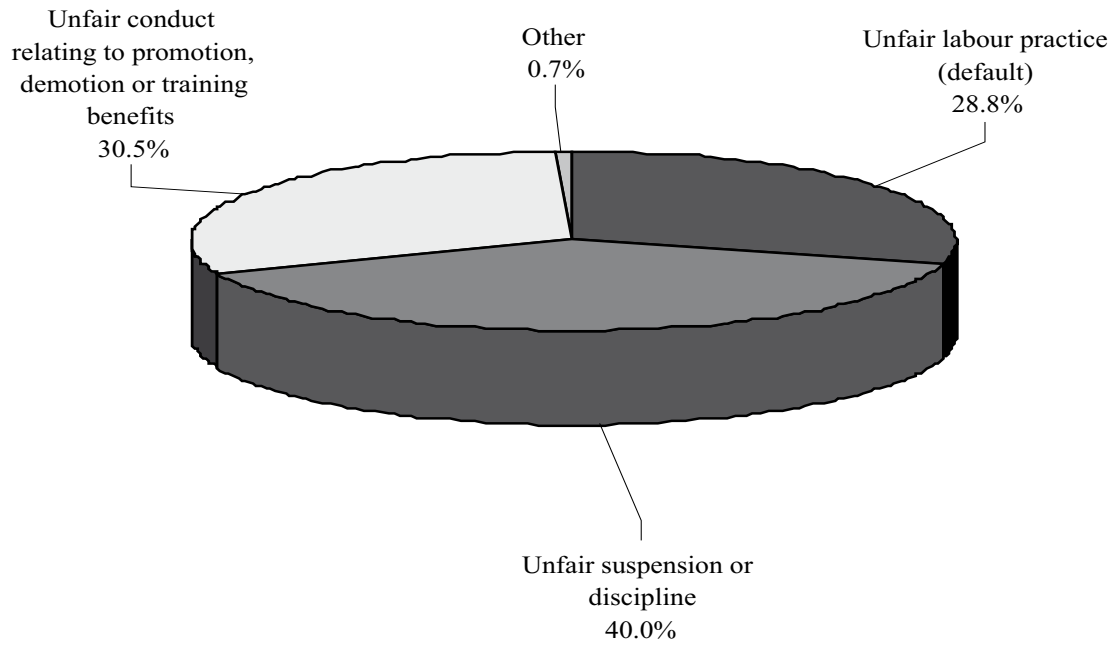

Source: CMS (2005/06) and Authors' Calculations.

Note: Only cases in jurisdiction included.

Dispute types are presumably selected from a drop-down list in the CMS. It should therefore not be difficult to clean the database and, firstly, reduce the number of possible options the data capturer can select, and secondly, remove any 'catch-all' or default categories to ensure more precise information is available to the analyst.

\subsection{2. 'Other' Dispute Types and Jurisdictional Information}

Since the 'other' category in Table 2 makes up such a significant share of all referrals, further analysis is justified. The CMS database records up to 72 types of disputes which, in the analysis here, was include under 'other' dispute types. As shown in Figure 13, in 2005/06, exactly 50 per cent of these 'other' disputes (that is, about 13600 cases) fell under jurisdiction of the Department of Labour (20 per cent), Bargaining Councils (17 per cent) or other organisations (13 per cent). About 12 per cent of 'other' is classified as 'incomplete referrals', of which about one half is eventually thrown out as in limine cases. The remaining 38 per cent are classified under 68 possible categories, many of which only contain a single observation per type of dispute. 


\section{Figure 13: Classification of 'Other' Disputes, 2005/06}

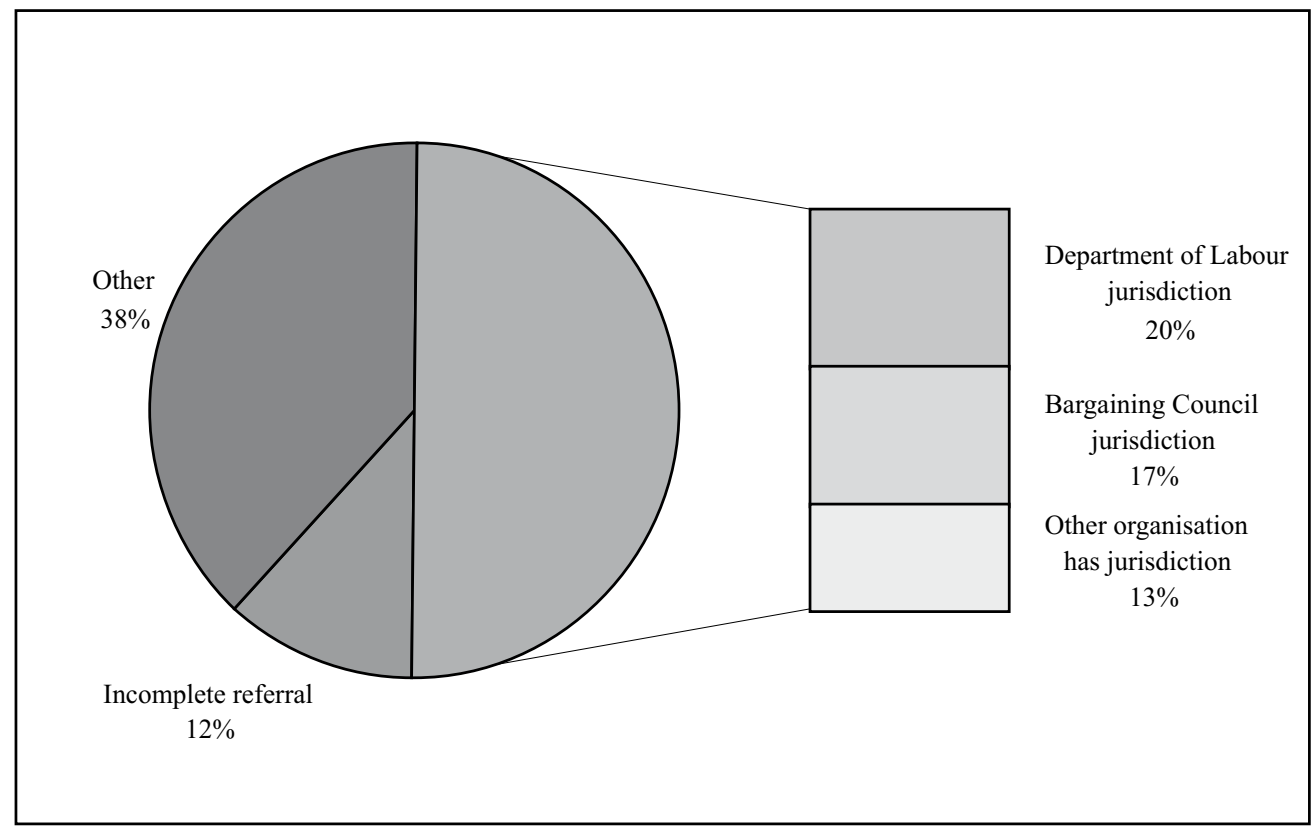

Source: CMS (2005/06) and Authors' Calculations.

Note: $\quad$ The out of jurisdiction categories were only properly disaggregated in the CMS 2005/06. Prior to that there was only a single out of jurisdiction category, hence it is not possible to analyse the trends in this regard.

Thus, while it is useful to know which institution has jurisdiction (the standard out of jurisdiction variable in the CMS does not mention this information), it is problematic to capture this information in the dispute type variable. Many of these out of jurisdiction cases may in fact be unfair dismissal or unfair labour market disputes, but given the way in which it is captured this information is lost. The proposal is therefore, as before, to firstly reduce the number of options that the data capturer can select for the dispute type variable, and to capture the jurisdictional information separately from this. 


\subsection{A Note on the Number of Hearings}

The CMS database keeps a record of the number of hearings conducted until a determinative process had been reached,that is, a case has been closed. Generally conciliation cases are meant to be finalised in a single hearing, while a second hearing is scheduled for arbitration cases. Consequently the majority of conciliation cases (between 87 and 90 per cent) are resolved in a single hearing. For arbitration cases most are resolved in two hearings (between 55 and 57 per cent) ${ }^{49}$. For con-arb cases the share of cases resolved in a single hearing has increased rapidly over the past five years. The estimates for 2001/02 included in Figure 14 are based on only three con-arb cases conducted in that year and can be ignored. From 2002/03 onwards the rate improved from 51 per cent to 74 per cent currently.

Figure 14: Number of Hearings: Conciliation, Arbitration and Con-Arb Cases

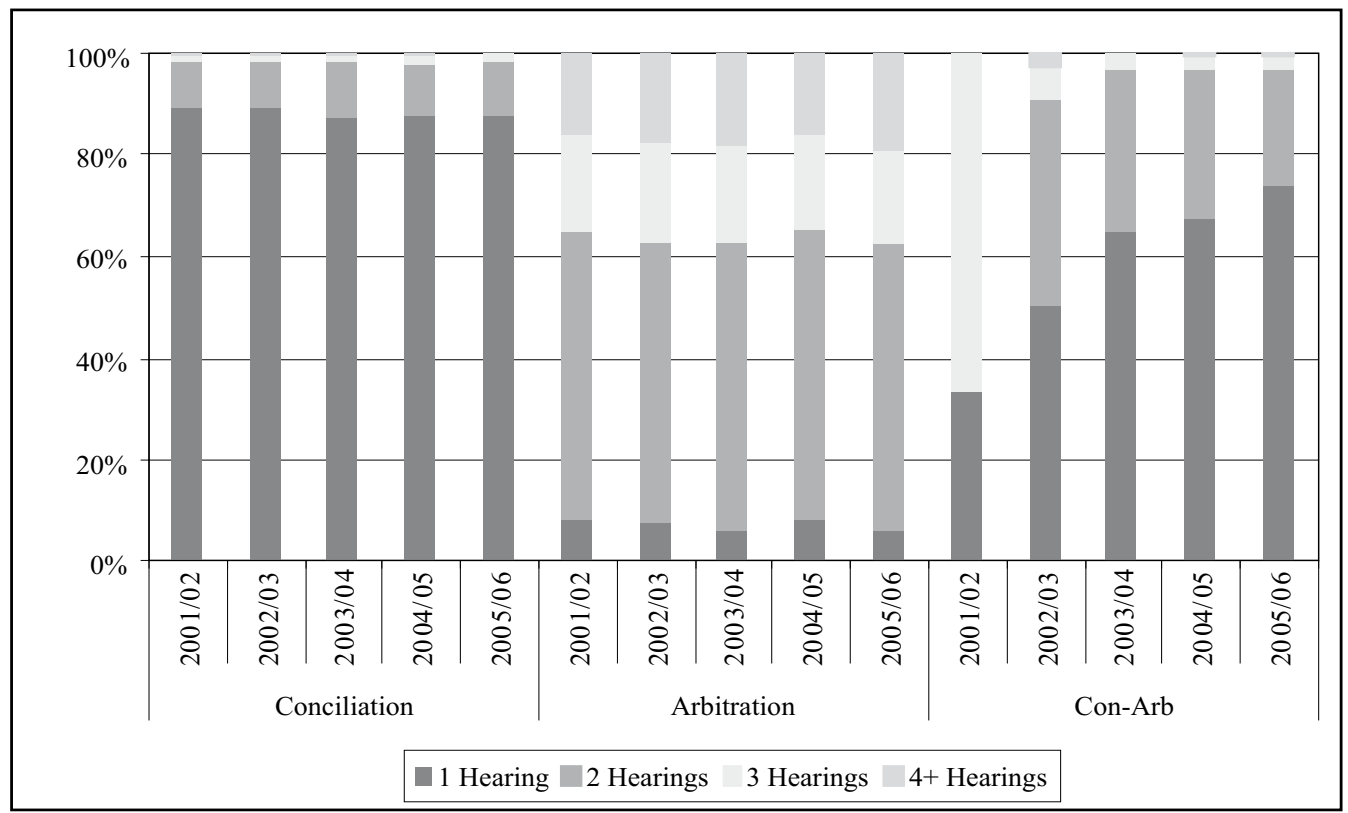

Source: CMS (various) and Authors' Calculations.

$\overline{49}$ If arbitration cases resolved in single hearing are added the share increases to between 63 and 65 per cent. 